\title{
COMPARAÇÃO ENTRE OS MÉTODOS DE QUADRANTES E PARCELAS NA CARACTERIZAÇÃO DA COMPOSIÇÃO FLORÍSTICA E FITOSSOCIOLÓGICA DE UM TRECHO DE FLORESTA OMBRÓFILA DENSA NO PARQUE ESTADUAL “CARLOS BOTELHO” - SÃO MIGUEL ARCANJO, SÃO PAULO
}

OSNY TADEU DE AGUIAR

B I Ó L O GO

Orientador: Prof. Dr. JOÃO LUÍS FERREIRA BATISTA

Dissertação apresentada à Escola Superior de Agricultura "Luiz de Queiroz", Universidade de São Paulo, para obtenção do título de Mestre em Recursos Florestais, com opção em Conservação de Ecossistemas Florestais.

P I R A C I C A B A

Estado de São Paulo - Brasil

Dezembro - 2003 


\section{Dados Internacionais de Catalogação na Publicação (CIP) DIVISÃO DE BIBLIOTECA E DOCUMENTAÇÃO - ESALQ/USP}

Aguiar, Osny Tadeu de

Comparaçāo entre os métodos de quadrantes e parcelas na caracterização da composiçāo florística e fitossociológica de um trecho de floresta ombrófila densa no Parque Estadual "Carlos Botelho" - Sāo Miguel Arcanjo, Sāo Paulo / Osny Tadeu de Aguiar. - - Piracicaba, 2003.

119 p. : il. 2003.

Dissertaçāo (mestrado) - Escola Superior de Agricultura Luiz de Queiroz, Bibliografia.

1. Composição florística 2. Comunidades vegetais 3. Florestas tropicais 4. Parque Estadual de Carlos Botelho, SP I. Título

CDD 581.5247

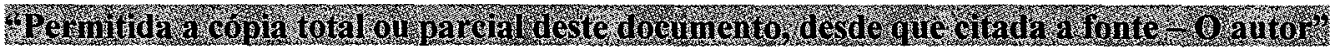


Ofereço

Aos meus pais, Sebastião de Aguiar (in memorian)

e Celina dos Santos Aguiar (in memorian), pelo exemplo de "luta", honestidade e esforço para a minha formação. 
Dedico

À minha esposa Ana Lucia, pela compressão, amor e incentivo. Ao meu filho filho Fabio Tadeu de Aguiar, pela preocupação. 


\section{AGRADECIMENTOS}

A Deus.

A todas as pessoas que contribuíram direta ou indiretamente para realização deste trabalho. A seguir, destaco meus sinceros agradecimentos:

Ao Instituto Florestal (IF) da Secretaria do Meio Ambiente do Estado de São Paulo, nas pessoas do Pesquisador Luiz Alberto Bucci e Dr. João Batista Baetello e Márcia Ballistiero Figliolia.

Ao Prof. João Batista, pela orientação, amizade, atenção e paciência.

Ao Pesquisador Antonio Cecílio Dias, companheiro de trabalho de campo.

Ao Diretor do Parque Estadual "Carlos Botelho", o Sr. José Luiz Camargo Maia pelo apoio e a todos os funcionários do Parque que de uma maneira ou de outra contribuíram para execução do trabalho.

Ao Francisco Bianco (Chico) pelo companheirismo "forte" ajuda nas atividades de camp.

Ao Fine, companheiro nas viagens e atencioso, prestimoso nos momentos solicitados.

Ao João Aurélio pela atenção e dicas sobre o texto.

À Sandra Monteiro Borges Florshein pelo incentivo.

Ao Geraldo pelo apoio nas identificações do material botânico.

Ao Dr. João Batista Baitello, novamente, pelo apoio na identificação das Lauraceae entre outras intervenções. 
À Pesquisadora Maria Gláucia Legaspe Vieira, pela correção do texto sempre sorridente e dedicada.

À Elizete, do Ibt, pela identificação das Rubiaceae.

Às Pesquisadoras Mariê e Margarida, também do Ibt, pelas bibliografias

Ao colegas do Laboratório de Métodos Quantitativos.

Ao Jefferson, pela atenção e pronta ajuda em tudo que foi necessário

À Eliza, pela confecção do mapa.

Ao Ernani, sempre atento ao material botânico.

Aos estagiários Fernando e Lucas, na organização do material botânico.

Ao companheiro Frederico, pela dedicação em trabalhar os dados de campo.

À Suzi e todos os funcionários e estagiários da Biblioteca.

Ao Antônio Sérgio Ferreira, pela atenção dispensada.

À Priscila, pela confecção dos gráficos.

À Yara, pela dedicação e forte apoio sem o qual não haveria condições da realização do trabalho

Á Ivete, pelo incentivo e preocupação com o tempo para a entrega do trabalho.

Ao Carlos, responsável pela Gráfica, por toda a atenção dispensada.

Ao Carlos Araújo, pela atenção dispensada em todos os momentos que foram necessários.

Ao companheiros da Garagem do IF: Silvestre, Zé Menino, Valdir, Laércio, Zé Armando e Milton (Bala).

Aos meus tios: D. Benedita, Maria Helena, Cinira e Lair por entenderem minhas ausências. 


\section{SUMÁRIO}

Página

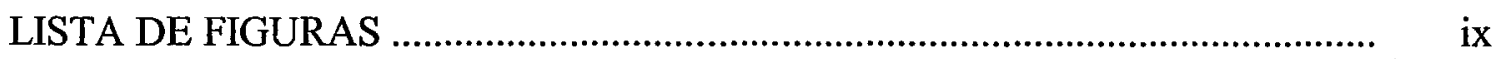

LISTA DE TABELAS ...........................................................................

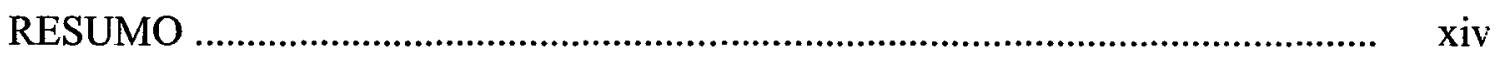

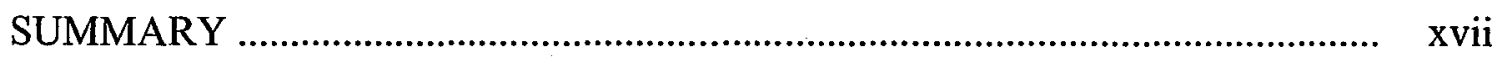

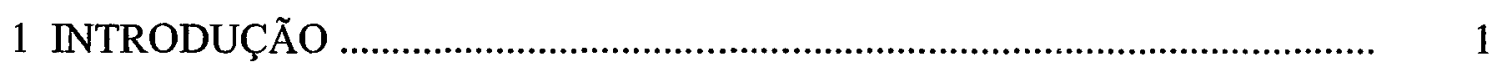

2 REVISÃO DE LITERATURA ……........................................................... 3

2.1 Antecedentes históricos da fitossociologia brasileira ..................................... 3

2.2 Método de parcelas .................................................................................... 4

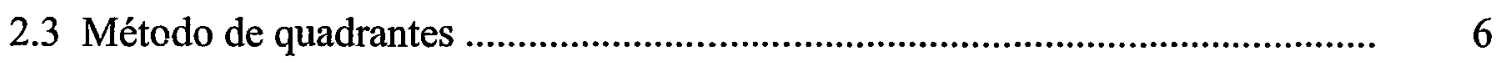

2.4 Comparação dos métodos .............................................................................. 7

2.5 Mata Atlântica ....................................................................................... 9

2.5.1 Aspectos gerais .................................................................................. 9

2.5.2 Levantamento por parcelas realizados na Mata Atlântica ............................. 16

2.5.3 Levantamento por quadrantes realizados na Mata Atlântica ........................... 19

3 MATERIAL E MÉTODOS ........................................................................ 21

3.1 Característica e localização da região de estudo ................................................. 21

3.1.1 Histórico .................................................................................................. 23

3.1.2 Questão fundiária ................................................................................... 24

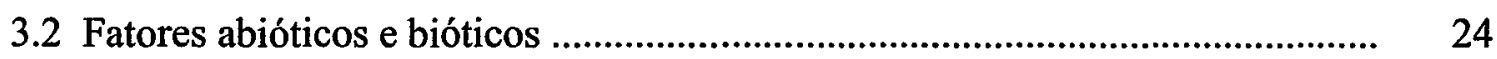

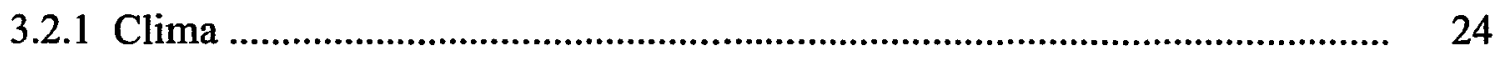


viii

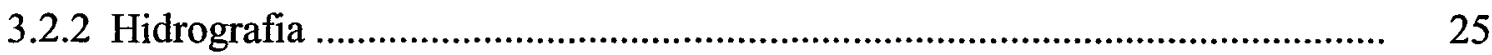

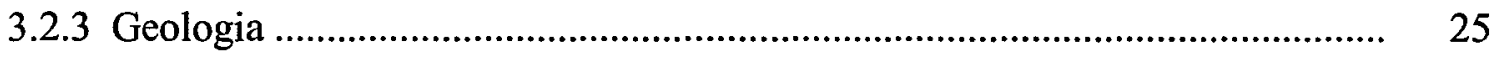

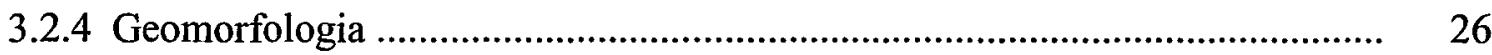

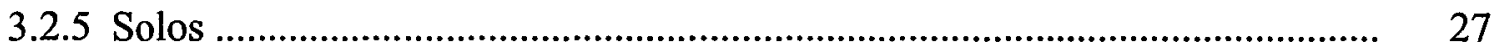

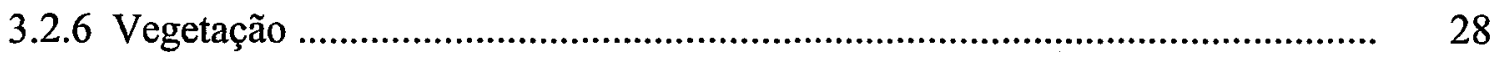

3.3 Procedimento de campo ................................................................................. 28

3.3.1 Demarcação da grade amostral ...................................................................... 28

3.3.2 Instalação das parcelas .................................................................................. 31

3.3.3 Instalação dos quadrantes ........................................................................ 32

3.3.4 Coleta dos dados e identificação dos indivíduos .......................................... 33

3.4 Parâmetros fitossociológicos .......................................................................... 34

3.4.1 Obtenção dos dados .................................................................................... 34

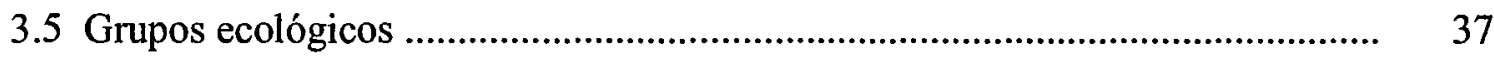

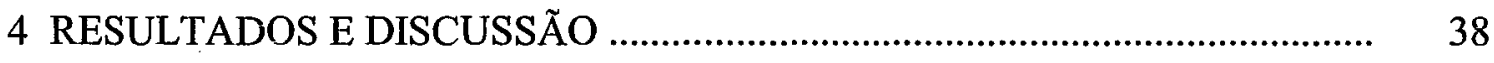

4.1 Tempo gasto para implantação da grade amostral ............................................ 38

4.2 Tempo gasto para coleta do material botânico ................................................. 39

4.3 Tempo gasto na identificação botânica ............................................................... 39

4.4 Comparação dos métodos ................................................................................. 39

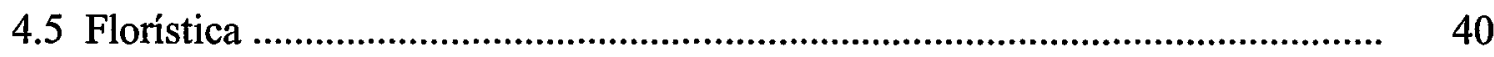

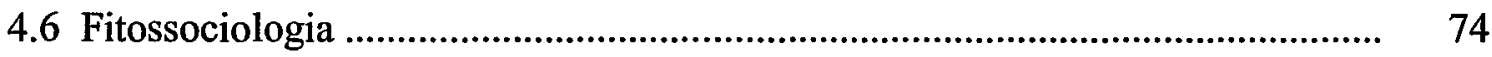

4.7 Distribuição da freqüência de árvores por classes de diâmetro .......................... 99

4.8 Perîlhamento .......................................................................................... 102

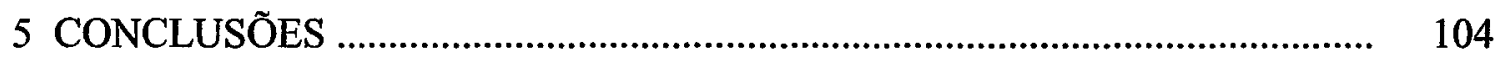

REFERÊNCIAS BIBLIOGRÁFICAS .......................................................... 106 


\section{LISTA DE FIGURAS}

Página

1 a) Localização do P.E.C.B. na região sul do Estado de São Paulo; b) Localização da área de estudo e parte dos municípios de São Miguel Arcanjo, Capão Bonito e Sete Barras

2 Localização da grade de amostragem no Parque Estadual "Carlos Botelho"

3 Desenho esquemático de oito trilhas e oito pontos por trilha

4 Desenho esquemático da grade de amostragem

5 Desenho esquemático da grade de amostragem com as parcelas

6 Desenho esquemático de duas parcelas com as respectivas subparcelas e localização dos pontos quadrantes. No inicío da subparcela 1 , entre a subparcela 2 e 3,4 e 5,6 e 7 e 8 e 9

7 Curva do coletor do número de espécies em função do número de árvores amostradas

8 Representação gráfica da curva do coletor para amostragem através dos métodos de parcelas e quadrantes, em Floresta do Parque Estadual "Carlos Botelho" - São Miguel Arcanjo - SP 
9 Contribuição das principais famílias em percentuais de número de gênero na composição florística da floresta ombrófila densa do Parque Estadual "Carlos Botelho" - São Miguel Arcanjo, SP. Amostragem pelo método de parcelas

10 Contribuição das principais famílias em percentuais de número de gênero na composição floristica da floresta ombrófila densa do Parque Estadual "Carlos Botelho" - São Miguel Arcanjo, SP. Amostragem pelo método de parcelas

11 Contribuição das principais famílias em percentuais de número de espécies na composição florística da floresta ombrófila densa no Parque Estadual "Carlos Botelho" - São Miguel Arcanjo, SP. Amostragem pelo método de parcelas

12 Contribuição das principais famílias em percentuais de número de espécies na composição florística da floresta ombrófila densa no Parque Estadual "Carlos Botelho" - São Miguel Arcanjo, SP. Amostragem pelo método de quadrantes

13 Contribuição das principais famiílias em percentuais de número de indivíduos na composição florística da floresta ombrófila densa no Parque Estadual "Carlos Botelho" - São Miguel Arcanjo, SP. Amostragem pelo método de parcelas

14 Contribuição das principais famiílias em percentuais de número de indivíduos na composição florística da floresta ombrófila densa no Parque Estadual "Carlos Botelho" - São Miguel Arcanjo, SP. Amostragem pelo método de quadrantes 
15 Distribuição das 10 principais espécies em IVI e suas respectivas densidade relativa (De.r), dominância relativa (Do.r) e freqüência relativa (Fr.r) na floresta ombrófila densa no Parque Estadual "Carlos Botelho" São Miguel Arcanjo, SP. Amostragem pelo método de parcelas

16 Distribuição das 10 principais espécies em IVI e suas respectivas densidade relativa (De.r), dominância relativa (Do.r) e freqüência relativa (Fr.r) na floresta ombrófila densa no Parque Estadual "Carlos Botelho" São Miguel Arcanjo, SP. Amostragem pelo método de quadrantes

17 Freqüência de árvores vivas (\%) por classes de diâmetro obtidas pelo método de parcelas, no Parque Estadual "Carlos Botelho" - São Miguel Arcanjo, SP. $1=$ Classe de 5,0 a $10,0 \mathrm{~cm}, 2=$ Classe de 10,1 a $15 \mathrm{~cm}$, $3=$ Classes de 15,1 a 20,0 cm, $4=$ Classe de 20,1 a 25,0 cm, $5=$ Classe de 25,1 a $30,0 \mathrm{~cm} \ldots 15=$ classes maiores que $80,1 \mathrm{~cm}$

18 Freqüência de árvores vivas (\%) por classes de diâmetro obtidas pelo método de quadrantes, no Parque Estadual "Carlos Botelho" - São Miguel Arcanjo, SP. $1=$ Classe de 5,0 a 10,0 cm, $2=$ Classe de 10,1 a $15 \mathrm{~cm}, 3=$ Classe de 15,1 a $20,0 \mathrm{~cm}, 4=$ Classe de 20,1 a $25,0 \mathrm{~cm}$, $5=$ Classe de 25,1 a $20,0 \mathrm{~cm} . . .15=$ Classe de 75,1 a $80,0 \mathrm{~cm}$ e $16=$ Classes maiores que $80,1 \mathrm{~cm}$ 


\section{LISTA DE TABELAS}

Página

1 Resultados referentes ao delineamento amostral pelos métodos de parcelas e quadrantes na floresta ombrófila densa no Parque Estadual "Carlos Botelho" - São Miguel Arcanjo, SP

2 Espécies arbóreas amostradas em 64 parcelas, de $900 \mathrm{~m}^{2}$, na floresta ombrófila densa no Parque Estadual "Carlos Botelho" - São Miguel Arcanjo, SP. $I$ = estrato inferior; $M=$ estrato médio; $D=$ dossel; $E=$ emergente; $G E$ = grupo ecológico

3 Espécies arbóreas amostradas em 320 pontos quadrantes, na floresta ombrófila densa no Parque Estadual "Carlos Botelho" - São Miguel Arcanjo, $\mathrm{SP} . \mathrm{I}=$ estrato inferior; $\mathrm{M}=$ estrato médio; $\mathrm{D}=$ dossel; $\mathrm{E}=$ emergente; $\mathrm{GE}=$ grupo ecológico

4 Espécies em ordem decrescente de índice de valor de importância (IVI) encontradas através de levantamento pelo método de parcelas no Parque Estadual "Carlos Botelho" - São Miguel Arcanjo, SP, onde $\mathrm{n}=$ número de indivíduos; fr.a = freqüência absoluta; fr.r = freqüência relativa; de. $a=$ densidade absoluta; de. $r=$ densidade relativa; do. $a=$ dominância absoluta; do.r = dominância relativa; ivi = índice de valor de importância e ivc $=$ índice de valor de cobertura 
5 Espécies em ordem decrescente de índice de valor de importância (IVI) encontradas através de levantamento pelo método de quadrantes no Parque Estadual "Carlos Botelho" - São Miguel Arcanjo, $\mathrm{SP}$, onde $\mathrm{n}=$ número de indivíduos; fr.a $=$ freqüência absoluta; fr.r $=$ freqüência relativa; de. $r=$ densidade relativa; de. $a=$ densidade absoluta; do.r = dominância relativa; do.a $=$ dominância absoluta; ivi = índice de valor de importância e ivc = índice de valor de cobertura...

6 Parâmetros fitossociológicos das sete espécies em comum entre os dez maiores IVIs, onde: De.r $=$ densidade relativa; Do.r $=$ dominância relativa; Fr.r = freqüência relativa; IVI = índice de valor de importância ..

7 Comparação do percentual de indivíduos das principais famílias 


\title{
COMPARAÇÃO ENTRE OS MÉTODOS DE QUADRANTES E PARCELAS NA CARACTERIZAÇÃO DA COMPOSIÇÃO FLORÍSTICA E FITOSSOCIOLÓGICA DE UM TRECHO DE FLORESTA OMBRÓFILA DENSA NO PARQUE ESTADUAL “CARLOS BOTELHO" - SÃO MIGUEL ARCANJO, SP
}

\author{
Autor: OSNY TADEU DE AGUIAR \\ Orientador: Prof. Dr. JOÃO LUÍS FERREIRA BATISTA
}

\section{RESUMO}

O potencial de recursos inaproveitados do bioma mata atlântica pode ser revelado através de estudos detalhados. Entretanto, embora haja inúmeros estudos enfocando o entendimento das florestas tropicais, ainda persiste a falta de conhecimento da composição florística e estrutura fitossociológica destas florestas. Estes estudos podem ocorrer em diferentes níveis proporcionando diretrizes para uma política de conservação realista, podendo fornecer uma gama de informações aplicáveis em diferentes campos do conhecimento. Neste sentido, desenvolveu-se o estudo em um trecho de floresta ombrófila densa no Parque Estadual "Carlos Botelho", objetivando avaliar e comparar como dois métodos de amostragem florestal (parcelas de área fixa $\mathrm{e}$ pontos quadrantes) representam a composição florística e os parâmetros estruturais de espécies arbóreas. Este trabalho faz parte do Projeto Temático "Métodos de Inventário da Biodiversidade de Espécies Arbóreas, cujo objetivo principal e desenvolver um sistema de amostragem para estudo e conhecimento da biodiversidade do Estado de São Paulo. Efetuou-se o levantamento numa grade de amostragem de 64 parcelas de $10 \times 90$ $\mathrm{m}\left(900 \mathrm{~m}^{2}\right)$, sistematicamente distribuídas. Foram alocados 5 pontos quadrantes em cada 
parcela, totalizando 320 pontos. Amostrou-se todas as árvores com DAP igual ou superior a $5 \mathrm{~cm}$. Avaliando-se os dados florísticos obtidos a partir do método de parcelas, observou-se que foram amostrados 9544 indivíduos, representando 252 espécies, 125 gêneros e 60 famílias. Nos pontos quadrantes, foram amostrados 1280 indivíduos que representam 177 espécies, 106 gêneros e 53 famílias. Para o método de parcelas, as famílias com maior número de gêneros foram: Myrtaceae, Lauraceae, Rubiaceae, Fabaceae, Sapotaceae e Euphorbiaceae. Quanto ao método dos quadrantes, se destacaram as mesmas famílias, não na mesma ordem. Os gêneros mais representados nas parcelas foram: Eugenia (Myrtaceae), Ocotea (Lauraceae), Myrcia (Myrtaceae), Miconia (Melastomataceae), Mollinedia (Monimiaceae), Myrceugenia (Myrtaceae), Inga (Mimosaceae), Rapanea (Myrsinaceae), Marlierea (Myrtaceae) e Ilex (Aquifoliaceae). Por quadrantes, os gêneros que mais se destacaram foram: Eugenia (Myrtaceae), Ocotea (Lauraceae), Myrcia (Myrtaceae), Miconia (Melastomataceae) Rapanea (Myrsinaceae), Marlierea (Myrtaceae) e Myrceugenia (Myrtaceae). A espécie com maior número de indivíduos no método de parcelas foi Euterpe edulis, Alibertia sp., Micropholis crassipedicellata, Bathysa australis, Ocotea catharinensis, Coussarea sp., Pouteria bullata, Eugenia stictosepala e Guapira opposita. Nos quadrantes, a espécie que mais se destacou também foi Euterpe edulis, seguida por Micropholis crassipedicellata, Bathisa australis, Mollinedia oligantha, Coussarea sp., Ocotea catharinensis, Alibertia sp., Pouteria bullata, Eugenia stictosepala, Ormosea dasycarpa. As dez principais espécies em IVI, para o método de parcelas foram: Micropholis crassipedicellata $(17,08)$, Euterpe edulis $(15,56)$, Ocotea catharinensis $(10,25)$, Pouteria bullata $(7,28)$, Alchornea triplinervia $(6,22)$, Mollinedia oligantha $(5,69)$, Alibertia sp. (5,57), Vantanea compacta $(5,53)$, Bathysa australis $(5,34)$ e Cabralea canjerana $(4,93)$. Enquanto que para os quadrantes os principais IVIs foram: Euterpe edulis (24,97), Micropholis crassipedicellata $(23,67)$, Bathysa australis $(12,49)$, Guapira opposita $(8,68)$, Mollinedia oligantha $(8,40)$, Ocotea catharinensis $(8,08)$, Pouteria bullata (7,15), Vantanea compacta $(6,31)$, Eugenia melanogina $(5,74)$, Coussarea sp. $(5,39)$. observou-se que os dois métodos amostraram a composição florística e a estrutura fitossociológica da comunidade estudada de maneira semelhante. 
Assim, considerando-se o esforço físico e as dificuldades da topografia, recomenda-se aplicação do método de quadrantes para estudar a vegetação florestal em ambientes com as mesmas características de relevo. 


\title{
COMPARISON BETWEEN CENTER QUARTER AND PARCELS METHODS ON THE FLORISTIC AND PHYTOSSOCIOLOGICAL COMPOSITION'S CHARACTERIZATION OF A SPACE OF RAINFOREST AT "CARLOS BOTELHO" STATE PARK - SÃO MIGUEL ARCANJO, SÃO PAULO
}

\author{
Author: OSNY TADEU DE AGUIAR \\ Adviser: Prof. Dr. JOÃO LUÍS FERREIRA BATISTA
}

\section{SUMMARY}

The potential of unused resources from atlantic forest biome, can be revealed through detailed researches. However, though it's been uncountable researches focusing the understanding of tropical forests, there is still a lack of knowledge concerning the floristic composition and phytossociological structure of these forests. These researches can occur in different levels and can provide standards to a realistic conservation policy as well as a lot of applicable information to different fields of knowledge. On this way, it was developed the research in a space of rainforest at "Carlos Botelho" State Park, which had as its aim to evaluate and compare how two methods of forest sample (fixed area plot and center-quarter points) applied to the same area, at the same time, represent the floristic composition and the structural parameters of arboreal species. This work is a part of the Thematic Project "Inventory Methods of the Arboreal Biodiversity Species" which main point is to develop a sample system to study and biodiversity knowledge of the state of São Paulo. The phytossociological survey used 64 fixed area plot $(10 \times 90 \mathrm{~m})$ in a sampling grid of $100 \times 100 \mathrm{~m}$. The center-quarter method was also implemented with 5 sampling points per fixed area plot, adding up 320 points in the study area. It was sampled all the trees with DBH (Diameter Breast Height) equal 
or superior to $5 \mathrm{~cm}$. Evaluating the floristic data obtained from the parcels method, we could observe that 9544 trees were sampled representing 252 species, 125 genera and 60 families. In the center-quarter points, were sampled 1280 trees, representing 177 species, 106 genera and 53 families. To the parcels method, the families with larger numbers of genera were: Myrtaceae, Rubiaceae, Fabaceae, Sapotaceae, Euphorbiaceae. As to the center-quarter method, the following families stood out, Myrtaceae, Rubiaceae, Lauraceae, Fabaceae, Sapotaceae and Euphorbiaceae. The most representative genera in the parcels were: Eugenia (Myrtaceae), Ocotea (Lauraceae), Myrcia (Myrtaceae), Miconia (Melatomataceae), Mollinedia (Monimiaceae), Myrceugenia (Myrtaceae) Inga (Mimosaceae), Rapanea (Myrsinaceae), Marlierea (Myrtaceae) and Ilex (Aquifoliaceae). By quarter centers, the most outstanding genera were: Eugenia (Myrtaceae), Ocotea (Lauraceae), Myrcia (Myrtaceae), Miconia (Melatomataceae), Rapanea (Myrsinaceae), Marlierea (Myrataceae) and Myrceugenia (Myrtaceaeu). The species with the greater number of trees in the parcel method was Euterpe edulis, followed by Alibertia sp., Micropholis crassipedicellata, Bathysa australis, Ocotea catharinensis, Coussarea sp., Pouteria bullata, Eugenia stictosepala, and Guapira opposita. In the quarter centers, the most outstanding species was Euterpe edulis too followed by Micropholis crassipedicellata, Bathysa australis, Mollinedia oligantha, Coussarea sp., Ocotea catharinensis, Alibertia sp., Pouteria bullata, Eugenia stictosepala, Ormosea dasycarpa. The ten main species in IVI for the parcel method were: Microphois crassipedicellata (17,08), Euterpe edulis (15.56), Ocotea catharinensis (10.25), Pouteria bullata (7.28), Alchornea triplinervia (6.22), Mollinedia oligantha (5.69), Alibertia sp. (5.57), Vantanea compacta (5.53), Bathysa australis (5.34) and Cabralea canjerana (4.93). While for the quarter centers the main IVIs were: Euterpe edulis (24,97), Micropholis crassipedicellata (23.67), Bathysa australis (12.49), Guapira opposita (8.68), Mollinedia oligantha (8.40), Ocotea catharinensis (8.08), Pouteria bullata (7.15), Vantanea compacta (6.31), Eugenia melanogina (5.74), Coussarea sp. (5.39). It has been observed that both methods sampled floristic composition and the phytossociological structure of the studied community in a similar way. Thus, considering the physical effort and the topography difficulties, it is 


\section{INTRODUÇÃO}

O potencial de recursos inaproveitados do bioma Mata Atlântica e ecossistemas associados, pode ser revelado através de estudos florísticos e fitossociológicos. Estes estudos podem ocorrer em diferentes níveis e, dependendo da atividade envolvida, proporcionar diretrizes para uma política de conservação realista, bem como fornecer uma gama de informações aplicáveis em diferentes campos do conhecimento. Estes campos em especial são: manejo de áreas silvestres, recuperação de áreas degradadas, produção de sementes e mudas, identificação de espécies ameaçadas, avaliação de impactos, licenciamento ambiental, indicação correta de espécies para revegetação, determinação de endemismos, localização de espécies para prospecção química, determinação de espécies raras, identificação de habitats preferenciais das espécies, entre outros.

Este complexo bioma abriga a maior diversidade de espécies que a maioria das formações amazônicas, bem como níveis elevados de endemismos (Morellato, 2000).

Embora haja inúmeros estudos enfocando o entendimento das florestas tropicais, em especial a mata atlântica, ainda persiste a falta de conhecimento da composição florística e estrutura fitossociológica destas florestas.

Este trabalho integra o projeto temático "Métodos de Inventário da Biodiversidade de Espécies Arbóreas" (BIOTA/FAPESP n 99/085-0)

Nesse sentido o objetivo do presente estudo de um trecho da vegetação do Parque Estadual "Carlos Botelho", é verificar como o método de quadrantes, aplicado simultaneamente na área física do método de parcelas, representou a composição 
florística e os parâmetros estruturais de espécies arbóreas. Considerou-se a florística e a estrutura, advindas do método de parcelas, como sendo as referências para tais análises. 


\section{REVISÃO DE LITERATURA}

\subsection{Antecedentes históricos da fitossociologia brasileira}

De acordo com Martins (1989) a primeira fase da fitossociologia no Brasil ocorreu a partir de 1930, caracterizando-se por estar ligada ao renomado Instituto Oswaldo Cruz, incumbido de buscar informações fundamentadas das epidemias de febre amarela e de malária.

A fitossociologia como ciência, refere-se ao estudo das comunidades vegetais, do ponto de vista florístico e estrutural, conforme proposto por Braun Blanquet (1979).

Estando baseada na teoria de comunidades, métodos de análises quantitativas e, tendo como unidades de trabalho as associações e comunidades vegetais, esta ciência proporcionou uma nova fase nos estudos de vegetação de forma mais detalhada.

Segundo Martins (1989), os primeiros trabalhos de fitossociologia florestal no Brasil foram os de Davis (1945) \& Velloso (1945), realizados na serra dos Órgãos, no Estado do Rio de Janeiro.

A estes trabalhos seguiram-se os de (Veloso \& Klein, 1957, 1961, 1963,1968a 1968b) realizados, principalmente, na encosta atlântica no Estado de Santa Catarina, aliados às descrições florísticas e estruturais de associações vegetais.

Particularmente, no Estado de São Paulo, coube a Heinsdjik \& Campos (1967) os primeiros levantamentos, em florestas latifoliadas nativas, na serra do Mar, representadas pelas Reservas: Carlos Botelho, Capão Bonito, Sete Barras e Travessão, nos municípios de São Miguel Arcanjo, Capão Bonito e Sete Barras, visando fornecer dados sobre a composição de matas nativas, o estoque de madeiras existentes por 
espécies, a distribuição diamétrica, entre outras informações. No estudo, abrangendo as quatro Reservas, amostraram indivíduos com DAP a partir de $20 \mathrm{~cm}$, em 143 parcelas de 0,2 ha. Os espécimens foram identificados através da anatomia do lenho, que possibilitou reunir um considerável número de espécies, com grande variação florística e abundância de algumas delas.

Campos \& Heinsdjik (1970), estudando a Reserva do Morro do Diabo, no município de Teodoro Sampaio, extremo sudoeste paulista, utilizando parcelas de 0,4 ha, distribuídas entre as várias fisionomias, previamente reconhecidas por fotografias aéreas, utilizaram como critério de inclusão, árvores a partir de $25 \mathrm{~cm}$ de DAP. As identificações, no caso, foram feitas, através da anatomia do lenho e material botânico fértil. Assinalaram cada fisionomia, da Reserva e propuseram modelos matemáticos para expressar as variações nas distribuições de diâmetros observados.

Os autores destacaram a grande riqueza florística e detectaram que a baixa qualidade silvicultural da floresta é, comprometida, em função da baixa fertilidade do solo arenoso. Chamaram a atenção para a grande agressão ambiental que a Reserva vinha sofrendo, necessitando, portanto, em caráter de urgência, de atitudes preservacionistas, face à importância biológica e científica da Unidade. Nos estudos que realizaram obtiveram os devidos méritos, voltados mais para o caráter silvicultural, do que fitossociológico.

\subsection{Método de parcelas}

A partir da década de 70 , do século passado, foram desenvolvidos no Brasil muitos trabalhos de fitossociologia ou relacionados com a descrição e a estrutura de vegetação.

Conforme Mueller-Dombois \& Ellenberg (1974), os primeiros métodos quantitativos empregados em fitossociologia consistiam no estabelecimento de pequenas parcelas quadradas. Os descritores registrados, periodicamente, para espécies em parcelas permanentes, como abundância, freqüência, cobertura e altura, podem indicar tendências na dinâmica vegetacional, sendo descritores sensíveis a variações sucessionais ou distúrbios. 
Para Martins (1978), os primeiros métodos quantitativos empregados em levantamentos fitossociológicos, consistiam no emprego de pequenas parcelas quadradas dentro da área de estudo.

Martins (1989) relata que o método de parcelas, comumente empregado na Europa, em estudos da vegetação de regiões temperadas, foi aplicado com sucesso no Brasil, após ter passado por certos ajustes quanto ao tamanho bem maior de parcelas, em relação ao tamanho das empregadas na vegetação temperada. Quanto às técnicas e análises foram praticamente as mesmas, conforme Braun Blanquet, (1979).

Segundo Martins (1993), o método de parcelas apresenta-se superior ao método de quadrantes, no que diz respeito à avaliação quantitativa e variabilidade dos parâmetros estimados, bem como a distribuição espacial dos indivíduos da população.

Quando o interesse é voltado para o conhecimento da riqueza e diversidade, os métodos fitossociológicos, atualmente empregados, principalmente, os que utilizam parcelas, não permitem obter amostragem satisfatória da comunidade florestal, já que são limitados a uma determinada área. $\mathrm{O}$ método de quadrantes, por sua vez, possibilita uma maior área de abrangência, podendo caracterizar melhor a diversidade arbórea.

Siqueira (1994) analisando vários trabalhos realizados no período de 1970 a 1994 constatou que, o método mais empregado nos levantamentos de vegetação, foi o de parcelas, adotado em cinqüenta e um dos sessenta e três trabalhos analisados, sendo que apenas sete trabalhos empregaram o método de quadrantes e cinco deles foram levantamentos florísticos realizados por transectos.

Outros trabalhos também fizeram uso do método de parcelas como os de: Almeida-Scabbia (1996) no município de Sete Barras, no Parque Estadual de Intervales; Ivanauskas (1997) no município de Pariquera-Açu, litoral sul do Estado de São Paulo; Pinto (1998) no município de Cananéia, no Parque Estadual da Ilha do Cardoso; Melo et al. (1998) no município de Peruíbe, na Estação Ecológica da JuréiaItatins; Assis (1999) no município de Ubatuba, no Parque Estadual da Serra do Mar Núcleo Picinguaba; Silva (1999) no município de Cubatão, Parque Estadual da Serra do Mar, Sanchez (2001) no município de Ubatuba, no Parque Estadual da Serra do Mar - 
Núcleo Picinguaba; Custódio Filho (2002) nos municípios de São Miguel Arcanjo, Capão Bonito e Sete Barras, no Parque Estadual "Carlos Botelho".

\subsection{Método de quadrantes}

No Estado de São Paulo, um dos primeiros a efetuar levantamentos fitossociológicos foi Martins $(1978,1979)$, no Parque Estadual de Vaçununga, município de Santa Rita do Passa Quatro, em floresta estacional semidecidual. Descreveu a origem dos métodos baseados em distâncias e aplicou o método de quadrantes. Dos dados obtidos, o autor fez uso como material de tese como, também, colaborou com sugestões para o aperfeiçoamento do método.

Cottan \& Curtis (1956) compararando cinco métodos de amostragem fitossociológica (indivíduos mais próximos, vizinhos mais próximos, pares ao acaso, métodos dos quadrantes e levantamento de parcelas múltiplas) já haviam destacado a simplicidade de execução, em campo, dos quatro primeiros métodos e definiram entre eles o método de quadrantes como o de resultados menos variáveis, fornecendo mais dados sobre as espécies. Concluíram ainda que o método de quadrantes era o menos susceptível à decisões arbitrárias na condução dos trabalhos no campo.

Segundo Gibbs et al. (1980) a grande utilização do método de quadrantes deve-se a economia de tempo na obtenção de dados na amostragem. Ainda, Cottan e Curtis (1956) \& Martins (1993), o método possibilita amostrar uma maior área quando comparada ao método de parcela de área fixa.

Tal procedimento executado por Silva \& Leitão Filho (1982), no trabalho que realizaram, definiram a composição florística de um trecho de Mata Attântica, onde as famílias botânicas foram organizadas pelo Índice de Valor de Importância (IVI). O procedimento foi, posteriormente, utilizado pela grande maioria dos pesquisadores que trabalham com fitossociologia.

Dentre outros trabalhos que utilizaram o método de quadrantes, pode-se destacar: Cavassan et al. (1984), na Reserva Estadual de Bauru; Pagano (1985) no Município de Rio Claro; De Vuono (1985) na Reserva Biológica do Instituto de 
Botânica, no município de São Paulo; Pagano et al. (1987), no município de Rio Claro; César (1988) na fazenda Barreiro Rico, no município de Anhembi; Mantovani (1990) no Município de Salesópolis; no Bosque Municipal Fábio Barreto, no município de Ribeirão Preto - São Paulo; Dias (1993) no Parque Estadual "Carlos Botelho"; Baitello et al. (1993) no Parque Estadual da Cantareira, Município de São Paulo, Mantovani (1993) na Estação Ecológica da Juréia-Itatins, no litoral sul do Estado de São Paulo; Castro (2001) na Estação Ecológica de Bananal, município de Bananal, extremo leste do Estado de São Paulo.

\subsection{Comparação dos métodos}

Considerando os trabalhos realizados em florestas de várzea, na Estação Experimental de Moji-Guaçu, Gibbs \& Leitão Filho (1978) amostraram por parcelas um pequeno número de espécies adaptadas à inundação periódica das matas não inundáveis. Dois anos mais tarde, Gibbs et al. (1980) a partir dos resultados obtidos com aplicação do método de quadrantes no levantamento florístico de um mata ripária em Moji Guaçu, fizeram comparações com aqueles obtidos para a mesma área por Gibbs \& Leitão Filho (1978), utilizando o método de parcelas. Detectaram que as nove primeiras espécies relacionadas de acordo com o (IVI) foram as mesmas. No método de quadrantes os (IVIs) foram, geralmente, os mais altos e a seqüência das espécies foi, correspondentemente, diferente. Concluíram que, ambos os métodos, são bastante válidos para a determinação das espécies mais comuns. Das cinqüenta e nove espécies amostradas, o método de quadrantes amostrou quarenta e oito e o método de parcelas, quarenta e seis. Ambos os métodos deixaram de registrar 1/5 das espécies mais raras existentes na área estudada.

Com o objetivo de encontrar um método mais simples de ser aplicado na floresta pluvial tropical, localizada no Núcleo Sete Barras, Parque Estadual de "Carlos Botelho"; onde, a amostragem, através de parcelas de tamanho fixo é dificultada pela topografia acidentada e pluviosidade elevada, Dias et al. (1989) testaram os principais métodos de amostragem empregados em inventários florestais. Os autores utilizaram, 
como parâmetro de comparação, o Índice de Valor de Importância (IVI) das espécies, resultante da análise, mediante o uso de parcelas de tamanho fixo. Da área amostrada por Negreiros (1983) utilizaram o correspondente a 3 hectares, ou seja, parcelas de 1 hectare cada de $(100 \times 100 \mathrm{~m})$, subdivididas em sub parcelas de $100 \mathrm{~m}^{2}(10 \times 10 \mathrm{~m})$, onde avaliaram todas as árvores com diâmetro DAP $\geq 15 \mathrm{~cm}$. Utilizaram parcelas de área fixa e distância, na ordem a seguir: planta mais próxima; pontos quadrantes; relascopia, com fatores de numeração (fn) 9, 16 e 25; vizinho mais próximo; pares aleatórios e, inglês. Concluíram que os (IVIs) conseguidos com o método de distância ponto à planta e planta à planta não ofereceram diferenças significativas através do método de parcelas. De acordo com os resultados obtidos, os métodos: relascopia com fator de numeração (fn 25) e árvore mais próxima, não são indicados, quando se trata de levantamento florístico da floresta.

Ainda, Dias et al. (1989) no levantamento da vegetação do Parque Estadual "Carlos Botelho", Núcleo Sete Barras, empregaram nove métodos de amostragem, considerando todas as árvores com DAP $\geq 15 \mathrm{~cm}$. Compararam o Índice de Valor de Importância (IVI) para cada método e na aplicação de testes não paramétricos ficou evidenciado não haver diferenças significativas entre o Índice de Valor de Importância obtido, através de parcelas e métodos baseados em distâncias.

Mello et al. (1996) na floresta semidecidual montana, em Minas Gerais, avaliaram a eficiência de vários procedimentos de amostragem: casual simples; casual simples com parcelas de tamanhos diferentes; casual estratificado; sistemática; sistemática com pós-estratificação e sistemática com parcelas de tamanhos diferentes. Verificaram que, os seis procedimentos utilizados na descrição da estrutura fitossociológica de uma floresta, quando avaliados, representaram, de forma adequada, os parâmetros da estrutura horizontal. No entanto, observaram, que considerando as distâncias euclidianas obtidas para cada procedimento, aqueles com base sistemática foram superiores aos que se basearam em aleatorização. Gorenstein (2002) na Estação Ecológica dos Caetetus (E.E.C.), floresta estacional semidecidual, utilizou três métodos de amostragem no levantamento de comunidade arbórea: parcela de área fixa, pontos quadrantes e ponto de Bitterlich e, a partir das análises, avaliou o desempenho dos referidos métodos na 
caracterização da biodiversidade. As análises permitiram-no concluir que, o método de Bitterlich e de quadrantes, apresentaram comportamentos semelhantes para amostragem de riqueza da comunidade, quando o esforço amostral é analisado de acordo com o número de indivíduos. Quando o esforço amostral é examinado sob o enfoque do tempo despendido, o método de Bitterlich aproximou-se do método de parcelas e o método de quadrantes superou os demais. $\mathrm{O}$ método de Bitterlich se destacou entre os outros dois quando, se analisou a amostragem de acordo com as unidades amostrais.

Durigan et al. (2002) aplicaram um método não convencional de levantamento florestal, na expectativa de evidenciar aspectos positivos e eliminar aspectos negativos de dois métodos, parcelas e quadrantes, tradicionalmente mais utilizados em levantamentos florestais. De acordo com os autores, o método alternativo consistiu apenas na mensuração do diâmetro (DAP maior ou igual a $10 \mathrm{~cm}$ ) e identificação botânica dos indivíduos em 100 parcelas, excetuando-se a medição da distância ponto-árvore. A densidade foi estimada com base no método de parcelas e, para cada cinco pontos quadrantes, levantou-se a densidade em uma parcela de $100 \mathrm{~m}^{2}$, dispensando-se as identificações e mensurações, visto que ainda a única finalidade dessa amostragem foi estimar a densidade absoluta da floresta.

Dentre as conclusões do estudo destacam-se: o método adotado mostrou-se de fácil aplicação no campo; evita as medições de distância ponto-árvore, logicamente, facilitando os cálculos e reduz o tempo de execução do levantamento sem perder a precisão.

\subsection{Mata Atlântica}

\subsubsection{Aspectos gerais}

As conseqüências, das significativas alterações ocorridas ao longo da história, surgiram com o desmatamento desenfreado e degradativo da cobertura vegetal, para dar lugar ao desenvolvimento econômico, que teve início com a cafeicultura, seguida pelo avanço das ferrovias e, conseqüentemente, a diversificação da agricultura e à industrialização. 
As florestas costeiras brasileiras ocupam menos de $8 \%$ de sua área original. No Estado de São Paulo esta cobertura vegetal reduziu-se a 8,3\% de sua extensão original, que representava $81,8 \%$ do Estado (Serra Filho 1974).

Victor (1975) ao analisar o processo evolutivo e histórico da situação florestal do Estado de São Paulo, enfatizando o desmatamento, revelou dados sobre a destruição da cobertura vegetal natural, demonstrou que diversos fatores foram responsáveis pelo agravamento do processo de destruição, no início do século passado, como também fez previsões que, até o ano 2000, a cobertura florestal natural estaria por volta de 3 a 5\%, restrita a terrenos de dificil acesso ou ainda em forma de Reservas Públicas.

Guillaumon (1989) apoiado em fontes primárias e secundárias do Brasil do século XIX, relata sobre os grandes ciclos econômicos, com enfoque no deslocamento do pólo econômico do Nordeste para o Sudeste do país. O autor procurou particularizar o caso do desenvolvimento do Estado de São Paulo, baseado na expansão da cafeicultura e, conseqüentemente, o desenvolvimento das ferrovias que, na substituição da hulha pela lenha, contribuíram para a destruição das florestas.

Para Kronka et al. (1993), de modo geral, a cobertura florestal remanescente no Estado de São Paulo, está restrita, principalmente, às escarpas íngremes de difícil acesso e ocupação nas serras costeiras, constituindo Unidades de Conservação ou áreas protegidas.

A maior área contínua, remanescente, da mata atlântica em toda costa brasileira é encontrada no Estado de São Paulo, como também, um dos maiores índices de áreas protegidas do país. Os Parques Estaduais, Estações Ecológicas e Estações Experimentais representam 3,15\% do território paulista e estão amparados por lei (São Paulo, 1996).

As Unidades de Conservação (UCs) do Estado têm função preponderante na conservação de grande parte da biodiversidade do país. Nessas Unidades são desenvolvidos muitos estudos sobre vegetação. Os remanescentes de mata atlântica, em São Paulo, cerca de $45 \%$, estão protegidos e, legalmente, amparados pelo governo, já que são partes das UCs (São Paulo, 1998). 
A mata atlântica, com mais de 6 mil espécies endêmicas de plantas, e reduzida a menos de $8 \%$ de sua extensão original, está entre os hotspots mais críticos do planeta. Buscar o equilíbrio entre conservação e desenvolvimento num domínio onde vivem $60 \%$ da população brasileira e quase $70 \%$ do PIB nacional é um desafio imenso, conforme opiniões na (Agenda 21, 2000).

A floresta pluvial tropical atlântica, denominada, genericamente, de "Mata Atlântica", é um domínio com múltiplas fitofisionomias, um verdadeiro mosaico florístico, que se estende sob diversas condições geológicas, geomorfológicas e climáticas; formado por um conjunto de ecossistemas florestais e ecossistemas associados. Trata-se de um dos mais diversificados ecossistemas florestais do Brasil, mas para muitos há ainda divergências sobre seu conceito e sobre seu limite.

As divergências de opiniões sobre a utilização do termo mata atlântica foram, incansavelmente, discutidas durante o XLVII Congresso Nacional de Botânica, realizado em 1996 em Nova Friburgo - Rio de Janeiro. Naquela oportunidade científica parece ter chegado a um consenso de que o termo mata atlântica seja usado sob duas denominações: mata atlântica sensu lato e mata atlântica sensu stricto.

Para este trabalho tomou-se como orientação o que foi definido pelo artigo $3^{\circ}$ do Decreto 750/93 e com base no Mapa de Vegetação do Brasil do IBGE, na escala 1: 5.000 .000 e adotou-se a definição Mata Atlântica sensu stricto, restringindo a floresta atlântica às áreas de floresta ombrófila densa, conforme Veloso et al. (1991).

Cabe salientar, que autores como Rizzini (1963) \& Romariz (1971) já mencionavam que essa formação vegetal adentrava, principalmente, para o interior do Estado de São Paulo, na região Sudeste.

Segundo Giulietti (1992) a mata atlântica representa um, entre os diferentes tipos de vegetação ocorrentes na região Sudeste do Brasil. Para Klein (1980) no sentido lato, ela é composta por formações de características florísticas e estruturais peculiares e próprias, mostrando-se complexa, apresentando riqueza e diversidade superiores às de algumas áreas da floresta amazônica. Estas situações peculiares da mata atlântica se devem à ampla extensão latitudinal, com manifestações nas características climáticas, geológicas, geomorfológicas, pedológicas e hidrográficas, como também, do 
distanciamento do oceano, dos estádios sucessionais e das variações locais (Veloso \& Klein, 1957; Meguro, 1987; Mantovani et al. 1990).

De acordo com a legislação vigente e a base cartográfica, o mapa de vegetação do Brasil (Fundação Instituto Brasileiro de Geografia e Estatística - IBGE, 1993) o domínio mata atlântica corresponde, à totalidade da floresta ombrófila densa que acompanha o litoral, indo do Rio Grande do Norte ao Rio Grande do Sul; às florestas estacionais deciduais e semideciduais do Rio Grande do Sul, Santa Catarina, Paraná, São Paulo, Rio de Janeiro e Espírito Santo; às florestas semideciduais de Mato Grosso do Sul, incluindo os vales dos rios da margem direita do rio Paraná; Minas Gerais, nos vales dos rios Paranaíba, Grande e afluentes; Minas Gerais e Bahia, nos vales dos rios Paraíba do Sul, Jequitinhonha, rios intermediários e afluentes; e de regiões litorâneas limitadas do nordeste, contíguas às florestas ombrófilas; à totalidade da floresta ombrófila; à totalidade da floresta ombrófila mista e os encraves de araucária nos Estados de São Paulo, Rio de Janeiro e Minas Gerais; às formações florísticas associadas, como manguezais, vegetação de restinga e das Ilhas oceânicas; aos encraves de cerrado, campos e campos de altitudes, compreendidos no interior das áreas citadas acima; às matas de topo de morros e encostas do nordeste, particularmente, os brejos de altitudes de Pernambuco e Paraíba e as chãs do Estado do Ceará, na serra de Ibiapaba e de Baturité, e na Chapada do Araripe; e às formações vegetais nativas de Fernando de Noronha.

A floresta ombrófila densa encontrada no sul do Estado de São Paulo, sobre a serra de Paranapiacaba, está sob influência do clima temperado quente úmido, sujeito à ocorrência de geadas, cuja flora tem contribuição significativa da floresta do Sul do Brasil. Nesta região, encontra-se o limite norte da distribuição contínua do domínio da floresta de araucária, nas altitudes mais elevadas (Mantovani, 1993).

Leitão Filho (1982) abordando os aspectos taxonômicos das florestas do Estado de São Paulo, concluiu que o ecossistema Mata Atlântica, em particular aquele ocorrente no litoral sul do Estado, além de pouco conhecido é uma área prioritária para investigações. O mesmo autor, considerando dois diferentes padrões florísticos existentes no litoral norte e sul do Estado de São Paulo, sugeriu que trabalhos de cunho 
florístico, enfatizasse a comparação entre as formações, como também, o conhecimento florístico destas comunidades. $\mathrm{O}$ autor finaliza ressaltando que, à medida que melhora o conhecimento da composição florística das diversas fisionomias florestais de uma comunidade, reforçam as etapas básicas de avaliação e manejo dos recursos naturais.

Para Monteiro (1973) o litoral norte do Estado de São Paulo, recebe maiores influências equatcriais e tropicais, estando menos sujeito a sensações e invasões de frio, enquanto o litoral sul está sob influência de massas tropicais polares, que provocam maiores variações na precipitação, ocasionando inverno com temperaturas baixas, mais sensíveis, freqüentes $e$, conseqüentemente, chuvas dependentes da topografia local.

Sabe-se que algumas das espécies exclusivas da mata atlântica esião limitadas a determinadas localidades, constituindo os endemismos restritos. Para as serranias do Rio de Janeiro, a região no norte do Espírito Santo, sul da Bahia e o litoral de Pernambuco, coube a indicação como centros de endemismos da mata atlântica (Mori, 1989; Peixoto, 1991, 1992). Recentemente, as serranias do Rio de Janeiro foram consideradas como um dos catorze centros de diversidade e endemismo de plantas do Brasil (Guedes-Bruni \& Lima, 1997).

De acordo com os fatos expostos acima, a mata atlântica foi reconhecida, internacionalmente, como uma das prioridades em termos de conservação de florestas tropicais (Mori, 1989).

" Leitão Filho et al. (1993) colocam que, embora represente o maior e o mais diversificado ecossistema florestal remanescente do Sudeste do Brasil, a floresta atlântica ainda é muito pouco conhecida sob o ponto de vista florístico Uma análise de ordenação de sessenta e quatro estudos sobre a composição florística da floresta atlântica realizada por Siqueira (1994) permitiu separar o ecossistema em dois blocos distintos de vegetação: um presente no Nordeste e outro na região Sudeste/Sul, com o Estado do Espírito Santo abrigando uma flora intermediária entre os dois blocos. Distingue ainda, dentro dos dois blocos, mais outro: sendo três no Nordeste e cinco no Sudeste/Sul, com separação mais nítida no Nordeste. 
A mata atlântica é um bioma que, além do contingente de plantas, abriga uma diversificada fauna caracterizada pelo grande número de espécies raras e, também, endêmicas, em muitos casos ameaçadas de extinção. As estimativas indicam que a região abriga 261 espécies de mamíferos (73 endêmicos), 620 espécies de pássaros (160 endêmicos), 260 anfíbios (128 endêmicos), além de, aproximadamente, 20.000 espécies de plantas vasculares das quais, mais da metade, são restritas. Mais de $2 / 3$ dos primatas da mata atlântica são endêmicos a essa região (São Paulo, 1996).

Joly et al. (1999) consideraram a Mata atlântica como resultado de diversas fisionomias. Os autores comentaram que durante o processo evolutivo, teria havido intensas alterações da flora, originando um complexo de ecossistemas estreitamente relacionados, devem ser preservados como uma unidade, caso contrário todas as fisionomias desapareceriam com o tempo.

Morellato (2000) teceu comentários, aproveitando o aniversário de 500 anos não só do descobrimento do Brasil, mas também, da intensa destruição da mata atlântica, tendo como causa a colonização européia. A autora menciona que a floresta atlântica está restrita a, aproximadamente, $98.000 \mathrm{~km}^{2}$ de remanescentes, ou seja, 7,6\% de sua extensão original e os remanescentes, ainda, existentes sofrem, violentas pressões antrópicas, com riscos iminentes de extinção. Os conhecimentos mais recentes sobre este complexo bioma são traduzidos, em termos de uma diversidade de espécies muito maior do que a das formações amazônicas, bem como níveis elevados de endemismos.

Oliveira Filho \& Fontes (2000) investigaram a flora arbórea das florestas atlânticas do Sudeste do Brasil sob dois aspectos: variações da composição florística de floresta ombrófila e semidecidual, com base em variáveis geográficas e climáticas, através de análises multivariadas e listagens florísticas existentes e, ainda, vínculos entre floresta ombrófila e semidecidual com Florestas Amazônicas e Cerrados. Os autores verificaram que há mais similaridade florística no nível de espécies entre floresta ombrófila e semidecidual do que entre qualquer destas florestas e as florestas amazônicas, ou mesmo Cerrados. No entanto, há pouco fundamento florístico para se pensar nas florestas ombrófilas como as mais próximas de suas correspondentes amazônicas, do que sua vizinha semidecidual. Mencionam que a abordagem mais 
correta para floresta ombrófila e semidecidual do Sudeste brasileiro seja de um contínuo de distribuição de espécies. Por final, sugerem que a definição de floresta atlântica seja tão abrangente quanto à da floresta amazônica.

- Scudeller et al. (2001) considerando a abrangência geográfica da mata atlântica lato sensu, sua extensão com variedades de condições ambientais e, conseqüentemente, de espécies adaptadas a essas condições, a mata atlântica é um conjunto bastante heterogêneo de formações florestais, uma vez que sua definição se dá, principalmente, devido à sua posição geográfica. Contudo, pode ser verificado uma tendência à formação de dois grandes grupos florísticos estruturais, a floresta ombrófila densa e a floresta estacional semidecidual.

Scudeller (2002) reuniu 112 trabalhos de florística e de fitossociologia, num total de 268 listas de espécies. Estas foram cadastradas, através do sistema conhecido por FITOGEO, um banco de dados, desenvolvido, especialmente para gerenciar as informações de seu estudo, visando conhecer a distribuição geográfica das espécies arbóreas da mata atlântica em toda a sua amplitude geográfica. Assim, procurou investigar, quantitativamente, a similaridade florística-estrutural e diferenças entre amostras vindas de diferentes localidades. Após análises de agrupamento e ordenação, a autora pode chegar nos seguintes resultados: 1. a mata atlântica é bastante heterogênea floristicamente, com substituições de espécies, sendo que mais de $50 \%$ das espécies ocorrem em menos de $20 \%$ das amostras. Esta predominância de espécies arbóreas com distribuição restrita e a grande variação espacial de abundância pode, aparentemente, indicar nichos restritos; 2. nenhum táxoiı mostrou distribuição disjunta e, a maioria das espécies mostraram padrão de distribuição restrito à região Sudeste do país. 3 . analisando a ocorrência de táxons da floresta ombrófila densa atlântica em formações arbóreas vizinhas (cerrado, floresta estacional semidecidual e floresta montana de Pernambuco) observa-se que $63 \%$ de todas as espécies, também, ocorrem em outra formação florestal; 4. observou-se uma tendência às localidades das florestas ombrófilas e às das florestas estacionais formarem dois grupos florísticos estruturais, mas devido á grande heterogeneidade florística e substituição contínua de espécies, esses grupos não são bem definidos; 5 . a altitude e a temperatura foram as variáveis ambientais que 
apresentaram maior correlação, com as similaridades entre as localidades sendo estas muito importantes para a caracterização do ambiente.

\subsubsection{Levantamento por parcelas realizados na Mata Atlântica}

Leitão Filho et al. (1993) desenvolveram estudos no município de Cubatão, SP, abrangendo duas áreas de floresta, com situações distintas de perturbações. $\mathrm{Na}$ área fortemente perturbada, no vale do rio Moji, foi instalado um módulo de $40 \times 50 \mathrm{~m}$, dividido em vinte parcelas de $10 \times 10 \mathrm{~m}$, perfazendo uma área de $2000 \mathrm{~m}^{2}$. Na região do rio Pilões, trecho em melhor estado de conservação, foi instalado um módulo de $20 \times 50 \mathrm{~m}$, no sopé da encosta, dividido em dez parcelas de $10 \times 10 \mathrm{~m}$, totalizando $1000 \mathrm{~m}^{2}$. Um segundo módulo, foi instalado na encosta do morro, distante $200 \mathrm{~m}$ do primeiro módulo, este com $20 \times 50 \mathrm{~m}$, dividido em dez parcelas de $10 \times 10 \mathrm{~m}$, também, totalizando $1000 \mathrm{~m}^{2}$. $\mathrm{O}$ terceiro módulo foi instalado na margem oposta ao rio Pilões, área relativamente plana de boa preservação, com $40 \times 50 \mathrm{~m}$, dividido em vinte parcelas de $10 \times 10 \mathrm{~m}$, totalizando $2000 \mathrm{~m}^{2}$.Como critério de inclusão, utilizou o PAP (perímetro a altura do peito) mínimo de $20 \mathrm{~cm}$ em todos os módulos. Nas áreas do rio Pilões, foram registrados 772 indivíduos vivos, que resultaram em 145 espécies. As áreas mostraram estádios sucessionais distintos. A área do sopé da encosta, e mais jovem que as outras duas, oferece maior contribuição de espécies pioneiras, as áreas do alto da encosta, com mais espécies secundárias iniciais e tardias, é mais madura, e a área da margem do rio Pilões, a situação foi intermediária entre as áreas anteriores. $\mathrm{Na}$ área do rio Moji, a concentração de espécies pioneiras é muito alta, encontraram um estádio inicial de sucessão, uma situação diferenciada, face à poluição do ar e do solo ali detectadas. Os autores concluíram que, na região do vale dos Pilões, a vegetação é nitidamente secundária, exibindo diversas categorias sucessionais, enquanto que na área do rio Moji os dados mostram, de forma bem clara, que a vegetação não está conseguindo se recuperar, em função da contínua e pesada poluição atmosférica.

Melo \& Mantovani (1994), no estudo realizado na ilha do Cardoso Cananéia, São Paulo, apresentaram dados sobre a composição florística e estrutura da 
mata atlântica de encosta. Empregaram o método de parcelas, em área de 1 hectare, situada nos dois terços inferiores do morro conhecido localmente como morro da captação d'água, entre as altitudes de 100 - 150 m.s.m.; a área é uma vertente norte, voltada para o continente, cortada por vários rios, com muitos afloramentos rochosos e pouca declividade. Para a análise estrutural foram implantadas parcelas de $10 \times 15 \mathrm{~m}$, com critério de inclusão de $8 \mathrm{~cm}$ de P.A.P., que resultaram em 157 espécies distribuídas por 109 gêneros e 47 famílias. Os autores efetuaram comparações dos resultados com os trabalhos realizados em Ubatuba, (Silva 1980) e Salesópolis, (Mantovani et al., 1990).

Pinto (1998) no município de Cananéia - São Paulo, no Parque Estadual da Ilha do Cardoso, analisou a vegetação de uma área de mata de planície e correlacionou, em cinco formações, os parâmetros fitossociológicos entre si e com as características físicas e químicas do solo. $\mathrm{O}$ autor fez uso dos dados de Melo e Mantovani (1994) sobre a mata de encosta e de Sugiyama (1993) sobre a mata de restinga. $\mathrm{O}$ levantamento florístico e fitossociológico da mata de planície foi realizado em parcela única de $800 \mathrm{~m}^{2}$, dividido em $32 \mathrm{sub}$ parcelas de $250 \mathrm{~m}^{2}$, com inclusão de indivíduos com diâmetro mínimo (DAP) de $2,5 \mathrm{~cm}$. Foram encontrados 2.147 indivíduos vivos, pertencentes a 108 espécies distribuídas por 79 gêneros e 39 famílias. Dentre as famílias, destacaram-se como a de maior riqueza: Myrtaceae, Leguminosae, Euphorbiaceae e Lauraceae.

Ivanauskas (1997) estudando a formação Pariquera-Açú, que ocorre em maior proporção no município de Pariquera-Açú, localizado no litoral sul do Estado de São Paulo, realizou um estudo fitossociológico em dois remanescentes florestais sendo, quatro em áreas de Latossolo Amarelo e duas em Podzólico Vermelho Amarelo, subdivididas em parcelas de $10 \times 10 \mathrm{~m}$, totalizando 1,2 ha. $O$ critério de inclusão adotado foi $P A P \geq 15 \mathrm{~cm}$. Nas áreas do estudo, não foram encontradas diferenças significativas nos atributos químicos do solo, diferenciando-se apenas por atributos físicos. As florestas que ocorrem sobre esses solos mostraram-se semelhantes, florística e estruturalmente. Foram realizadas comparações florísticas entre localidades presentes no planalto atlântico e nas zonas que constituem a província costeira, sendo que as mesmas foram agrupadas, através de métodos de classificação e ordenação, evidenciando a presença de 
quatro blocos distintos. Um dos blocos reuniu os trabalhos realizados no planalto atlântico e os outros três reuniram os trabalhos executados na província costeira, da morraria costeira e nas áreas de floresta ombrófila da baixada litorânea. Um segundo grupo restringiu-se às elevadas altitudes da serrania costeira. $\mathrm{O}$ terceiro grupo, às áreas de restinga da baixada litorânea.

Sanchez (2001) estudando uma encosta de vegetação situada no vale, formado pelos morros do Corisco e Cruzeiro, no Parque Estadual da Serra do Mar Núcleo Picinguaba, em Ubatuba, verificou como ocorrem as mudanças na composição florística e na estrutura da vegetação, em função da altitude. Em uma área de 2,34 hectares, marcou todas as árvores, palmeiras e fetos arborescentes com PAP mínimo de $\geq 15 \mathrm{~cm}$. Realizou um levantamento fitossociológico na altitude de $2 \mathrm{~m}$ planície, denominada de floresta ombrófila densa das terras baixas, na meia encosta de 100 a $600 \mathrm{~m}$ em floresta ombrófila densa submontana, e no topo de morro a $1000 \mathrm{~m}$ em floresta ombrófila densa montana. A autora concluiu que, nessas formações, há espécies características a da uma delas, e que as principais mudanças na estrutura da vegetação, entre planície e a encosta, estão representadas pelo aumento da diversidade, área basal e altura e à diminuição da densidade.

Custódio Filho (2002) instalou, no Parque Estadual "Carlos Botelho", seis faixas com 1000 metros de comprimento, divididas em parcelas de 2 x $20 \mathrm{~m}\left(40 \mathrm{~m}^{2}\right)$. Amostrou todas as árvores com DAP maior ou igual a $10 \mathrm{~cm}$, num total de 1.218 árvores distribuídas em 54 famílias e 211 espécies. As faixas 1 e 2, instaladas respectivamente a 1000 e 800 m.s.m. estão localizadas no município de São Miguel Arcanjo; a faixa 3 a 600 m.s.m., foi instalada no trecho de floresta pertencente ao município de Capão Bonito; as faixas 4, 5, e 6, a 400, 200 e 50 m.s.m., respectivamente, estão no município de Sete Barras. $O$ autor concluiu que a flora e a estrutura da floresta ombrófila densa respondem ao gradiente altitudinal, havendo diminuição na biomassa total, riqueza e na diversidade alfa $\left(\mathrm{H}^{\prime}\right)$ das baixas altitudes às mais elevadas. Inferiu ainda que pode ter sido determinante nas alterações estruturais e florísticas. Trechos de florestas são ricos em espécies e se modificam de forma gradual, quanto maior à distância da área comparada. 


\subsubsection{Levantamento por quadrantes realizados na Mata Atlântica}

Dias et al. (1989) compararam métodos empregados na amostragem de vegetação e aplicaram testes não paramétricos, que evidenciaram não haver diferenças significativas entre os índices de valor de importância (IVI) conseguidos, através de parcelas e métodos baseados em distâncias. Cabe salientar que o (IVI) constitui um parâmetro importante para testar as aplicações de métodos de levantamento da vegetação, uma vez que reúne, num só valor, a área basal, o número de indivíduos e a distribuição horizontal de cada essência.

Mantovani et al. (1990), em Salesópolis, na serra do Juqueriquerê, detectaram quatro padrões de vegetação: mata de topo de morro, mata de encosta voltada para o oceano atlântico, mata de encosta voltada para o vale do Paraíba e mata de fundo de vale. Delimitaram em cada padrão, 25 pontos, perfazendo um total de 100 pontos e 400 indivíduos, cujo DAP mínimo foi $15 \mathrm{~cm}$, como critério de inclusão. Os autores constataram, entre os diferentes padrões, a presença de poucas espécies com ampla distribuição e abundantes, como também muitas espécies raras.

As matas de encosta, padrão intermediário entre o padrão topo de morro e fundo de vale, quanto mais próximas aos padrões extremos, tendem a se assemelhar em estrutura e florística.

Dias et al. (2000) realizaram estudo fitossociológico em trecho da floresta pluvial atlântica em estádio secundário, objetivando determinar a diversidade de espécies arbóreas, através do emprego de seis diferentes índices de diversidade. No levantamento realizado, utilizando-se do método de quadrantes, com 156 pontos, foram amostrados 1248 indivíduos, sendo 624 pertencentes à classe 1 de diâmetro (DAP $\geq 10 \mathrm{~cm}$ ) e 624 pertencente a classe 2 de diâmetro $(5 \leq \mathrm{DAP}<10 \mathrm{~cm})$. Na classe 1 foram identificadas 152 espécies e 41 famílias vegetais. Na classe 2 foram identificadas 163 espécies e 43 famílias. No total foram identificadas 219 espécies e 45 famílias. Foram anexados seis índices de diversidade: Margalef; Menhinick; McIntosh; Berger-Paker;

Shannon e Simpson. Concluíram que: a) o índice de Margalef mostrou ser o mais 
sensível à variação do tamanho da amostra; Shannon e Menhinick mostraram-se sensíveis e os de Simpson e McIntosh os menos sensíveis; b) há necessidade do emprego de um mesmo tamanho de amostra, para se obter valores comparáveis de diversidade, $\mathrm{e}$ c) os índices de Simpson e McIntosh são os mais indicados para determinar a diversidade de espécies arbóreas, quando se pretende comparar resultados provenientes de diferentes locais.

Negreiros et al. (1995) no Núcleo Sete Barras do Parque Estadual "Carlos Botelho", estudaram a estrutura do componente arbóreo, através de 40 pontos de amostragem, com distância média, entre pontos, de $120 \mathrm{~m}$. Determinaram os parâmetros necessários à obtenção da densidade, dominância, freqüência e dos índices de importância e de cobertura, de espécies raras, de concentração, de densidade, de mescla e de variação. As análises envolveram as seguintes classes diamétricas: DAP maior ou igual a 2,8 cm e DAP maior e igual a $10 \mathrm{~cm}$. Foram amostradas 597 árvores, 112 espécies pertencentes a 37 famílias, totalizando, aproximadamente, 15 indivíduos por ponto e área basal de $29,85 \mathrm{~m}^{2}$. ha- ${ }^{1}$. Dentre as famílias com maior índice de valor de importância (IVI), destacaram-se: Myrtaceae, Arecaceae, Euphorbiaceae, Leguminosae e Rubiaceae.

Almeida-Scabbia (1996) analisou comunidades ripárias em Sete Barras, Estado de São Paulo, no Parque Estadual Intervales. Utilizando o método de quadrantes, amostrou quatro áreas entre 60 a $150 \mathrm{~m}$ de faixa altitudinal. Dentre os 201 pontos, 50 pontos foram marcados em ambiente ripário, 43 pontos na baixa encosta, 50 na média encosta e 58 na alta encosta. A autora, utilizando-se da análise de agrupamento (método UPGM e coeficiente de distâncias euclidianas quadradas para comparar as áreas), detectou que o ambiente ripário mostrou-se mais distinto, seguido da alta encosta e, com maior semelhança entre si, a baixa e média encostas. Concluiu, que se tratam de duas comunidades, a ripária e a da encosta, constituídas por três associações: baixa, média e alta encostas. 


\section{MATERIAL E MÉTODOS}

\subsection{Característica e localização da região de estudo}

O presente trabalho foi desenvolvido no Parque Estadual Carlos Botelho (PECB) (Figura 1), numa das regiões mais importantes do Estado, do ponto de vista ambiental. Conforme Leitão Filho (1982), no estado de São Paulo a mata atlântica está situada nas encostas da Serra do Mar, com penetrações mais para o interior, particularmente no Sul do Estado, onde adquire dimensões razoavelmente grandes e representa a maior área de floresta natural remanescente existente, como também corresponde a área menos desenvolvida do Estado. O Parque, com área de 37.797,43 hectares, ocupa parte dos municípios de São Miguel Arcanjo, Capão Bonito, Sete Barras e Tapiraí, possui cobertura vegetal classificada como floresta pluvial atlântica (Dias et al., 1995). Esta Unidade de conservação é administrada pelo Instituto Florestal, órgão da Secretaria do Meio Ambiente do Estado de São Paulo.

Compreende um trecho localizado no setor norte do Parque, próximo à sede, em área de relevo montanhoso denominado de planalto de Guapiara, entre os paralelos $24^{\circ} 03^{\prime} 15^{\prime \prime}$ e $24^{\circ} 04^{\prime} 00^{\prime \prime}$, de latitude sul e $47^{\circ} 59^{\prime} 00^{\prime \prime}$ e $48^{\circ} 00^{\prime} 00^{\prime \prime}$ de longitude oeste. Trata-se de uma bacia conhecida como ribeirão dos Fornos, com 102 hectares, e compõe áreas entre as altitudes de 690 a 821 m, onde estão implantadas duas estradas: nos limites inferiores a SP.- 139 e nos limites superiores uma estrada de serviço com $28 \mathrm{~km}$ de extensão, que liga a sede ao interior do Parque (Domingues et al., 1993). 


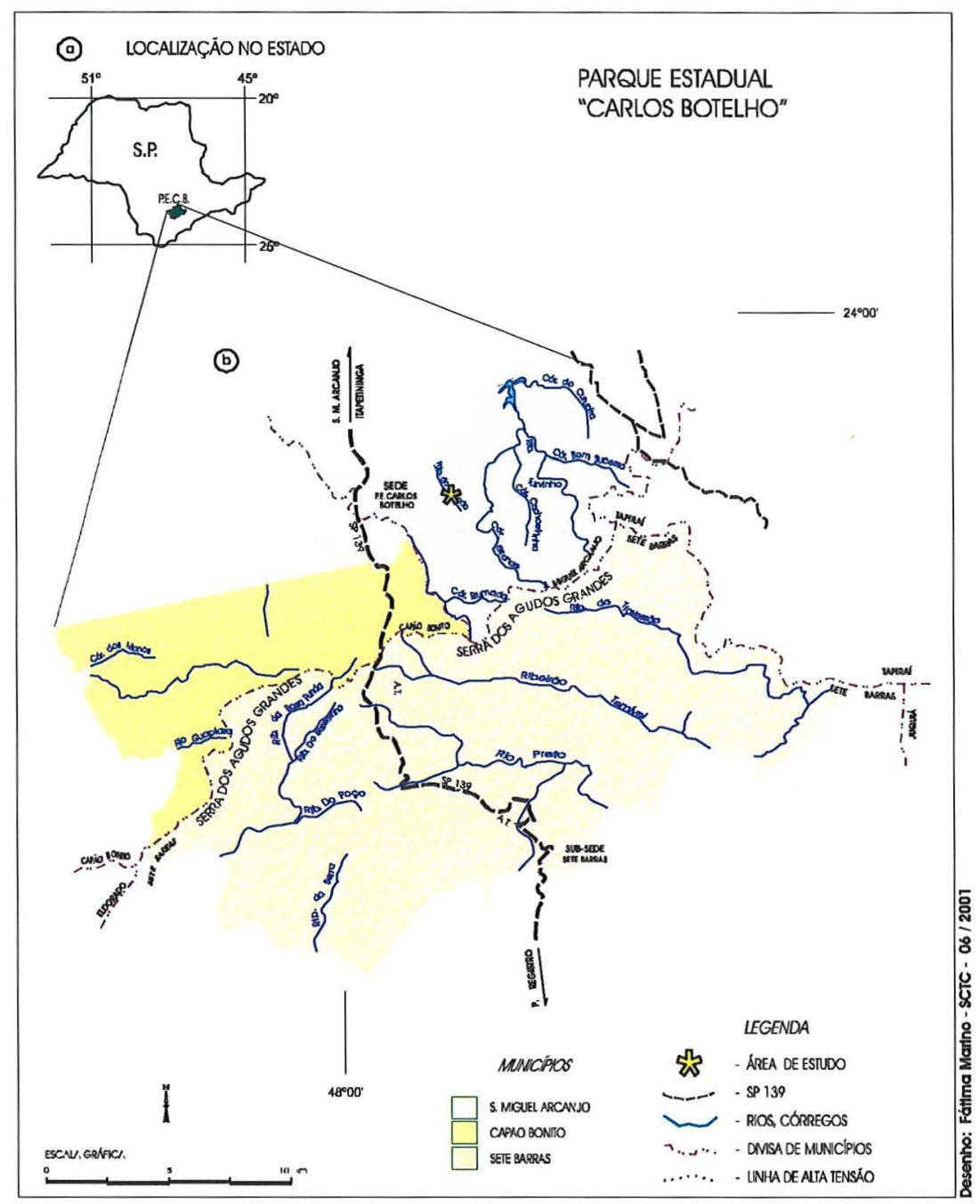

Figura 1 - a) Localização do P.E.C.B. na região sul do Estado de São Paulo; b) Localização da área de estudo e parte dos municípios de São Miguel Arcanjo, Capão Bonito e Sete Barras

Este Parque, localizado na região da serra de Paranapiacaba, em conjunto com o PETAR (Parque Estadual Turístico do Alto Ribeira), Parque Estadual de Jacupiranga e a Estação Ecológica de Xitué, receberam da UNESCO o título de Patrimônio Natural da Humanidade. Estas áreas, também, fazem parte da Reserva da Biosfera da Mata Atlântica (Reserva da Biosfera da Mata Atlântica, 1998), um dos habitats do mono carvoeiro. 


\subsubsection{Histórico}

O governo do Estado, através do decreto $\mathrm{n}^{0} 12.272$ de 27/10/1941, criou o núcleo colonial Carlos Botelho, com área de 7.457 hectares, no primeiro perímetro do município de São Miguel Arcanjo. Para o núcleo, previa-se que, 746 hectares seriam destinados a conservação da flora e da fauna, 150 hectares para os campos de demonstração agrícola e os 6.561 hectares, restantes, divididos em lotes rurais de 15 a 30 hectares cada. O objetivo era a concessão de lotes à colonos estrangeiros e nacionais, ou seja, cerca de 435 lotes de 15 hectares ou 215 de 30 hectares. Mas o decreto $\mathrm{n}^{0} 13.251$ de 26/02/1943, felizmente, converteu o núcleo colonial, ainda não implantado, em Reserva Florestal com fins de conservação da flora e fauna estaduais.

Outras Reservas foram criadas, como a do Travessão, a partir do decreto $\mathrm{n}^{\circ} 28.862$ de 03/07/1957, a Reserva florestal de Sete Barras, com o decreto ${ }^{\circ} 12.276$ de 29/10/1941 e a Reserva Florestal de Capão Bonito, pelo decreto $\mathrm{n}^{0} 12.277$ de 29/10/1941.

A criação do Parque Estadual Carlos Botelho se deu, através do decreto estadual $\mathrm{n}^{\circ} 19.499$, de 10/09/1982. Este mesmo decreto reuniu, em uma só Unidade, as Reservas Estaduais de São Miguel Arcanjo, Sete Barras, Capão Bonito e Travessão.

Antecedendo à criação do Parque, a lei estadual $n^{\circ} 1.293$ de 23 de dezembro de 1991, autorizou o governo, na época, a construir uma estrada de rodagem de São Miguel Arcanjo à Sete Barras, obra que só foi concluída em 1937.

A rodovia SP 139, com seus 112 quilômetros, dos quais 52 são asfaltados, secciona o Parque num trecho de 33 quilômetros, sem pavimentação. A estrada é o elo de ligação entre o planalto e a planície costeira e, ao mesmo tempo, motivo de diversas discussões acerca de seu asfaltamento no trecho que atravessa o Parque.

O nome Carlos Botelho, é uma homenagem ao médico urologista que foi Secretário da Agricultura, Viação e Obras Públicas do Estado de São Paulo, em 1904. Carlos José de Arruda Botelho nasceu em Piracicaba, aos 14 de maio de 1855, filho do Coronel Antonio Carlos de Arruda Botelho, mais tarde Visconde de Pinhal, 
e de Francisca Coelho de Arruda Botelho. Carlos Botelho, numa de suas viagens, visitou a cidade de Odessa, na Ucrânia, Rússia, porto situado às margens do Mar Negro; impressionado com a simetria e topografia da cidade, suas amplas avenidas, ruas largas e casas com jardins, guardou muito bem essa imagem e, quando retornou ao Brasil (São Paulo), na atual região metropolitana de Campinas, decidiu criar um núcleo colonial e deu-lhe o nome de Nova Odessa e planejou a sua urbanização nos mesmos moldes da cidade que visitou.

\subsubsection{Questão fundiária}

A questão fundiária do P.E.C.B. é considerada privilegiada, em relação às demais Unidades de Conservação que compõem o continuum ecológico da mata atlântica no Vale do Ribeira. Na década de 40, do século passado, as Reservas Florestais que originaram o Parque eram terras devolutas do Estado ou áreas particulares que foram desapropriadas.

\subsection{Fatores abióticos e bióticos}

\subsubsection{Clima}

A região apresenta duas áreas com tipos climáticos diferenciados, Cfa e Cfb, de acordo com a classificação de Köppen (1948), separados pela serra de Paranapiacaba. $\mathrm{O}$ tipo climático $\mathrm{Cfa}$, ou clima quente úmido sem estiagem, ocupa áreas do planalto de Guapiara com altitudes inferiores a 800 metros, assim como, a média e a baixa escarpa da serra de Paranapiacaba, possui temperaturas inferiores à $18^{\circ} \mathrm{C}$ no mês mais frio, enquanto no mês mais quente ultrapassa $22^{\circ} \mathrm{C}$. O total pluviométrico do mês mais seco é superior à $30 \mathrm{~mm}$. O tipo climático $\mathrm{Cfb}$, ou clima temperado úmido, sem estiagem, aparece nas partes elevadas da serra de Paranapiacaba e difere do anterior, apenas pela temperatura média do mês mais quente, a qual não ultrapassa $22^{\circ} \mathrm{C}$ (Setzer, 1946). 


\subsubsection{Hidrografia}

Quanto aos cursos d'água, do PECB, pode se destacar, na serra de Paranapiacaba, os rios Preto e Quilombo, os ribeirões Temível e Travessão, além do ribeirão da Serra, todos formadores da bacia do rio Ribeira de Iguape. Estes apresentam um complexo e denso sistema de drenagem. Os principais canais que drenam o planalto de Guapiara pertencem à bacia do rio Paranapanema, dentre os quais podemos citar o rio Taquaral, o ribeirão Turvinho, ribeirão Grande, ribeirão Lajeado, rio Lajeado e rio Guapiara. Nessa área, o sistema de drenagem é menos denso, quando comparado à região serrana, ben como o padrão de drenagem que apresentam ângulos bem mais agudos e drenos mais longos. Em ambas unidades morfológicas, ocorre um forte controle estrutural dos cursos d'água, principalmente, nas escarpas da serra de Paranapiacaba e nas áreas próximas ao falhamento dos Agudos Grandes.

\subsubsection{Geologia}

A litologia do Parque é formada basicamente pelos filitos e quartzitos do grupo Açungui e por rochas graníticas intrusivas. Há, também, a presença de diques e diabásicos de espessuras variadas que cortam tanto os metassedimentos do Açungui, quanto os granitos. Os granitos sustentam os principais divisores d'água, ao longo da serra de Paranapiacaba, enquanto os diques de diabásio sustentam elevações menores (Domingues \& Silva, 1988).

Os filitos típicos do grupo Açungui estão localizados nas porções norte e noroeste do Parque (planalto Guapiara), compreendendo a sede da Unidade. Possuem orientação ENE e se estendem até o $\mathrm{Km} 214$ da SP. 139. Seguindo a rodovia, em direção à Sete Barras, é possível encontrar expressivos diques de diabásio com direção EW (Domingues \& Silva, 1988).

Intensas perturbações tectônicas geraram um grande número de falhamentos, com direção predominante SW-NE. As intrusões de rochas básicas, do Mezozóico, formaram numerosos diques de diabásicos. 


\subsubsection{Geomorfologia}

A serra de Paranapiacaba caracteriza-se pelo relevo montanhoso, com vertentes de altas declividades, forte dissecação e presença marcante de processos erosivos no planalto de Guapiara, uma subdivisão do planalto atlântico, caracterizado por relevo de morros paralelos e morrotes baixos (Ponçano et al., 1981). No primeiro aspecto morfológico, destacam-se os topos arredondados, vertentes retilíneas à convexas, alta densidade de drenagem de padrão retangular e planícies aluvionares restritas. O último tipo de aspecto morfológico apresenta um relevo ondulado, amplitudes locais inferiores a $50 \mathrm{~m}$, topos arrcdondados, vertentes convexas à retilíneas, alta densidade de drenagem com padrão retangular e planícies aluviais restritas.

No planalto se encontram áreas entre 700 e 800 metros de altitude, representando um local de transição entre o planalto e as escarpas da serra de Paranapiacaba. Verifica-se, também, forte influência do grande falhamento dos Agudos Grandes na geomorfologia local, com predominância de declividade superior a $20 \%$ (Domingues \& Silva, 1988).

As altitudes superiores a $800 \mathrm{~m}$ se encontram na porção noroeste do Parque e em algumas cimeiras da serra dos Monos e da serra dos Agudos Grandes. As altitudes entre 600 a $800 \mathrm{~m}$ ocupam cerca de $40 \%$ de toda a extensão do Parque e correspondem, principalmente, ao rebordo do planalto de Guapiara e sua transição para o setor de escarpas da serra de Paranapiacaba. Altitudes entre 400 e 600 m podem ser encontradas na parte centro - leste do Parque e, estas áreas, correspondem à parte alta das escarpas da serra. As faixas altitudinais entre 200 - $400 \mathrm{~m}$ estão nas porções sul do Parque e representam as baixas escarpas da serra de Paranapiacaba. Por último, as faixas entre 0 e $200 \mathrm{~m}$ estão associadas a colúvios de vertentes e à planície aluvionar do ribeirão da Serra.

$\mathrm{Na}$ área de escarpas, as declividades predominantes são aquelas superiores a $20 \%$, com algumas áreas de topo de vales com declividades menores. No planalto, os vales são mais amplos $\mathrm{e}$ as variações altimétricas menores, 
predominando as declividades inferiores a $20 \%$. Declives inferiores à $3 \%$ no (PECB), estão restritos aos pequenos alvéolos aluviais e à planície fluvial do Ribeirão da Serra.

\subsubsection{Solos}

As unidades de solos identificadas na área foram: latossolo vermelho amarelo (LV), argiloso vermelho-amarelo latossólico (PVL), latossolo vermelhoamarelo argilúvio (LVP), cambissolos húmicos alumínicos sômbricos (CHA) e neossolos regolíticos psamíticos lépticos (RRQ) (Pfeiffer et al., 1986).

Latossolo vermelho-amarelo: solos argilosos relativamente profundos, baixa saturação de bases (inferior a 11\%), ácidos, estrutura granular pequena, porosa e pouco coesa. Coloração variando do bruno ao amarelo, nas altitudes superiores a $600 \mathrm{~m}$, declividades superiores a $12 \%$ e caracterizados pelos morros paralelos e rebordo do planalto, formado sobre o Açungui e as Intrusivas Graníticas.

Argiloso vermelho-amarelo Latossólico (PVL): estrutura em blocos sub angulares, ausência do sub horizonte A2, cerosidade, ácidos e baixa saturação em bases $(<17 \%)$. Altitudes elevadas $(>800 \mathrm{~m})$ e declividades superiores a $20 \%$. Ocorrem à noroeste e a centro-leste, nas serras dos Agudos Grandes e em escarpas inclinadas, respectivamente, formado sobre o Açungui e as Intrusivas Graníticas.

Latossolo vermelho-amarelo Argilúvico (LVP): ausência de cerosidade, estrutura em bloco sub angulares e angulares, ácido e baixa saturação de bases (<13\%); elevados teores de alumínio $(>70 \%)$. Ocorrem, à noroeste, na faixa montanhosa da serra dos Agudos Grandes, preferencialmente, em altitudes entre $600 \mathrm{e}$ $900 \mathrm{~m}$ e em declividades superiores a $20 \%$. São ácidos e com baixa saturação de bases intocáveis. A ausência de materiais primários evidencia intensa pedogênese, formado sobre o Açungui e as Intrusivas Graníticas

Neossolo regolíticos psamilítico lépticos (RRQ): ocorrem ao sul do Parque em relevo montanhoso e, predominantemente, em declividades superiores à $20 \%$. Solos pouco desenvolvidos, $\operatorname{rasos}(<40 \mathrm{~cm})$ se formam, preferencialmente. 
Cambissolos húmicos alumínicos sômbricos (CHA): estão ao sul do Parque, em relevo escarpado, com afloramentos rochosos, vertentes íngremes ( $>40 \%)$. Solos rasos, estrutura em blocos sub-angulares, sem cerosidade, horizonte " $A$ " escuro. Ocorrem em altitudes de até $1000 \mathrm{~m}$ e acima das rochas graníticas.

Os neossolos e cambissolos são rasos e estão associados às vertentes íngremes. Os cambissolos do Parque são ácidos e estão associados às áreas altas ( $>800 \mathrm{~m})$. Sobre as rochas do grupo Açungui, formam-se, predominantemente, os argissolos (ácidos e ricos em húmus) e os latossolos (ácidos, mais profundos e típicos de áreas de morro).

\subsubsection{Vegetação}

A cobertura vegetal, do Parque Estadual Carlos Botelho, pode ser classificada como floresta ombrófila densa, esta denominação equivale à floresta pluvial tropical, baseada no sistema fisionômico-ecológico de classificação da vegetação brasileira (Veloso et al., 1991), genericamente, conhecida por mata atlântica. A floresta ombrófila do sul do estado recebe ainda contribuição florística significativa das florestas do sul do Brasil. Nesta região encontra-se o limite norte da distribuição contínua do domínio da floresta de araucaria, nas altitudes mais elevadas (Mantovani, 1993).

\subsection{Procedimento de campo}

\subsubsection{Demarcação da grade amostral}

Para demarcação da grade amostral, utilizou-se de uma carta aerofotográfica, na escala 1: 35.000 como subsídio inicial para a escolha da área.

O trecho de vegetação escolhido apresenta altitude média, em torno, de 650 metros e dista da sede cerca de $4 \mathrm{~km}$. É um local considerado de transição, entre o planalto e a escarpa, da serra de Paranapiacaba (Figura 2). 


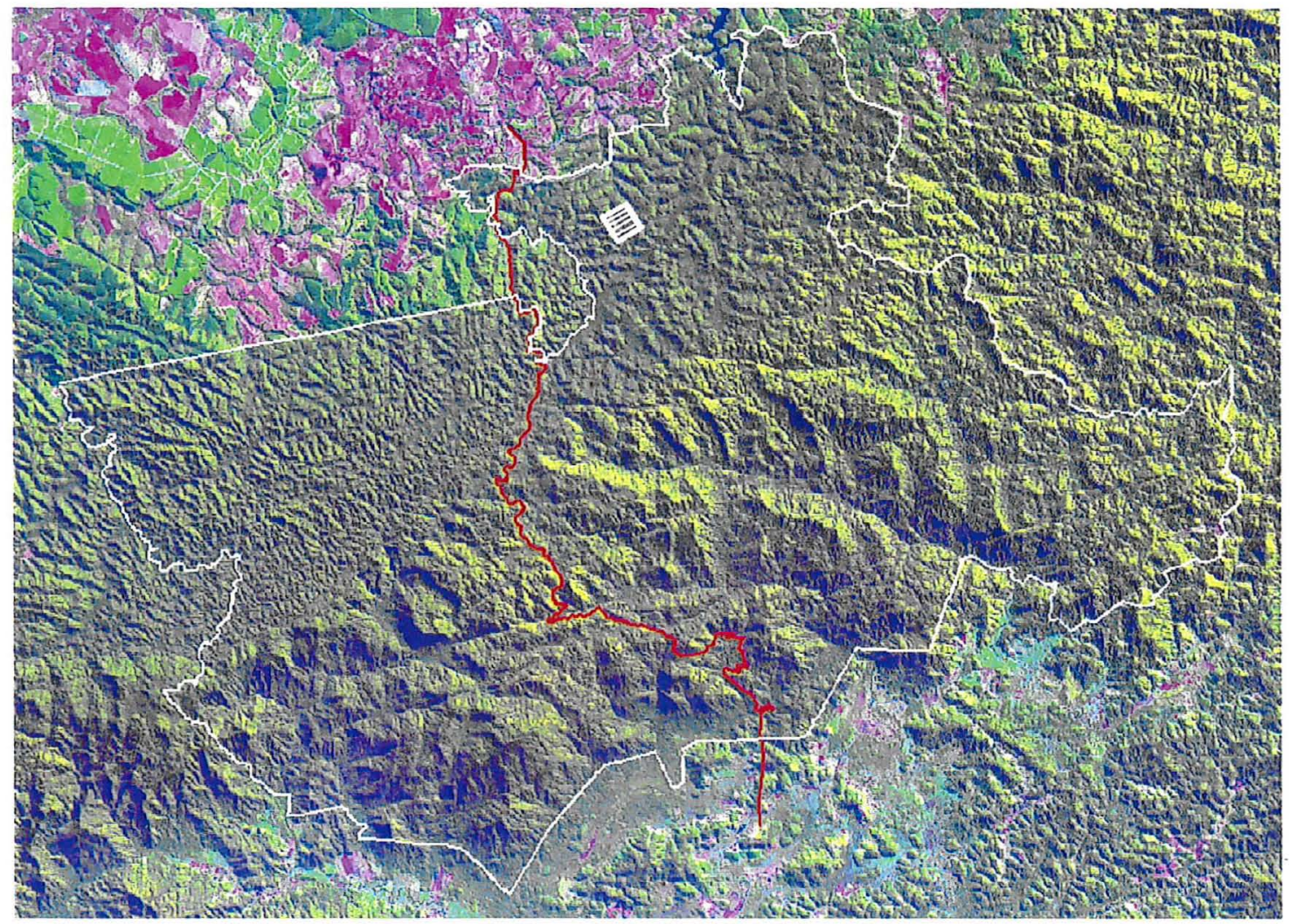

Figura 2 - Localização da grade de amostragem no Parque Estadual "Carlos Botelho"

Nesta área, no sentido sudoeste-noroeste, instalou-se uma grade de 8 trilhas paralelas e 8 pontos em cada trilha, sistematicamente distribuídos, onde a distância estabelecida foi de 100 metros entre trilhas e entre pontos (Figura 3).

Os 64 pontos amostrais, da grade, totalizaram uma área de abrangência de $640.000 \mathrm{~m}^{2}$ ou seja, 64 hectares.

Cada trilha recebeu a denominação de uma letra $(\mathrm{A}$ a $\mathrm{H})$ e, cada ponto amostral, um número seqüencial (1 a 8), perfazendo os pontos amostrais A1, A2, A3, A4, A5, A6, A7, A8 e assim, sucessivamente, para as demais trilhas (Figura 4). 
PONTO AMOSTRAL

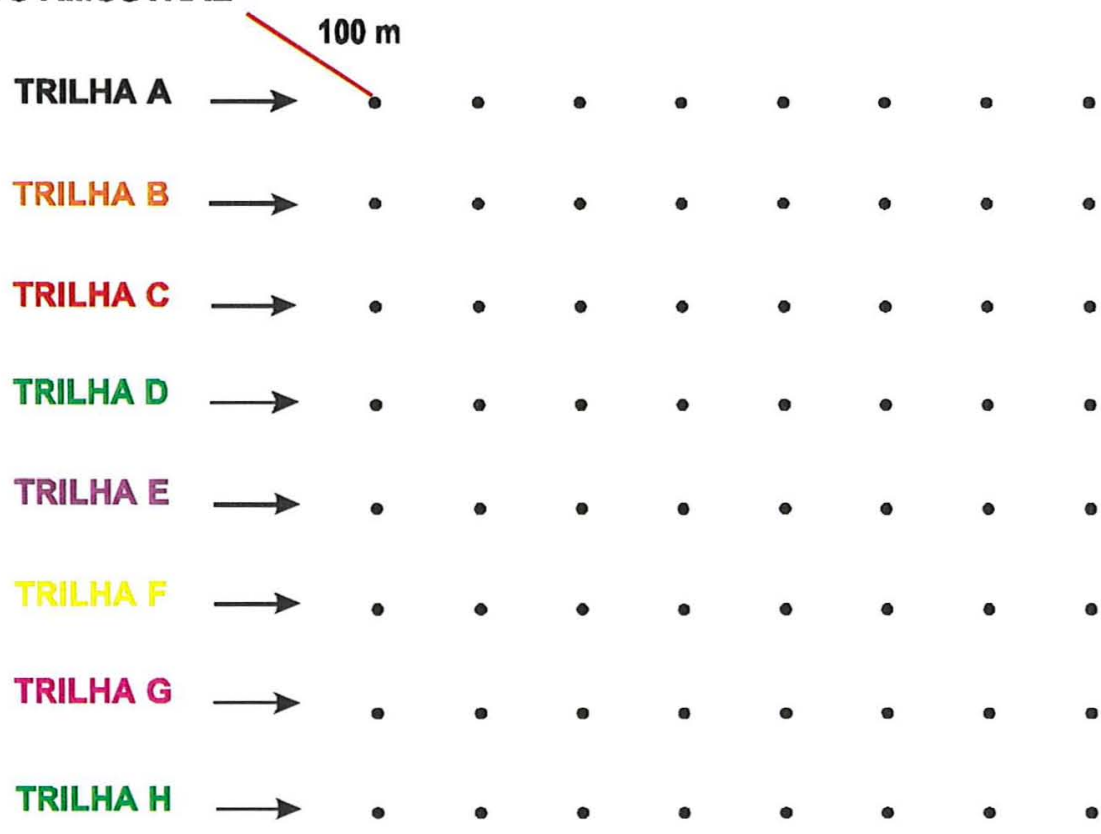

Figura 3 - Desenho esquemático de oito trilhas e oito pontos por trilha

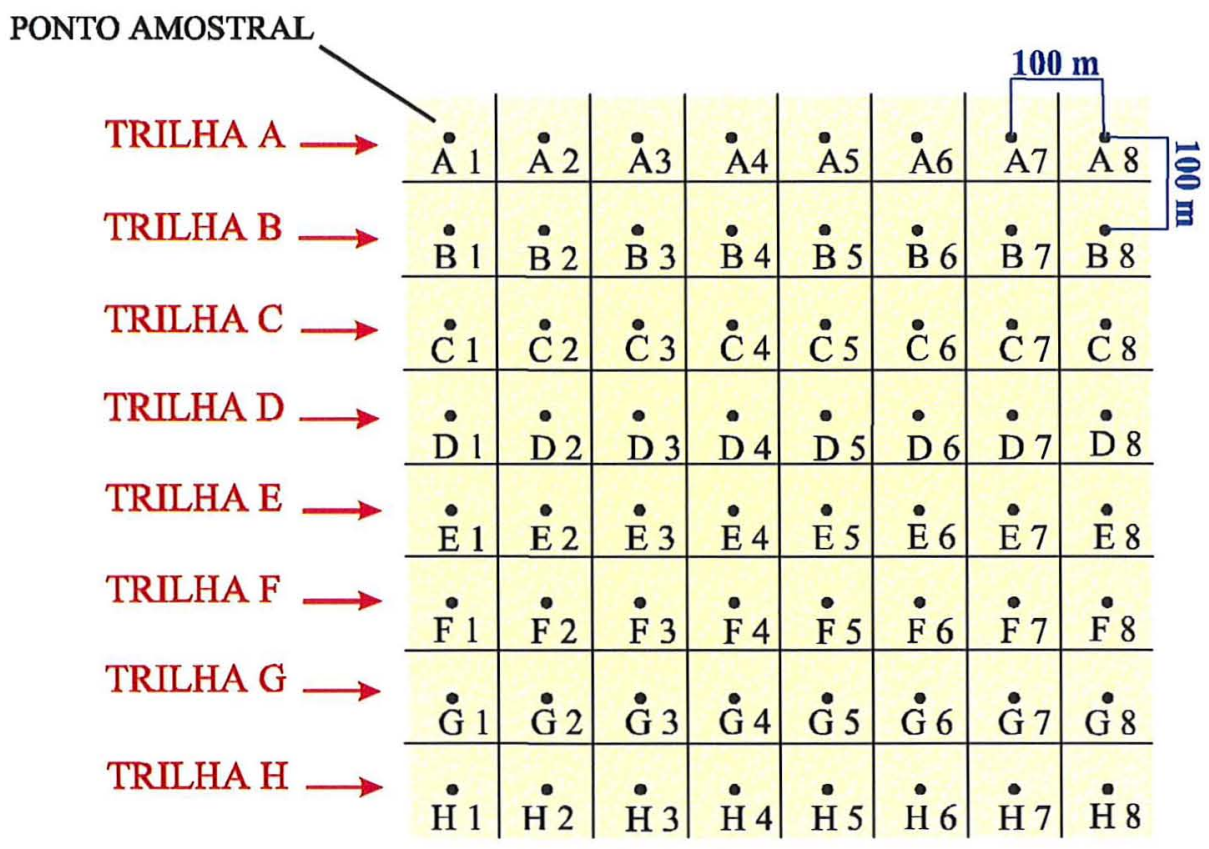

Figura 4 - Desenho esquemático da grade de amostragem 
Para auxiliar a abertura e orientação das trilhas, utilizou-se de uma bússola e três balizas, sendo duas metálicas e uma de madeira, a baliza de madeira esteve sempre às mãos do balizeiro, que efetuava a leitura da bússola e as outras duas balizas às mãos de um balizeiro de vante e outro de ré. Assim, procurou-se manter o alinhamento na abertura de cada linha e, conseqüentemente, diminuir os desvios que pudessem comprometer a demarcação da grade.

A distância entre trilhas e entre os pontos foi obtida, através de um instrumento da classe dos hipsômetros, denominado (Forestor Vertex), que possibilita a medição da altura das árvores, sem escala de distâncias horizontais fixas, e permite o cálculo direto de distâncias corrigidas.

\subsubsection{Instalação das parcelas}

$\mathrm{Na}$ área correspondente aos 64 pontos amostrais, foram instaladas 64 parcelas de $10 \times 90 \mathrm{~m}\left(900 \mathrm{~m}^{2}\right)$. Nesta área, cada ponto marcado (com cano PVC) foi considerado o centro de uma parcela retangular $\left(\right.$ de $\left.900 \mathrm{~m}^{2}\right)$, totalizando uma área de 5,76 hectares.

A demarcação das parcelas foi realizada de forma que seus lados maiores acompanhassem a ordenação prévia, no sentido sudoeste-noroeste, em que as trilhas foram abertas.

$\mathrm{Na}$ demarcação das parcelas, estas receberam as mesmas denominações de letras e números, conforme estabelecido na instalação da grade amostral (parcelas: $\mathrm{A} 1, \mathrm{~A} 2, \mathrm{~A} 3, \mathrm{~A} 4, \mathrm{~A} 5, \mathrm{~A} 6, \mathrm{~A} 7 \mathrm{e} \mathrm{A8)} \mathrm{e,} \mathrm{assim,} \mathrm{sucessivamente,} \mathrm{para} \mathrm{as} \mathrm{demais} \mathrm{trilhas.}$

Cada parcela, definitivamente estabelecida, distantes 10 metros entre si e 100 metros entre trilhas, foi subdividida em 9 subparcelas amostrais de $10 \times 10 \mathrm{~m}$ $\left(100 \mathrm{~m}^{2}\right)$ e, por sua vez, cada subparcela, foi novamente, dividida em duas pequenas subunidades de $5 \times 10 \mathrm{~m}\left(50 \mathrm{~m}^{2}\right)$, caracterizando-se, assim, o lado esquerdo e direito das subparcelas (Figura 5). 


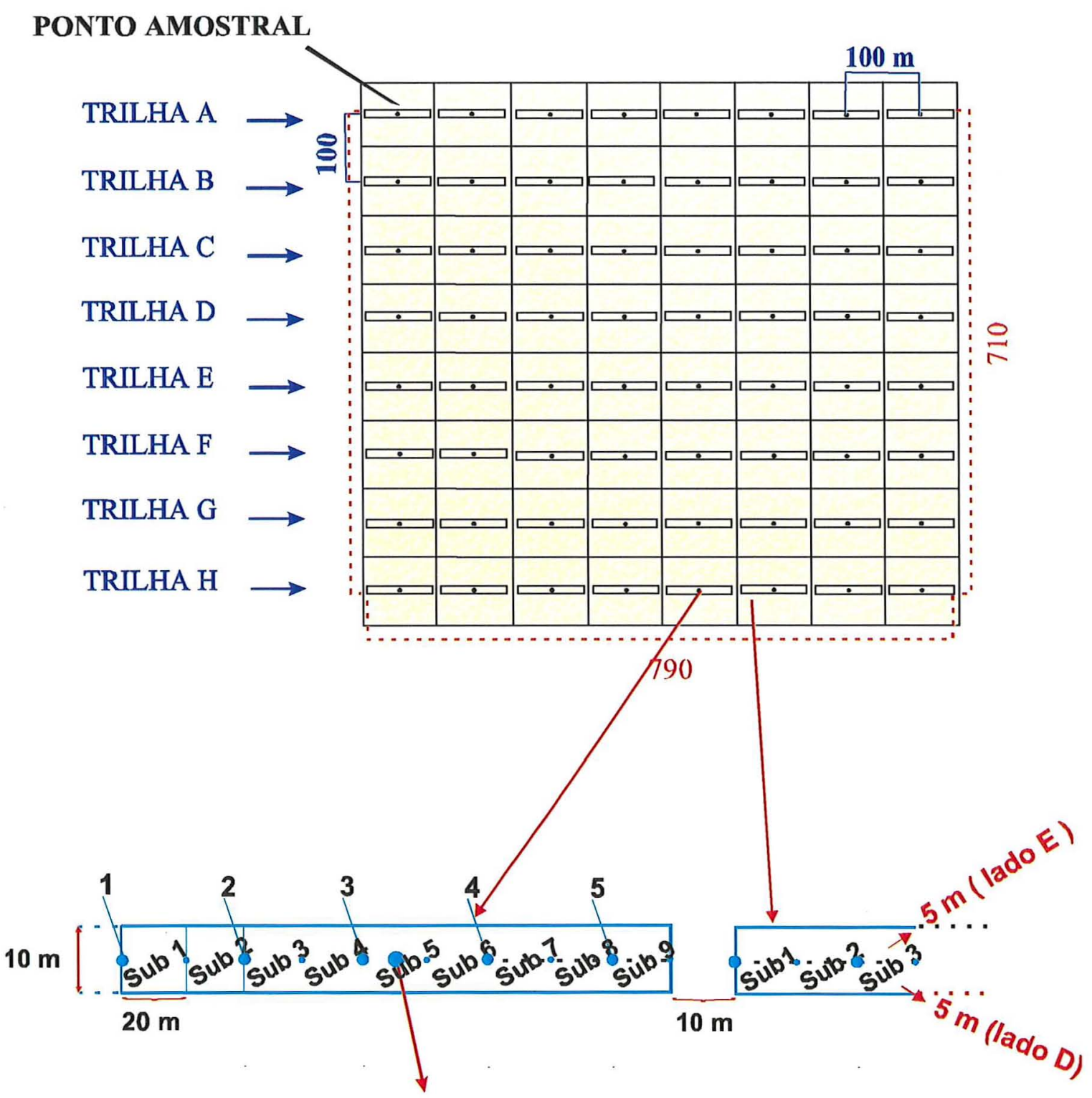

Figura 5 - Desenho esquemático da grade de amostragem com as parcelas

\subsubsection{Instalação dos quadrantes}

Utilizando-se da mesma área física da instalação das parcelas, foram alocados 320 pontos quadrantes, distantes 20 metros entre si e distribuídos, sistematicamente, sobre as trilhas. 
$\mathrm{Na}$ área de estudo, foram alocados 5 pontos quadrantes para cada parcela de $900 \mathrm{~m}^{2}$ de A1 a A8 e ao longo de cada trilha de $\mathrm{A} \mathrm{a} \mathrm{H}$, totalizando 40 pontos por trilha. Para tanto, ficou estabelecido o primeiro ponto no início das subparcelas e os demais entre as subparcelas 2 e 3, 4 e 5, 6 e 7, 8 e 9 (Figura 6). Desta maneira, no interior de cada uma das 64 parcelas, foram, efetivamente, amostrados 18 indivíduos, totalizando 1152 árvores. Neste caso, os outros 128 exemplares, estão fora dos limites internos das parcelas, perfazendo no cômputo geral os 1280 indivíduos amostrados nos 320 pontos quadrantes.

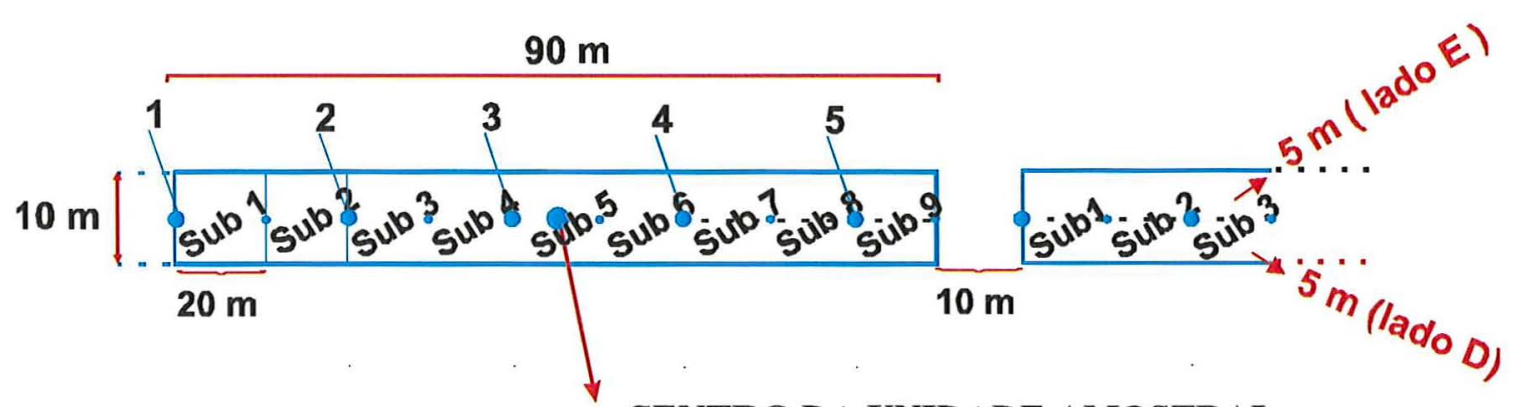

\section{CENTRO DA UNIDADE AMOSTRAL (ESTACA DE CANO PLÁSTICO)}

Figura 6 - Desenho esquemático de duas parcelas com as respectivas subparcelas e localização dos pontos quadrantes. No início da subparcela 1, entre a subparcela 2 e 3,4 e 5,6 e 7 e 8 e 9

\subsubsection{Coleta dos dados e identificação dos indivíduos}

Em cada parcela e quadrante foram considerados os indivíduos arbóreos que apresentaram, no mínimo, $5 \mathrm{~cm}$ de diâmetro a altura do peito (DAP a 1,30 m do solo). Os indivíduos perfilhados também foram considerados, quando pelo menos uma das ramificações estivesse enquadrada no critério de inclusão.

Todos os indivíduos, de acordo com o critério de inclusão, foram mensurados e marcados com plaquetas de alumínio numeradas e fixadas nas árvores com pregos galvanizados. As árvores mortas e em pé e os fetos arborescentes não foram considerados. 
As amostras botânicas, férteis ou não, foram coletadas com o auxílio de tesouras de poda alta, acopladas à hastes de coleta, as quais atingiam cerca de 10 metros de altura. Para as árvores mais altas, utilizou-se o "estilingue" com pedras britadas e facetadas, para facilitar o corte dos ramos.

As amostras coletadas foram individualizadas com fitas adesivas, numeradas e acondicionadas em saco plástico, maneira prática e correta para facilitar as atividades de campo. Na sede do Parque, foi improvisado um espaço para manuseio do material botânico coletado. As amostras foram separadas e colocadas entre jornais, papelões e amarradas entre prensas de madeira e levadas para estufa de lâmpadas, especialmente preparada para secagem do material coletado.

Os exemplares com estruturas férteis receberam tratamentos diferenciados, de acordo com a metodologia usual (Fidalgo \& Bononi, 1984; Mori et al., 1985).

Os exemplares, após a secagem, foram identificados aos níveis de família, gênero e espécies, inicialmente, com ajuda de bibliografia especializada, comparações com materiais depositados nos herbários do Instituto Florestal (SPSF) e do Instituto de Botânica (SP) e consulta à especialistas. Adotou-se, no presente trabalho, o sistema de classificação de Cronquist (1988).

Todos os indivíduos vivos mensurados e identificados, de acordo com o porte, foram classificados, de forma visual, quanto a sua posição na estrutura vertical. As posições consideradas estão representadas pelas letras (I M D E ): I = inferior, $\mathrm{M}=$ médio, $\mathrm{D}=$ dossel e $\mathrm{E}=$ emergente.

\subsection{Parâmetros fitossociológicos}

\subsubsection{Obtenção dos dados}

Os dados do trabalho foram obtidos com base em dois métodos de amostragem fitossociológica, mais comumente utilizados no Estado de São Paulo: método de parcelas Chapman (1976) e método de quadrantes (Cottan \& Curtis, 1956). 
Para a estimativa dos parâmetros fitossociológicos, foram utilizadas as seguintes fórmulas:

DTA (método de parcelas) $=$ N/A

DTA (método de quadrantes) $=\mathrm{U} / \mathrm{AM}$

DAi (método de parcelas) $=$ ni $/ \mathrm{A}$

DAi (método de quadrantes) $=n i / N$. DTA

$\mathrm{AM}$ (método de quadrantes $)=\left(\sum \mathrm{di} / \mathrm{N}\right)^{2}$

$\mathrm{DRi}$ (método de parcelas) $=\mathrm{ni} / \mathrm{N} .100$

$\mathrm{DRi}$ (método de quadrantes $)=100 . \mathrm{DAi} / \Sigma \mathrm{DA}$

$\mathrm{FA} \mathrm{i}=$ pi/PT. 100

$\mathrm{FRi}=\mathrm{FAi} / \mathrm{FAT} .100$

$\mathrm{FAT}=\sum \mathrm{FAi}$

DoTA $=\mathrm{ABT} / \mathrm{A}$

$\mathrm{ABmi}=\mathrm{ABi} / \mathrm{ni}$

Abi $=\left(\right.$ PI. $\left.d^{2}\right) / 4$

$\mathrm{ABi}=\sum \mathrm{Abi}$

$\mathrm{ABT}=\sum \mathrm{ABi}$

DoAi $=$ DAi. ABmi

$\mathrm{DoRi}=\mathrm{ABi} / \mathrm{ABT} .100$

$\mathrm{IVIi}=\mathrm{DR} \mathrm{i}+\mathrm{FRi}+\mathrm{DoRi}$

$\mathrm{IVCi}=\mathrm{DRi}+\mathrm{DoRi}$

Onde:

DTA é a densidade absoluta total ou Densidade Total por Área. Estima o número total de indivíduos, independente da espécie, por unidade de área. A unidade de área é considerada 1 há ou $\left(10.000 \mathrm{~m}^{2}\right)$. É expressa $\mathrm{em} \mathrm{n}^{\circ}$ de indivíduos por ha (hectare);

$\mathbf{N}$ é o número total de indivíduos amostrados, independentes da espécie; 
U é a unidade de área $\left(1 \mathrm{ha}=10.000 \mathrm{~m}^{2}\right)$;

A é a área amostrada;

AM é a área média

di é a distância média geométrica corrigida. A distância corrigida referese à soma da distância individual obtida para cada árvore com o raio de seu diâmetro.

DAi é a densidade absoluta da espécie i. É o número de indivíduos de uma dada espécie por unidade de área. É também expressa em indivíduo por ha;

DRi é a densidade relativa da espécie i. Expressa, em percentagem, é a relação entre o número de indivíduos de uma determinada espécie e o número total de indivíduos amostrados. A densidade dá uma idéia do tamanho das populações na área estudada, mas não do tamanho dos indivíduos, nem da forma como estão distribuídos no espaço, embora o padrão espacial da população influa nos valores da densidade.

ni é o número de indivíduos amostrados da espécie i;

FAi é a freqüência absoluta da espécie i. É a percentagem de unidades de amostragem em que a espécie i ocorreu, em relação ao total de unidades amostradas;

FAT é a freqüência absoluta total (soma aritmética das freqüências absolutas de todas as espécies amostradas);

pi é o número de unidades de amostragem com a presença da espécie i;

PT é o número total de unidades de amostragem;

FRi é a frequência relativa da espécie i. Expressa, em percentagem, é a relação entre a freqüência absoluta da espécie $i$, com as freqüências absolutas de todas as espécies amostradas. A freqüência determina a regularidade da distribuição de cada espécie sobre o terreno. Os valores de freqüência estimam a probabilidade de encontrar a espécie i numa unidade de amostragem lançada ao acaso na formação vegetal. Depende da abundância da população e é influenciado pelo padrão de distribuição espacial.

DoAi é a dominância absoluta da espécie i. Dá a taxa de ocupação do ambiente pelos indivíduos da espécie i, por unidade de área. É expressa $\mathrm{em} \mathrm{m}^{2} / \mathrm{ha}$;

DoRi é a dominância relativa da espécie i. Expressa, em percentagem, a área ocupada pelos indivíduos da espécie $\mathrm{i}$, em relação à área total ocupada pelos individuos de todas as espécies. 
DoTA é a dominância absoluta total. Estima o total de área ocupada pela vegetação, por unidade de área. É expressa $\mathrm{em} \mathrm{m}^{2} / \mathrm{ha}$;

ABi é a área basal total da espécie i $\left(\mathrm{m}^{2}\right)$;

ABmi é a área basal média da espécie i $\left(\mathrm{m}^{2}\right)$;

ABT é a área basal total de todas as espécies amostradas $\left(\mathrm{m}^{2}\right)$;

Abi é a área basal de um indivíduo da espécie i $\left(\mathrm{m}^{2}\right)$;

d = é o diâmetro à altura do peito;

IVli é o índice do valor de importância da espécie i. Trata-se um índice constituído pela soma dos valores relativos de freqüência, densidade e dominância, podendo variar até no máximo 300 ;

IVCi é o índice do valor de cobertura da espécie i. Trata-se de um índice constituído pela soma dos parâmetros relativos, excluindo-se a freqüência, podendo variar até 200 .

\subsection{Grupos ecológicos}

As espécies amostradas foram agrupadas em pioneiras $(\mathrm{P})$, secundárias iniciais (SI), secundárias tardias (ST) e não classificadas (NC) segundo critérios de classificação sucessional adotado por Gandolfi et al. (1995).

$\mathrm{O}$ enquadramento das espécies nos respectivos grupos ecológicos ou estádios sucessionais baseou-se, também em observações feitas na área estudada pelo autor sobre a ocorrência e hábito das espécies e locais do entorno e consulta às literaturas onde a ocorrência ou a dinâmica da espécie é referida (Mantovani, 1993; Tabarelli et al., 1994; Rodrigues e Gandolfi, 1996; Aguiar et al., 2001; Ivanauskas et al., 2002). 


\section{RESULTADOS E DISCUSSÃO}

\subsection{Tempo gasto para implantação da grade amostral}

$\mathrm{Na}$ implantação da malha, demarcada em um trecho de floresta ombrófila densa no Parque Estadual "Carlos Botelho", local de topografia relativamente acentuada, foram necessários 10 dias de atividades abrangendo abertura de picadas e locação dos pontos.

Para locação das 64 parcelas de $10 \times 90 \mathrm{~m}\left(900 \mathrm{~m}^{2}\right)$ plaqueamento e mensuração das árvores, necessitou-se de 70 dias de plena atividade de campo. $\mathrm{Na}$ mesma área física, para instalação dos 320 pontos quadrantes, necessitou-se de 10 dias, sem considerar o tempo despendido para a coleta do material botânico.

A implantação de cada parcela, demandou em média 1 dia de trabalho exigindo, portanto, um tempo 7 vezes maior que o tempo utilizado para implantar os quadrantes.

Dias et al. (1989) mencionam que a mata atlântica é um bioma complexo e diversificado, conhecê-lo; através de amostragem por parcelas, é viável, mas a topografia acidentada da área e a pluviosidade impõem sérias dificuldades.

No transcorrer da demarcação das primeiras parcelas, ou seja, a primeira linha da grade amostral, foi possível sentir as dificuldades e adaptar a sistemática de trabalho, no sentido de otimizar a seqüência e o rendimento na execução das próximas etapas.

Considerou-se que três pessoas seriam suficientes para as atividades de campo e execução das tarefas optando-se, também, por uma quarta pessoa, prevendo-se revezamento semanal ou substituição, na equipe, caso fosse necessário. 


\subsection{Tempo gasto para coleta do material botânico}

Para coleta do material botânico, realizada logo após o término da implantação dos métodos de amostragem, embora a equipe estivesse bem treinada e adaptada a esse tipo de serviço, sentiu as dificuldades advindas da topografia com encostas íngremes, característica predominante da mata atlântica. Assim, para a realização desta tarefa, a equipe levou em média 70 dias, sendo necessário mais de um dia para cada uma das 64 parcelas implantadas, que por sua vez englobam os quadrantes.

\subsection{Tempo gasto na identificação botânica}

Cabe salientar que, além dos esforços já mencionados, requereu-se muito empenho no processo da identificação do material botânico coletado. As identificações taxonômicas, também representam entraves, principalmente, quando os trabalhos são desenvolvidos em ambientes de grande riqueza florística, como é o caso da área estudada.

Em estudos desta natureza, muitas vezes não é possível aguardar as fases reprodutivas (flores e frutos) dos espécimens, estruturas fundamentais e básicas para as identificações. Sendo assim, o reconhecimento taxonômico através dos caracteres vegetativos apresenta-se como uma das opções de suma importância, mas requer muitos anos de experiência. O esforço despendido para a identificação das espécies, utilizando-se da estrutura vegetativa, ramos com folhas, foi relevante e permitiu em alguns casos, a definição destas.

Cabe salientar, ainda, que o montante de testemunhos botânicos coletados ultrapassou 10 mil exemplares.

\subsection{Comparação dos métodos}

Neste estudo, pretendeu-se, na mesma área fisica, comparar a amostragem feita pelo método de parcelas, 5,76 hectares, e o método de quadrantes representados por 320 pontos que, convertidos em área, para efeito de comparação, equivale à soma das 
áreas das árvores amostradas, ou seja, 1,04 hectares. Na Tabela 1, são apresentados os dados dos dois métodos aplicados. Nota-se, que o número de indivíduos amostrados pelo método de quadrantes (1280) significou, 13,41\% do número de indivíduos encontrados pelo método de parcelas (9544). Tal discrepância deve-se à diferença de indivíduos amostrados por cada método, uma vez que na parcelas foram amostrados em média 149 indivíduos, por unidade amostral, enquanto no método de quadrantes, foram amostrados apenas 4 indivíduos por ponto.

\subsection{Florística}

A Tabela 1 apresenta alguns resultados obtidos pela aplicação dos dois métodos como também relativos à amostragem do delineamento amostral. Nota-se que o número de indivíduos amostrados pelo método de quadrantes representa $13,41 \%$ do número encontrado pelo método de parcelas. Enquanto no método de parcelas são amostradios em média 149 indivíduos, no método de quadrantes foram amostrados 4 indivíduos por ponto quadrantes, ou seja, um por quadrante.

Tabela 1. Resultados referentes ao delineamento amostral pelos métodos de parcelas e quadrantes na floresta ombrófila densa no Parque Estadual "Carlos Botelho" São Miguel Arcanjo, SP

\begin{tabular}{lcc}
\hline \multicolumn{1}{c}{ Critérios } & Parcelas & Quadrantes \\
\hline Unidade amostral & $900 \mathrm{~m}^{2}$ & Ponto (4 árvores) \\
Número de unidades amostrais & 64 & 320 \\
Área de abrangência (ha) & 64 & 64 \\
Área efetivamente amostrada (ha) & 5,76 & 1,04 \\
Indivíduos amostrados & 9544 & 1280 \\
Indivíduos mortos & $1,12 \%$ & $0,93 \%$ \\
Número de famílias & 60 & 53 \\
Número de gêneros & 125 & 106 \\
Número de espécies & 252 & 177 \\
Média de indivíduos/unidade amostral & 149 & 4 \\
\hline
\end{tabular}


Avaliando-se os dados florísticos obtidos a partir do método de parcelas observa-se que, amostraram-se 9544 indivíduos 107 (1,12\%) mortos em pé, representando 252 espécies, 125 gêneros e 60 famílias. Dentre os indivíduos amostrados, 29 (11,50\%) foram identificados apenas até gênero e $7(2,77 \%)$ deixados apenas em família (Tabela 2).

Tabela 2. Espécies arbóreas amostradas em 64 parcelas, de $900 \mathrm{~m}^{2}$, na floresta ombrófila densa no Parque Estadual "Carlos Botelho" - São Miguel Arcanjo, SP. I = estrato inferior; $\mathrm{M}=$ estrato médio; $\mathrm{D}=$ dossel; $\mathrm{E}=$ emergente; $\mathrm{GE}=$ grupo ecológico

\section{Estrato}

Família/Espécies

I $\quad$ M $\quad$ D $\quad$ E $\quad$ GE

1 ANACARDIACEAE

1 Tapirira guianensis Aubl. $\mathrm{X}$

SI

\section{ANNONACEAE}

2 Guatteria australis A.St. Hil.

3 Rollinia parviflora A.St. Hil

4 Rolinia sericiea (R.E Fries) R.E. Fries

5 Xylopia langsdorffiana A.St. Hil. \& Tul.

$\begin{array}{cccc}\mathrm{X} & \mathrm{X} & \mathrm{X} & \mathrm{ST} \\ \mathrm{X} & & & \text { ST } \\ \mathrm{X} & \mathrm{X} & & \text { ST } \\ \mathrm{X} & \mathrm{X} & \mathrm{X} & \mathrm{SI}\end{array}$

\section{APOCYNACEAE}

6 Aspidosperma olivaceum Muell. Arg.

$\mathrm{X} \quad \mathrm{X} \quad \mathrm{X}$

ST

4 AQUIFOLIACEAE

7 Ilex amara (Vell.) Loesener

8 Ilex paraguaryensis A. St.Hil

9 Ilex taubertiana Loes

10 Ilex theezans Mart.

$\begin{array}{llll}\text { X } & \text { X } & \text { X } & \text { ST } \\ \text { X } & \text { X } & \text { X } & \text { ST } \\ \text { X } & \text { X } & \text { X } & \text { ST } \\ \text { X } & \text { X } & \text { X } & \text { ST }\end{array}$


Tabela 2. Espécies arbóreas amostradas em 64 parcelas, de $900 \mathrm{~m}^{2}$, na floresta ombrófila densa no Parque Estadual "Carlos Botelho" - São Miguel Arcanjo, SP. I = estrato inferior; $\mathrm{M}=$ estrato médio; $\mathrm{D}=$ dossel; $\mathrm{E}=$ emergente; $\mathrm{GE}=$ grupo ecológico

\section{Estrato}

$\begin{array}{llllll}\text { Família/Espécies } & \text { I } & \text { M } & \text { D } & \text { E } & \text { GE }\end{array}$

5 ARALIACEAE

11 Didymopanax angustissimum E. Marchal

12 Didymopanax navarroi A. Samp.

$\mathrm{X} \quad \mathrm{X} \quad \mathrm{SI}$

$\mathrm{X} \quad \mathrm{X} \quad \mathrm{SI}$

6 ARECACEAE

13 Attalea dubia (Mart.) Burr.

14 Euterpe edulis Mart.

$\begin{array}{llll} & \mathrm{X} & \mathrm{X} & \mathrm{ST} \\ \mathrm{X} & \mathrm{X} & \mathrm{X} & \mathrm{ST}\end{array}$

7 ASTERACEAE

15 Piptocarpha macropoda (DC) Baker

16 Piptocarpha sp1

17 Vernonia diffusa Less.

$\begin{array}{cccc}\text { X } & \text { X } & & \text { P } \\ X & \text { X } & & \text { P } \\ \text { X } & \text { X } & \text { X } & \text { P }\end{array}$

8 BIGNONIACEAE

18 Jacaranda puberula Cham.

19 Tabebuia heptaphylla (Vell.) Toledo

$\begin{array}{llll}X & X & X & \text { SI }\end{array}$

$X \quad X \quad$ ST

\section{BORAGINACEAE}

20 Cordia sellowiana Cham.

21 Cordia sp 1

$\begin{array}{llll}X & X & X & \text { ST } \\ X & X & & \text { NC }\end{array}$

10 BURSERACEAE

22 Protium heptaphyllum (Aubl.) Marchand

$\begin{array}{lllll}X & X & X & X & \text { SI }\end{array}$

11 CAESALPINIACEAE

23 Copaifera langsdorffii Desf.

24 Copaifera trapezifolia Hayne

$\begin{array}{lllll}X & X & X & X & \text { ST } \\ X & X & X & X & \text { ST }\end{array}$

$\begin{array}{lllll}X & X & X & X & \text { ST }\end{array}$ 
Tabela 2. Espécies arbóreas amostradas em 64 parcelas, de $900 \mathrm{~m}^{2}$, na floresta ombrófila densa no Parque Estadual "Carlos Botelho" - São Miguel Arcanjo, SP. I = estrato inferior; $\mathrm{M}=$ estrato médio; $\mathrm{D}=$ dossel; $\mathrm{E}=$ emergente; $\mathrm{GE}=$ grupo ecológico

\section{Estrato}

\begin{tabular}{llllll} 
Familia/Espécies & I & M & D & E & GE \\
\hline
\end{tabular}

25 Sclerolobium denudatum Vogel

$\begin{array}{lllll}\text { X } & \text { X } & \text { X } & \text { X } & \text { ST }\end{array}$

12 CANELLACEAE

26 Capsicodendron dinisii Schwacke

$\begin{array}{lllll}X & X & X & X & \text { SI }\end{array}$

\section{CECROPIACEAE}

27 Cecropia glaziouii Snethl.

$\mathrm{X}$

$\mathrm{P}$

14 CELASTRACEAE

28 Maytenus robusta Reissek

$\mathrm{X} \quad \mathrm{X} \quad \mathrm{X}$

ST

\section{CRYSOBALANACEAE}

29 Hirtella hebeclada Moric. ex DC.

30 Parinari excelsa Sabine

$\begin{array}{lllll}X & X & X & & \text { SI } \\ X & X & X & X & \text { ST }\end{array}$

16 CLETHRACEAE

31 Clethra scabra Pers.

$\mathrm{X} \quad \mathrm{X} \quad \mathrm{X}$

SI

17 CLUISIACEAE

32 Clusia criuva Cambess.

33 Garcinia gardneriana (Planch. \& Triana) D. Zappi

$\begin{array}{lllll}X & & X & X & \text { ST } \\ X & X & & & \text { ST }\end{array}$

18 COMBRETACEAE

34 Buchenavia kleinii Exell

$\begin{array}{lllll}X & X & X & X & \text { ST }\end{array}$ 
Tabela 2. Espécies arbóreas amostradas em 64 parcelas, de $900 \mathrm{~m}^{2}$, na floresta ombrófila densa no Parque Estadual "Carlos Botelho" - São Miguel Arcanjo, SP. I = estrato inferior; $\mathrm{M}=$ estrato médio; $\mathrm{D}=$ dossel; $\mathrm{E}=$ emergente; $\mathrm{GE}$ = grupo ecológico

\section{Estrato}

\section{Família/Espécies}

19 CUNONIACEAE

35 Lamanonia ternata Vell

36 Weinmannia discolor Gardner

37 Weinmannia paulliniffolia Pohl ex Ser.

Estrato

\section{ELAEOCARPACEAE}

38 Sloanea monosperma Vell.

\section{ERYTROXYLACEAE}

39 Erythroxylum sp. 1

\section{EUPHORBIACEAE}

40 Alchornea triplinervia (Spreng.) Mull. Arg.

41 Hyeronima alchorneoides Allemão

42 Pera glabrata (Schott) Baill.

43 Sapium glandulatum (Vell.) Pax

\section{FABACEAE}

44 Andira anthelmia (Vell.) J.F. Macbr.

45 Dalbergia brasiliensis Vogel

46 Dalbergia frutescens (Vell.) Britton

47 Fabaceae 1

48 Machaerium nictitans (Vell.) Benth.

49 Machaerium sp.

50 Myrocarpus frondosus M.Allemão

51 Ormosia dasycarpa Jacks.

52 Pterocarpus rohrii Vahl

53 Zollernia ilicifolia (Brongn.) Vogel $\begin{array}{lllll}\text { I } & \text { M } & \text { D } & \text { E } & \text { GE }\end{array}$

$\begin{array}{llll}X & X & X & \text { SI }\end{array}$

$\begin{array}{llll}X & X & X & \text { ST }\end{array}$

$\begin{array}{llll}X & X & X & \text { ST }\end{array}$

X $\quad \mathrm{X} \quad \mathrm{X}$

ST

$\mathrm{X}$

SI

$\begin{array}{ccccc}\mathrm{X} & \mathrm{X} & \mathrm{X} & \mathrm{X} & \mathrm{SI} \\ \mathrm{X} & \mathrm{X} & \mathrm{X} & & \mathrm{P} \\ \mathrm{X} & \mathrm{X} & \mathrm{X} & & \mathrm{SI} \\ \mathrm{X} & \mathrm{X} & \mathrm{X} & \mathrm{X} & \mathrm{P}\end{array}$

$\begin{array}{llllr}\mathrm{X} & \mathrm{X} & \mathrm{X} & & \text { ST } \\ \mathrm{X} & & \mathrm{X} & & \text { SI } \\ \mathrm{X} & \mathrm{X} & \mathrm{X} & & \text { SI } \\ & \mathrm{X} & & & \text { NC } \\ \mathrm{X} & & & & \text { ST } \\ & & \mathrm{X} & & \text { ST } \\ & \mathrm{X} & & & \text { ST } \\ \mathrm{X} & \mathrm{X} & \mathrm{X} & \mathrm{X} & \text { ST } \\ \mathrm{X} & \mathrm{X} & \mathrm{X} & & \text { CL } \\ & \mathrm{X} & \mathrm{X} & & \text { CL }\end{array}$


Tabela 2. Espécies arbóreas amostradas em 64 parcelas, de $900 \mathrm{~m}^{2}$, na floresta ombrófila densa no Parque Estadual "Carlos Botelho" - São Miguel Arcanjo, SP. I = estrato inferior; $\mathrm{M}=$ estrato médio; $\mathrm{D}=$ dossel; $\mathrm{E}=$ emergente; $\mathrm{GE}=$ grupo ecológico

\section{Estrato}

Família/Espécies

I $\quad \mathbf{M} \quad \mathbf{D} \quad \mathbf{E} \quad \mathbf{G E}$

24 FLACOURTIACEAE

54 Casearia decandra Jacq.

55 Casearia obliqua Spreng

56 Casearia sylvestris $\mathrm{Sw}$.

57 Xylosma glaberrimum Sleumer

$\begin{array}{llll}X & X & X & \text { ST } \\ X & X & X & \text { ST } \\ X & X & & \text { SI } \\ & \text { X } & & \text { SI }\end{array}$

\section{HIPPOCRATEACEAE}

58 Cleiloclinium cognatum (Miers) A. C. Sm.

$\begin{array}{ll}\mathrm{X} & \mathrm{ST} \\ \mathrm{X} & \mathrm{ST}\end{array}$

59 Salacia elliptica (Mart. ex Schult.) G. Don

$\mathrm{X}$

ST

\section{HUMIRIACEAE}

60 Vantanea compacta (Schnizl.) Cuatrec.

$\begin{array}{lllll}X & X & X & X & \text { ST }\end{array}$

27 ICACINACEAE

61 Citronella paniculata (Mart.) R. A. Howard

$\mathrm{X} \quad \mathrm{X} \quad \mathrm{X}$

ST

\section{LAURACEAE}

62 Aiouea acarodomatifera Vattimo-Gil

63 Aiouea saligna Meisn.

64 Aniba firmula (Ness \& Mart.) Mez

65 Aniba viridis Mez

66 Beilschmiedia emarginata (Meisn.) Kosterm.

67 Cinnamomum hirsutum Lorea-Hern.

68 Cryptocarya moschata Ness

69 Cryptocarya sp. 1

70 Endlicheria paniculata (Spreng.) J.F. Macbr.

71 Lauraceae indet. 1

72 Lauraceae indet. 2

$\begin{array}{lllll}\text { X } & \text { X } & \text { X } & & \text { ST } \\ \text { X } & \text { X } & & & \text { ST } \\ & & \text { X } & & \text { ST } \\ \text { X } & \text { X } & \text { X } & & \text { ST } \\ \text { X } & \text { X } & \text { X } & & \text { ST } \\ & \text { X } & & & \text { ST } \\ \text { X } & \text { X } & \text { X } & \text { X } & \text { ST } \\ \text { X } & \text { X } & \text { X } & \text { X } & \text { ST } \\ \text { X } & \text { X } & \text { X } & & \text { ST } \\ \text { X } & \text { X } & & & \text { NC } \\ & \text { X } & & & \text { NC }\end{array}$


Tabela 2. Espécies arbóreas amostradas em 64 parcelas, de $900 \mathrm{~m}^{2}$, na floresta ombrófila densa no Parque Estadual "Carlos Botelho" - São Miguel Arcanjo, SP. I = estrato inferior; $\mathrm{M}=$ estrato médio; $\mathrm{D}=$ dossel; $\mathrm{E}=$ emergente; $\mathrm{GE}=$ grupo ecológico

Estrato

Família/Espécies

I $\quad$ M $\quad$ D $\quad$ E $\mathbf{G E}$

73 Lauraceae indet. 3

74 Nectandra debilis $\mathrm{Mez}$

75 Nectandra membranacea (Sw.) Griseb.

76 Nectandra oppositifolia Ness

77 Ocotea aciphylla (Ness) Mez

78 Ocotea aff. lancifolia (Schott.)Mez

79 Ocotea bicolor Vattimo-Gil

80 Ocotea brachybotra (Meisn.) Mez

81 Ocotea catharinensis Mez

82 Ocotea daphinifolia $\mathrm{Mez}$

83 Ocotea dispersa (Ness) $\mathrm{Mez}$

84 Ocotea elegans Mez

85 Ocotea glaziovii Mez

86 Ocotea nectandrifolia $\mathrm{Mez}$

87 Ocotea odorifera (Vell.) Rohwer

88 Ocotea pulchella (Nees) Mez

89 Ocotea pulchra Vatimo-Gil

90 Ocotea silvestris Vattimo-Gil

91 Ocotea sp. 1

92 Ocotea sp. 2

93 Ocotea tabacifolia (Meisn.) Rohwer

94 Ocotea teleiandra (Meisn.) Mez

95 Ocotea vaccinioides (Meisn.) Mez

96 Ocotea velloziana (Meisn.) Mez

97 Ocotea venulosa (Ness) Benth. Ccb

98 Persea pyrifolia Ness \& Mart. ex Ness

99 Persea sp 1

100 Rhodostemonodaphne macrocalyx (Meisn.) Rohwer ex S. Madrinãn

$\begin{array}{rrrrr} & & \text { X } & \text { NC } \\ & \text { X } & & & \text { ST } \\ \text { X } & \text { X } & \text { X } & & \text { ST } \\ \text { X } & \text { X } & \text { X } & \text { X } & \text { ST } \\ & & \text { X } & & \text { ST } \\ \text { X } & \text { X } & \text { X } & \text { X } & \text { ST } \\ \text { X } & \text { X } & \text { X } & & \text { ST } \\ \text { X } & \text { X } & \text { X } & \text { X } & \text { ST } \\ \text { X } & \text { X } & & & \text { ST } \\ \text { X } & \text { X } & \text { X } & & \text { ST } \\ \text { X } & \text { X } & \text { X } & \text { X } & \text { XL } \\ \text { X } & \text { X } & \text { X } & & \text { ST } \\ & \text { X } & \text { X } & & \text { ST } \\ \text { X } & \text { X } & \text { X } & \text { X } & \text { ST } \\ & & \text { X } & \text { X } & \text { SI } \\ \text { X } & \text { X } & \text { X } & \text { X } & \text { ST } \\ & \text { X } & & & \text { SI } \\ & \text { X } & & & \text { NC } \\ & & \text { X } & \text { X } & \text { NC } \\ \text { X } & \text { X } & & & \text { ST } \\ & & & & \text { ST } \\ & \text { X } & \text { X } & & \text { ST } \\ & \text { X } & \text { X } & & \text { ST } \\ & \text { X } & \text { X } & & \text { ST } \\ \text { X } & \text { X } & \text { X } & \text { X } & \text { ST } \\ & \text { X } & \text { X } & & \text { NC } \\ & \text { X } & \text { X } & & \text { ST }\end{array}$


Tabela 2. Espécies arbóreas amostradas em 64 parcelas, de $900 \mathrm{~m}^{2}$, na floresta ombrófila densa no Parque Estadual "Carlos Botelho" - São Miguel Arcanjo, SP. I = estrato inferior; $\mathrm{M}$ = estrato médio; $\mathrm{D}=$ dossel; $\mathrm{E}=$ emergente; $\mathrm{GE}$ = grupo ecológico

\section{Estrato}

Família/Espécies

I M D E GE

29 LECYTHIDACEAE

101 Cariniana estrellensis (Raddi) O. Kuntze

X ST

30 MAGNOLIACEAE

102 Talauma ovata A. St. Hil.

$\mathrm{X} \quad \mathrm{X} \quad \mathrm{P}$

31 MALPIGHIACEAE

103 Byrsonima ligustrifolia A. Juss

104 Byrsonima myricifolia Griseb.

$\begin{array}{llll}X & X & X & \text { ST }\end{array}$

$\begin{array}{llll}X & X & X & \text { ST }\end{array}$

\section{MELASTOMATACEAE}

105 Leandra dasytricha (A. Gray) Cogn.

106 Leandra sp.

107 Meriania clausenii (Naud.) Triana

108 Miconia cabussu Hoehne

109 Miconia cubatanensis Hoehne

110 Miconia petropolitana Cogn.

111 Miconia pusilliflora (DC.) Triana

112 Miconia sellowiana Naud.

113 Miconia sp 1

114 Miconia valtherii Naud.

115 Tibouchina pulchra (Cham.) Cogn.

116 Tibouchina sellowiana (Cham.) Cogn.

\begin{tabular}{|c|c|c|c|}
\hline \multirow{3}{*}{$X$} & \multicolumn{2}{|c|}{$X$} & SI \\
\hline & & & SI \\
\hline & $\mathrm{X}$ & & SI \\
\hline$X$ & $X$ & $\mathrm{X}$ & $\mathbf{P}$ \\
\hline$X$ & $\mathrm{X}$ & & \\
\hline$X$ & $\mathrm{X}$ & $\mathrm{X}$ & \\
\hline$X$ & $X$ & $\mathrm{X}$ & \\
\hline & X & $\mathrm{X}$ & \\
\hline & & $\mathrm{X}$ & \\
\hline$X$ & $\mathrm{X}$ & & \\
\hline$x$ & $X$ & $\mathrm{X}$ & $X$ \\
\hline $\mathrm{y}$ & $\mathrm{X}$ & & $X$ \\
\hline
\end{tabular}

\section{MELIACEAE}

117 Cabralea canjerana (Vell.) Mart.

118 Cedrela fissilis Vell.

$\begin{array}{llll} & & \text { X } & \text { ST } \\ X & X & X & \text { SI } \\ X & X & & \text { ST }\end{array}$


Tabela 2. Espécies arbóreas amostradas em 64 parcelas, de $900 \mathrm{~m}^{2}$, na floresta ombrófila densa no Parque Estadual "Carlos Botelho" - São Miguel Arcanjo, SP. I = estrato inferior; $\mathrm{M}=$ estrato médio; $\mathrm{D}=$ dossel $; \mathrm{E}=$ emergente; $\mathrm{GE}=$ grupo ecológico

Estrato

Família/Espécies

I $\quad$ M D E GE

34 MIMOSACEAE

120 Inga laurina $(\mathrm{Sw}$.$) Willd.$

121 Inga marginata Willd.

123 Inga sessilis (Vell.) Mart.

124 Pithecellobium langsdorffi Bentham

$\begin{array}{llll}X & X & & \text { ST } \\ X & X & X & \text { SI } \\ X & X & X & \text { ST } \\ X & X & X & \text { ST }\end{array}$

\section{MONIMIACEAE}

125 Mollinedia aff. elegans Tul.

126 Mollinedia aff. uleana Perkins

$X \quad$ SI

127 Mollinedia oligantha Perkins

$\begin{array}{lll}X & X & \text { SI }\end{array}$

128 Mollinedia oligotricha

129 Mollinedia schottiana (Spreng.) Perkins

130 Mollinedia sp 1

$\begin{array}{llll}X & X & X & \text { SI }\end{array}$

$X \quad X \quad$ SI

$\begin{array}{lll}X & X & \text { ST }\end{array}$

$\mathrm{X} \quad \mathrm{X} \quad \mathrm{X} \quad \mathrm{NC}$

36 MORACEAE

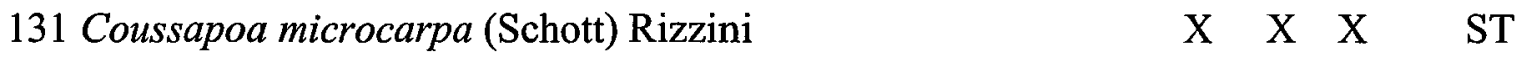

132 Sorocea bonplandii (Baill.) W.C. Burger, Lanj.\&Wees.Bo. $\quad \begin{array}{lllll}\text { X } & X & X & \text { ST }\end{array}$

\section{MYRSINACEAE}

133 Rapanea ferruginea (Ruiz \& Pav.) Mez

134 Rapanea gardneriana (A. DC.) Mez

135 Rapanea hermogenii Jung-Mendaçolli \& Bernacci

136 Rapanea umbellata (Mart.) Mez

137 Stylogine laevigata (Mart.) Mez

$\begin{array}{llll}X & X & X & \text { SI } \\ X & X & & \text { SI } \\ X & X & & \text { SI } \\ X & X & X & \text { SI } \\ X & & & \text { SI }\end{array}$

\section{MYRTACEAE}

138 Calycorectes australis D. Legrand

$\begin{array}{llll}X & X & X & \text { ST } \\ X & & & \text { ST }\end{array}$

139 Calyptranthes lanceolata O. Berg 
Tabela 2. Espécies arbóreas amostradas em 64 parcelas, de $900 \mathrm{~m}^{2}$, na floresta ombrófila densa no Parque Estadual "Carlos Botelho" - São Miguel Arcanjo, SP. I = estrato inferior; $\mathrm{M}=$ estrato médio; $\mathrm{D}=$ dossel; $\mathrm{E}=$ emergente; $\mathrm{GE}=$ grupo ecológico

\section{Estrato}

\section{Família/Espécies}

140 Calyptranthes aff. lucida Mart. ex DC.

141 Calycorectes aff. psidiiflorus (O. Berg) Sobral

142 Calyptranthes sp. 1

143 Calyptranthes sp. 2

144 Calyptranthes sp. 3

145 Campomanesia guaviroba (A. D.C.) Kiaersk.

146 Campomanesia schlechtendaliana (O. Berg) Nied.

147 Eugenia beaurepaireana (Kiaersk.) D. Legrand

148 Eugenia cambucarana Kiaersk.

149 Eugenia capitulifera Berg

150 Eugenia cerasiflora Miq.

151 Eugenia cereja D. Legrand

152 Eugenia handroana D. Legrand

153 Eugenia involucrata DC.

154 Eugenia melanogina (D. Legrand) Sobral

155 Eugenia mosenii (Kausel) Sobral

156 Eugenia neoglomerata Sobral

157 Eugenia prasina O. Berg

158 Eugenia pruinosa D. Legrand

159 Eugenia riedeliana O. Berg

160 Eugenia sp. 1

161 Eugenia sp. 2

162 Eugenia sp. 3

163 Eugenia sp. 4

164 Eugenia sp. 5

165 Eugenia stictosepala Kiaersk.

166 Eugenia subavenia O. Berg

167 Eugenia umbelliflora $\mathrm{O}$. Berg

168 Gomidesia schaueriana O. Berg

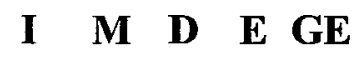

\begin{tabular}{|c|c|c|c|c|}
\hline \multirow[t]{2}{*}{$\bar{X}$} & \multirow[t]{2}{*}{$\mathrm{X}$} & \multirow[b]{2}{*}{$X$} & \multirow{2}{*}{\multicolumn{2}{|c|}{ ST }} \\
\hline & & & & \\
\hline & $X$ & $\mathrm{X}$ & & $\mathrm{NC}$ \\
\hline & $X$ & $X$ & & $\mathrm{NC}$ \\
\hline & $X$ & & & $\mathrm{NC}$ \\
\hline & $X$ & $\mathrm{X}$ & $X$ & ST \\
\hline & $X$ & $\mathrm{X}$ & & ST \\
\hline & $X$ & $X$ & $X$ & SI \\
\hline & $X$ & $X$ & & SI \\
\hline & $X$ & & & SI \\
\hline & $X$ & $\mathrm{X}$ & & SI \\
\hline & $X$ & & $X$ & SI \\
\hline & $X$ & $X$ & & SI \\
\hline & $X$ & $X$ & & ST \\
\hline & $X$ & $X$ & & ST \\
\hline & $X$ & $X$ & & ST \\
\hline & $X$ & & & ST \\
\hline & $\mathrm{X}$ & & & ST \\
\hline & $\mathrm{X}$ & $X$ & & ST \\
\hline & $X$ & & & SI \\
\hline & $X$ & $X$ & & $\mathrm{NC}$ \\
\hline & $X$ & $X$ & & $\mathrm{NC}$ \\
\hline & $X$ & X & & $\mathrm{NC}$ \\
\hline & $\mathrm{X}$ & & & $\mathrm{NC}$ \\
\hline & $\mathrm{X}$ & $\mathrm{X}$ & & $\mathrm{NC}$ \\
\hline & $X$ & $X$ & & SI \\
\hline & $X$ & & & SI \\
\hline & $X$ & $X$ & & ST \\
\hline & $X$ & $\mathrm{X}$ & & SI \\
\hline
\end{tabular}


Tabela 2. Espécies arbóreas amostradas em 64 parcelas, de $900 \mathrm{~m}^{2}$, na floresta ombrófila densa no Parque Estadual "Carlos Botelho" - São Miguel Arcanjo, SP. I = estrato inferior; $\mathrm{M}=$ estrato médio; $\mathrm{D}=\operatorname{dossel} ; \mathrm{E}=$ emergente; $\mathrm{GE}=$ grupo ecológico

\section{Estrato}

Família/Espécies

169 Gomidesia tijucensis (Kiaersk.) D. Legrand

170 Marlierea eugeniopsoides (Legrand \& Kausel) D. Legrand 171 Marlierea parviflora O. Berg

172 Marlierea reitzii D. Legrand

173 Marlierea sp.1

174 Marlierea tomentosa Cambess.

175 Myrceugenia aff. pilotantha (Kiaersk.) Landrum

176 Myrceugenia campestris (DC.) D. Legrand \& Kausel

177 Myrceugenia glaucescens (Cambess.) D.Legrand \& Kausel

178 Myrceugenai kleinii D.Legrand \& Kausel

179 Myrceugenia myrcioides (Cambess.) O. Berg

180 Myrceugenia sp.1

181 Myrcia fallax (Rich.) DC.

182 Myrcia aff. glabra (O. Berg) D. Legrand

183 Myrcia hatschbachii D. Legrand

184 Myrcia heringii D. legrand

185 Myrcia aff. obtecta (O. Berg) Kiaersk.

186 Myrcia pubipetala Miq.

187 Myrcia richardiana O.Berg

188 Myrcia tenuivenosa Kiaersk.

189 Myrcia sp. 1

190 Myrcia sp. 2

191 Myrciaria sp. 1

192 Myrtaceae 1

193 Myrtaceae 2

194 Myrtaceae 3

195 Myrtaceae 4

196 Neomitranthes glomerata (D.Legrand) D.Legrand

197 Plinia complanata M.L. kawasaki \& B. Holst.
I M D E GE

$\begin{array}{llll}\mathrm{X} & \mathrm{X} & \mathrm{X} & \mathrm{SI}\end{array}$

$\begin{array}{llll}X & X & X & \text { ST }\end{array}$

$\begin{array}{llll}X & X & X & \text { ST }\end{array}$

$\begin{array}{llll}X & X & X & \text { ST }\end{array}$

$X \quad N C$

$\begin{array}{llll}X & X & X & \text { ST }\end{array}$

$X \quad$ SI

$\begin{array}{llll}X & X & X & \text { SI }\end{array}$

$\begin{array}{lllll}X & X & \text { SI }\end{array}$

$\begin{array}{llll}X & X & X & \text { SI }\end{array}$

$\begin{array}{lllll}X & X & \text { SI }\end{array}$

$\begin{array}{llll}X & X & X & N C\end{array}$

$\begin{array}{llll}X & X & X & P\end{array}$

$\begin{array}{llll}X & X & X & \text { SI }\end{array}$

$\begin{array}{lll}X & X & \text { SI }\end{array}$

$X \quad$ SI

$\begin{array}{llll}X & X & \text { ST }\end{array}$

$\begin{array}{lllll}X & X & X & X & \text { ST }\end{array}$

$\begin{array}{lllll}X & X & X & X & \text { SI }\end{array}$

$\begin{array}{llll}X & X & \text { ST }\end{array}$

$\begin{array}{llll}X & X & X & \text { NC }\end{array}$

$X \quad X \quad N C$

$\mathrm{X} \quad \mathrm{NC}$

$\begin{array}{llll}X & X & X & \text { NC }\end{array}$

$\begin{array}{llll}X & X & X & N C\end{array}$

$\begin{array}{llll}X & X & X & N C\end{array}$

$\begin{array}{llll}X & X & X & N C\end{array}$

$X \quad X \quad$ ST

$\begin{array}{lll}X & X & \text { ST }\end{array}$ 
Tabela 2. Espécies arbóreas amostradas em 64 parcelas, de $900 \mathrm{~m}^{2}$, na floresta ombrófila densa no Parque Estadual "Carlos Botelho" - São Miguel Arcanjo, SP. I = estrato inferior; $M=$ estrato médio; $\mathrm{D}=$ dossel $; \mathrm{E}=$ emergente $\mathrm{GE}=$ grupo ecológico

Estrato

Família/Espécies $\begin{array}{lllll}\text { I } & M & \mathbf{D} & \mathbf{E} & \mathbf{G E}\end{array}$

198 Plinia pauciflora pauciflora M.L. kawasaki \& B. Holst.

199 Siphoneugena densiflora O. Berg

$\begin{array}{lllll}X & X & X & X & \text { ST }\end{array}$

$\begin{array}{llllll}X & X & X & X & \text { ST }\end{array}$

39 NYCTAGINACEAE

200 Guapira opposita (Vell.) Reitz

$\begin{array}{lllll}X & X & X & \text { ST }\end{array}$

40 OCHNACEAE

201 Ouratea parviflora (DC.) Baill.

$\begin{array}{llll}X & X & X & \text { SI }\end{array}$

41 OLACACEAE

202 Heisteria silvianii Schwacke

$\begin{array}{llll}X & X & X & \text { SI }\end{array}$

42 OLEACEAE

203 Chionanthus filiformis (Vell.) P.S. Green

$\begin{array}{llll}X & X & X & \text { SI }\end{array}$

43 PIPERACEAE

204 Piper arboreum Aubl.

$\mathrm{X}$

$\mathbf{P}$

44 PODOCARPACEAE

205 Podocarpus sellowii Klotzsch

$\mathrm{X} \quad \mathrm{X} \quad \mathrm{X} \quad \mathrm{X}$ NC

45 POLYGONACEAE

206 Coccoloba aff.latifolia Lam.

$\begin{array}{llll}X & X & X & \text { ST }\end{array}$

46 PROTEACEAE

207 Roupala sp. 1

$\mathrm{X} \quad \mathrm{X} \quad \mathrm{NC}$ 
Tabela 2. Espécies arbóreas amostradas em 64 parcelas, de $900 \mathrm{~m}^{2}$, na floresta ombrófila densa no Parque Estadual "Carlos Botelho" - São Miguel Arcanjo, SP. I = estrato inferior; $\mathrm{M}=$ estrato médio; $\mathrm{D}=$ dossel $; \mathrm{E}=$ emergente; $\mathrm{GE}=$ grupo ecológico

\section{Estrato}

Família/Espécies

47 QUINACEAE

208 Quina magalano-gomesii Schwacke

48 ROSACEAE

209 Prunus myrtifolia (L.) Urb.

49 RUBIACEAE

210 Alibertia aff. myrciifolia (Spreng) K. Schum.

211 Alibertia sp.

212 Alseis floribunda Schott

213 Amaioua intermedia Mart.

214 Bathysa australis (A St. Hil.) Hook

215 Chomelia sp.

216 Coussarea sp.

217 Ixora burcheliana Mull. Arg.

218 Posoqueria acutifolia Mart.

219 Psychotria suterella Mull. Arg.

220 Psychotria velloziana Benth.

221 Rudgea jasminoides (Cham.) Mull. Arg.

\section{RUTACEAE}

222 Esenbeckia grandiflora Mart.

223 Zanthoxylum rhoifolium Lam.
I M D E GE

$\begin{array}{llll}X & X & X & \text { ST }\end{array}$

$\begin{array}{lllll}X & X & X & X & \text { SI }\end{array}$

$\begin{array}{llll}X & X & X & \text { ST }\end{array}$

$\begin{array}{lll}X & X & N C\end{array}$

$\begin{array}{llll}X & X & \text { SI }\end{array}$

$\begin{array}{lllll}X & X & X & \text { SI }\end{array}$

$\begin{array}{lllll}X & X & X & X & \text { SI }\end{array}$

$X \quad N C$

$\begin{array}{lllll}X & X & X & X & \text { SI }\end{array}$

$\begin{array}{lllll}X & X & X & \text { SI }\end{array}$

$\begin{array}{llll}X & X & X & \text { SI }\end{array}$

$X \quad X \quad$ ST

$\begin{array}{lll}X & X & \text { ST }\end{array}$

$\begin{array}{llll}X & X & X & \text { SI }\end{array}$

$\begin{array}{lllll}X & X & X & & \text { SI }\end{array}$

$\begin{array}{llllll}X & X & X & X & \text { SI }\end{array}$

\section{SABIACEAE}

224 Meliosma sellowii Urban.

225 Meliosma sinuata Urban.
$\begin{array}{llll}X & X & & \text { SI } \\ X & X & X & \text { SI }\end{array}$ 
Tabela 2. Espécies arbóreas amostradas em 64 parcelas, de $900 \mathrm{~m}^{2}$, na floresta ombrófila densa no Parque Estadual "Carlos Botelho" - São Miguel Arcanjo, SP. I = estrato inferior; $\mathrm{M}=$ estrato médio; $\mathrm{D}=$ dossel; $\mathrm{E}=$ emergente; $\mathrm{GE}=$ grupo ecológico

Estrato

Família/Espécies

I $\quad$ M $\quad$ D $\quad$ E $\mathbf{G E}$

52 SAPINDACEAE

226 Allophylus edulis ( A. St.Hil.) Radlk.

227 Allophylus petiolulatus Radlk.

228 Cupania oblogifolia Cambess.

$\begin{array}{llll}X & X & X & \text { SI }\end{array}$

229 Cupania vernalis Cambess.

$\begin{array}{lll}\mathrm{X} & \mathrm{SI} \\ \mathrm{X} & \mathrm{X}\end{array}$

230 Matayba guianensis Aubl.

231 Matayba juglandifolia (Cambess.) Radlk.

$\begin{array}{llll}X & X & X & \text { SI }\end{array}$

$\mathrm{XI}$

$\begin{array}{llll}X & X & X & \text { SI }\end{array}$

$\begin{array}{llll}X & X & X & \text { SI }\end{array}$

53 SAPOTACEAE

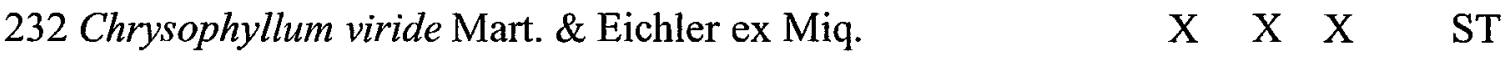

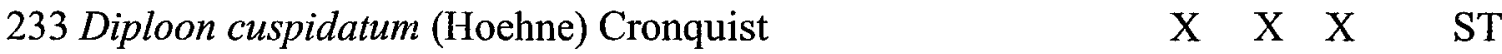

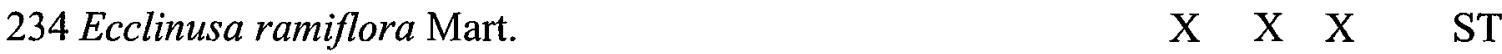

235 Micropholis crassipedicellata (Mart. \& Eichler) Pierre $\quad$ X X X X ST

236 Pouteria bullata (S. Moore) Baehni $\quad$ X $\quad X \quad X \quad X \quad$ ST

237 Pouteria caimito (Ruiz \& Pavon) Radlk. $\quad$ X $\quad X \quad X \quad X \quad$ ST

54 SOLANACEAE

238 Solanum bullatum Vell.

239 Solanum excelsum A.St. Hil.

240 Solanum pseudoquina A. St. Hil.

$\begin{array}{llll}\text { X } & \text { X } & & \text { P } \\ \text { X } & \text { X } & \text { P } \\ \text { X } & & & \text { P }\end{array}$

55 STYRACACEAE

241 Styrax acuminatus Pohl.

$\begin{array}{llll}X & X & X & \text { SI }\end{array}$

56 SYMPLOCACEAE

242 Symplocos celastrinea Mart.

243 Symplocos falcata Brand.

244 Symplocos variabilis Mart. ex Miq.

$\begin{array}{llll} & & \text { X } & \text { ST } \\ \text { X } & \text { X } & \text { X } & \text { ST } \\ & \text { X } & \text { X } & \text { ST }\end{array}$ 
Tabela 2. Espécies arbóreas amostradas em 64 parcelas, de $900 \mathrm{~m}^{2}$, na floresta ombrófila densa no Parque Estadual "Carlos Botelho" - São Miguel Arcanjo, SP. I = estrato inferior; $\mathrm{M}=$ estrato médio; $\mathrm{D}=$ dossel; $\mathrm{E}=$ emergente; $\mathrm{GE}=$ grupo ecológico

\section{Estrato}

Família/Espécies

I $\quad \mathbf{M} \quad \mathbf{D} \quad \mathbf{E}$ GE

57 THYMELIACEAE

245 Daphnopsis gemmiflora (Miers) Domke

$\mathrm{X} \quad \mathrm{X} \quad \mathrm{ST}$

58 VERBENACEAE

246 Aegiphila sellowiana Cham.

247 Aegiphila sp.

248 Vitex aff. polygama Cham.

249 Verbenaceae 1

$\begin{array}{cccc} & \mathrm{X} & \mathrm{X} & \mathrm{P} \\ & \mathrm{X} & & \mathrm{NC} \\ \mathrm{X} & & & \mathrm{ST} \\ \mathrm{X} & & & \mathrm{NC}\end{array}$

59 VOCHYSIACEAE

250 Vochysia selloi Warm.

251 Vochysia sp. 1

$\begin{array}{lll}\mathrm{X} & & \mathrm{ST} \\ \mathrm{X} & \mathrm{X} & \mathrm{NC}\end{array}$

60 WINTERACEAE

252 Drymis winteri Miers

$\begin{array}{llll}X & X & \text { ST }\end{array}$

Nos pontos quadrantes, foram amostrados 1280 indivíduos vivos e 12 mortos em pé (0,93\%), que representam 177 espécies, 106 gêneros e 53 famílias. As espécies deixadas apenas em gênero, somam $17(9,60 \%)$ e famílias 4 (2,25\%) (Tabela 3). 
Tabela 3. Espécies arbóreas amostradas em 320 pontos quadrantes, na floresta ombrófila densa no Parque Estadual "Carlos Botelho" - São Miguel Arcanjo, SP. I = estrato inferior; $\mathrm{M}=$ estrato médio; $\mathrm{D}=$ dossel; $\mathrm{E}=$ emergente; $\mathrm{GE}=$ grupo ecológico

\section{Estrato}

Família/Espécie

I M D E GE

1 ANACARDIACEAE

1 Tapirira guianensis Aubl.

$\begin{array}{llllll}X & X & X & X & \text { SI }\end{array}$

\section{ANNONACEAE}

2 Guatteria australis A.St. Hil.

$\begin{array}{llll}X & X & \text { ST }\end{array}$

3 Rollinia parviflora A. St. Hil.

$X \quad S T$

4 Rollinia sericea (R. E. Fries) R.E. Fr.

$X X \quad$ ST

5 Xylopia langsdorffiana A.St. Hil. \& Tul.

$\mathrm{X} X \mathrm{X}$

\section{APOCYNACEAE}

6 Aspidospema olivaceum Muel. Arg.

$\mathrm{X} \quad \mathrm{X} \quad \mathrm{X} \quad \mathrm{X}$ ST

4 AQUIFOLIACEAE

7 Ilex amara (Vell.) Loesener

$\begin{array}{llll}X & X & \text { ST }\end{array}$

8 Ilex paraguaryensis Hook

$X \quad X \quad X \quad$ ST

9 Ilex taubertiana Loes

$X X X \quad$ ST

\section{ARALIACEAE}

10 Didymopanax angustissimum E. Marchal

11 Didymopanax navarroi A.Samp.

$\begin{array}{lll}X & X & \text { SI } \\ X & X & \text { SI }\end{array}$

\section{ARECACEAE}

12 Euterpe edulis Mart.

$\mathrm{X} \quad \mathrm{X} \quad \mathrm{X} \quad \mathrm{X} \quad \mathrm{ST}$

\section{ASTERACEAE}

13 Piptocarpha macropoda (DC.) Baker

14 Piptocarpha sp. 1

$\begin{array}{lll}\mathrm{X} & \mathrm{X} & \mathrm{P}\end{array}$

15 Vernonia diffusa Less.

$X \quad X \quad N C$

$\begin{array}{llllllllll}X & X & X & P\end{array}$

\section{BIGNONIACEAE}

16 Jacaranda puberula Cham.

$\mathrm{X} X \mathrm{X}$

SI 
Tabela 3. Espécies arbóreas amostradas em 320 pontos quadrantes, na floresta ombrófila densa no Parque Estadual "Carlos Botelho" - São Miguel Arcanjo, SP. I = estrato inferior; $\mathrm{M}=$ estrato médio; $\mathrm{D}=$ dossel; $\mathrm{E}=$ emergente; $\mathrm{GE}=$ grupo ecológico

\section{Estrato}

Família/Espécie

I M D E GE

9 BORAGINACEAE

17 Cordia selowiana Cham.

18 Cordia sp. 1

$\begin{array}{lll}X & X \quad S T\end{array}$

$\mathrm{X} X$

NC

10 BURSERACEAE

19 Protium heptaphyllum (Aubl.) Marchal

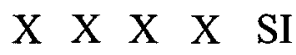

11 CAESALPINIACEAE

20 Copaifera langsdorffii Desf.

$\begin{array}{llllll}X & X & X & X & S T\end{array}$

21 Copaifera trapezifolia Hayne

22 Sclerolobium denudatum Vog.

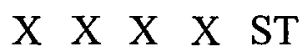

$X \times \quad$ ST

12 CANELLACEAE

23 Capsicodendron dinisii Schwacke

$\begin{array}{lll}X & \text { SI }\end{array}$

\section{CECROPIACEAE}

24 Cecropia glaziouii Sneth.

14 CELASTRACEAE

25 Maytenus robusta Reiss.

X X

$$
\text { X P }
$$

15 CRYSOBALANACEAE

26 Hirtella hebeclada Moric. Ex DC.

27 Parinari excelsa Sabine

$\begin{array}{lll}X & X & \\ X & X & \text { ST }\end{array}$

16 CLETHRACEAE

28 Clethra scabra Pers.

$\mathrm{X} \quad \mathrm{SI}$

17 CLUSIACEAE

29 Garcinia gardneriana (Planch. \& Triana) D. Zappi

$\mathrm{X} X$

ST

18 COMBRETACEAE

30 Buchenavia kleinii Exell. 
Tabela 3. Espécies arbóreas amostradas em 320 pontos quadrantes, na floresta ombrófila densa no Parque Estadual "Carlos Botelho" - São Miguel Arcanjo, SP. I = estrato inferior; $\mathrm{M}=$ estrato médio; $\mathrm{D}=$ dossel; $\mathrm{E}=$ emergente; $\mathrm{GE}=$ grupo ecológico

Estrato

Família/Espécie

I M D E GE

19 CUNONIACEAE

31 Lamanonia ternata Vell.

32 Weinmannia discolor Gardner

33 Weinmannia paulliniifolia Pohl ex. Ser.

$\begin{array}{llll}X & X & X & \text { SI }\end{array}$

$\mathrm{X} \quad \mathrm{X} \quad \mathrm{ST}$

$\mathrm{X} \quad \mathrm{ST}$

20 ELAEOCARPACEAE

34 Sloanea monosperma Vell.

$\mathrm{X} \quad \mathrm{X}$

ST

\section{EUPHORBIACEAE}

35 Alchornea triplinervia (Spreng.) Mull. Arg.

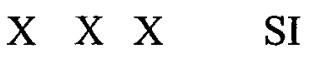

36 Hieronyma alchorneoides Allemão

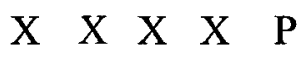

37 Sapium glandulatum (Vell.) Pax

$X \quad X \quad S T$

\section{FABACEAE}

38 Andira anthelmia (Vell.) J. F.Macbr.

39 Fabaceae 1

40 Myrocarpus frondosus M. Allemão

41 Ormosia dasycarpa Jacks.

42 Pterocarpus rohrii Vahl

43 Zollernia ilicifolia (Brongn.) Vogel.

$\begin{array}{lllll}\text { X } & \text { X } & \text { X } & & \text { ST } \\ & \text { X } & & & \text { NC } \\ \text { X } & \text { X } & \text { X } & \text { X } & \text { ST } \\ \text { X } & \text { X } & \text { X } & & \text { ST } \\ \text { X } & \text { X } & \text { X } & & \text { ST } \\ & \text { X } & \text { X } & & \text { ST }\end{array}$

23 FLACOURTIACEAE

44 Casearia decandra Jacq.

45 Casearia obliqua Spreng

$\mathrm{X} \quad \mathrm{X}$

ST

$\begin{array}{lll}X & X & \text { ST }\end{array}$

24 HUMIRIACEAE

46 Vantanea compacta (Schnizl.) Cuatrec.

$\begin{array}{llllll}X & X & X & X & \text { ST }\end{array}$

25 ICACINACEAE

47 Citronella paniculata (Mart.) R. A. Howard

$\mathrm{X} \quad \mathrm{ST}$ 
Tabela 3. Espécies arbóreas amostradas em 320 pontos quadrantes, na floresta ombrófila densa no Parque Estadual "Carlos Botelho" - São Miguel Arcanjo, SP. I = estrato inferior; $\mathrm{M}=$ estrato médio; $\mathrm{D}=$ dossel; $\mathrm{E}=$ emergente; $\mathrm{GE}=$ grupo ecológico

Estrato

Família/Espécies

I $\quad$ M D $\mathbf{D}$ E $\mathbf{G E}$

26 LAURACEAE

48 Aionea acarodomatifera Vatimo-Gil

49 Aniba viridis $\mathrm{Mez}$

50 Beilschmiedia emarginata (Meisn.) Kosterm.

51 Cryptocarya moschata Ness

52 Cryptocarya sp. 1

53 Endlicheria paniculata (Spreng.) J.F. Macbr.

54 Ocotea aciphylla (Nees) Mez

55 Ocotea bicolor Vattimo-Gil

56 Ocotea brachybotra (Meisn.) Mez

57 Ocotea catharinensis Mez

58 Ocotea dispersa (Nees) Mez

59 Ocotea elegans Mez

60 Ocotea glaziovii Mez

61 Ocotea odorifera (Vell.) Rohwer

62 Ocotea pulchra Vattimo- Gil

63 Ocotea silvestris Vattimo-Gil

$\begin{array}{lllll} & & \text { X } & & \text { ST } \\ & \text { X } & \text { X } & & \text { ST } \\ & & \text { X } & & \text { ST } \\ \text { X } & \text { X } & \text { X } & \text { X } & \text { ST } \\ \text { X } & \text { X } & \text { X } & & \text { NC } \\ & \text { X } & & & \text { ST } \\ & \text { X } & \text { X } & & \text { ST } \\ \text { X } & \text { X } & \text { X } & & \text { ST } \\ \text { X } & & & \text { ST } \\ \text { X } & \text { X } & \text { X } & & \text { ST } \\ & \text { X } & & & \text { ST } \\ \text { X } & \text { X } & \text { X } & & \text { ST } \\ & \text { X X } & & \text { ST } \\ \text { X } & \text { X X } & & \text { ST } \\ \text { X } & \text { X } & \text { X } & & \text { ST } \\ \text { X } & & \text { X } & & \text { SI }\end{array}$

\section{MELASTOMATACEAE}

72 Miconia petropolitana Cogn.

73 Miconia pusilliflora (DC.) Triana

74 Miconia sellowiana Naud.

75 Tibouchina pulchra (Cham.) Cogn.

76 Tibouchina sellowiana (Cham.) Cogn.

$\begin{array}{llll}\mathrm{X} & \mathrm{X} & & \mathrm{SI} \\ \mathrm{X} & \mathrm{X} & \mathrm{SI} \\ & \mathrm{X} & \mathrm{P} \\ & \mathrm{X} \mathrm{X} & \mathrm{P} \\ & & \mathrm{X} & \mathrm{P}\end{array}$

\section{MELIACEAE}

77 Cabralea canjerana (Vell.) Mart.

78 Cedrela fissilis Vell.

$\begin{array}{lll}\text { X X X } & \text { ST } \\ \text { X } & \text { SI } \\ \text { X } & \text { ST }\end{array}$


Tabela 3. Espécies arbóreas amostradas em 320 pontos quadrantes, na floresta ombrófila densa no Parque Estadual "Carlos Botelho" - São Miguel Arcanjo, SP. I = estrato inferior; $\mathrm{M}=$ estrato médio; $\mathrm{D}=$ dossel; $\mathrm{E}=$ emergente; $\mathrm{GE}$ = grupo ecológico

Estrato

Família/Espécies

I M D E GE

31 MIMOSACEAE

80 Inga marginata Willd

81 Inga sellowiana Benth

$\mathrm{X} \quad \mathrm{SI}$

82 Inga sessilis (Vell.) Mart.

$\begin{array}{llll}X & X & \text { ST }\end{array}$

83 Pithecellobium langsdorffi Bentham

$\begin{array}{llll}X & X & X & \text { ST }\end{array}$

$\mathrm{X} \times \mathrm{X} \quad \mathrm{ST}$

32 MONIMIACEAE

84 Mollinedia oligantha Perkins

$\begin{array}{llll}X & X & X & \text { SI }\end{array}$

85 Mollinedia oligotricha Perkins

$X \quad X \quad$ SI

33 MORACEAE

86 Mollinedia schottiana (Spreng.) Perkins

87 Coussapoa microcarpa (Schott) Rizzini

88 Sorocea bonplandii (Baill.) W.C. Burger,Lanj. \& Wees. Boer

$\mathrm{X} \quad \mathrm{X}$

ST

$X \quad S T$

$\mathrm{X} \quad \mathrm{X}$

ST

\section{MYRSINACEAE}

89 Rapanea ferruginea (Ruiz \& Pav.) Mez

90 Rapanea gardneriana (A. DC.) Mez

91 Rapanea hermogenessi (Jung-Mendaçolli \& Bernacci Pipoly

92 Rapanea umbellata (Mart.) Mez

$\begin{array}{llllll} & X & X & & \text { SI } \\ X & & & & \text { SI } \\ X & X & & & \text { SI } \\ X & X & X & X & \text { SI }\end{array}$

\section{MYRTACEAE}

93 Calycorectes australis D. Legrand

94 Calyptranthes aff. lucida Mart. ex DC.

95 Calyptranthes sp. 2

96 Calyptranthes sp. 3

97 Campomanesia guaviroba ( A. D.C.) Kiaersk.

98 Eugenia beaurepaireana (Kiaersk.) D. Legrand

99 Eugenia cambucarana Kiaersk.

\begin{tabular}{|c|c|c|}
\hline \multirow{2}{*}{\multicolumn{2}{|c|}{$\mathrm{X}$}} & $S^{\prime}$ \\
\hline & & $\mathrm{S}$ \\
\hline$X \quad X$ & $x$ & $\mathrm{~N}$ \\
\hline $\mathrm{X}$ & $X$ & N \\
\hline & $X$ & $\mathrm{~S}$ \\
\hline$X \quad X$ & & \\
\hline$X$ & $\mathrm{X}$ & \\
\hline
\end{tabular}


Tabela 3. Espécies arbóreas amostradas em 320 pontos quadrantes, na floresta ombrófila densa no Parque Estadual "Carlos Botelho" - São Miguel Arcanjo, SP. I = estrato inferior; $\mathrm{M}=$ estrato médio; $\mathrm{D}=$ dossel; $\mathrm{E}=$ emergente; $\mathrm{GE}=$ grupo ecológico

\section{Estrato}

Família/Espécies

I M D E GE

100 Eugenia capitulifera Berg

101 Eugenia cerasiflora Miq.

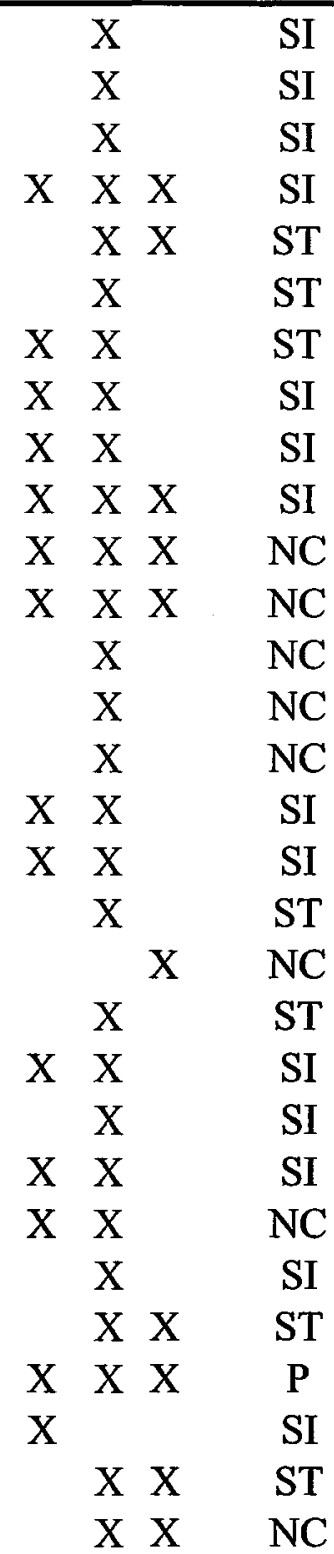

102 Eugenia cereja D. Legrand

103 Eugenia handroana D. Legrand

104 Eugenia involucrata DC.

105 Eugenia melanogina (D. Legrand) Sobral

106 Eugenia mosenii (Kausel) Sobral

107 Eugenia riedeliana O. Berg

108 Eugenia stictosepala Kiaersk.

109 Eugenai subavenia O. Berg

110 Eugenia sp. 1

111 Eugenia sp. 2

112 Eugenia sp. 3

113 Eugenia sp. 4

114 Eugenia sp. 5

115 Gomidesia tijucensis (Kiaersk.) D.Legrand

116 Marlierea parviflora $\mathrm{O}$. Berg

117 Marlierea reitzii D. Legrand

118 Marlierea sp.1

119 Marlierea tomentosa Cambess.

120 Myrceugenia glaucescens (Cambess.) D. Legrand \& Kausel

121 Myrceugenia kleinii D. Legand \& Kausel

122 Myrceugenia myrcioides (Cambess.) O. Berg

123 Myrceugenia sp.1

124 Myrcia aff. glabra (O. Berg) D.Legrand

125 Myrcia aff.obtecta (O. Berg) Kiaersk.

126 Myrcia fallax (Rich.) DC.

127 Myrcia heringii D. Legrand

128 Myrcia pubipetala Miq.

129 Myrcia sp.1 
Tabela 3. Espécies arbóreas amostradas em 320 pontos quadrantes, na floresta ombrófila densa no Parque Estadual "Carlos Botelho" - São Miguel Arcanjo, SP. I = estrato inferior; $\mathrm{M}=$ estrato médio; $\mathrm{D}=$ dossel; $\mathrm{E}=$ emergente; $\mathrm{GE}=$ grupo ecológico

\section{Estrato}

Família/Espécies

I $\quad \mathbf{M} \mathbf{D} \quad \mathbf{E} \mathbf{G E}$

130 Myrciaria sp. 1

131 Myrtaceae 1

132 Myrtaceae 2

133 Myrtaceae 4

134 Neomitranthes glomerata (D. Legrand) D. Legrand

135 Plinia complanata M.L. Kawasaki \& B. Holst.

136 Plinia pauciflora M.L. Kawasaki \& B. Holst.

137 Siphoneugena densiflora O. Berg

\begin{tabular}{|c|c|c|}
\hline$X$ & $\mathrm{X}$ & $\mathrm{NC}$ \\
\hline$X$ & & $N$ \\
\hline$X$ & X & $\mathbf{N}$ \\
\hline$X$ & $\mathrm{X}$ & $\mathbf{N}$ \\
\hline$X$ & & $S^{\prime}$ \\
\hline$X$ & & \\
\hline$X$ & & \\
\hline $\begin{array}{ll}X \quad 2 \\
\end{array}$ & $X$ & \\
\hline
\end{tabular}

36 NYCTAGINACEAE

138 Guapira opposita (Vell.) Reitz

$\begin{array}{llll}X & X & X & \text { ST }\end{array}$

37 OCHNACEAE

139 Ouratea parviflora (DC.) Baill.

$\begin{array}{llll}X & X & X & \text { SI }\end{array}$

38 OLACACEAE

140 Heisteria silvianii Schwacke

$\mathrm{X} \quad \mathrm{X}$

SI

39 OLEACEAE

141 Chionathus filiformis (Vell.) P.S. Green $\quad$ X $\quad X \quad X \quad$ SI

40 PIPERACEAE

142 Piper arboreum Aubl.

$\mathrm{X}$

$\mathbf{P}$

41 POLYGONACEAE

143 Coccoloba aff. latifolia Lam.

$\begin{array}{llll}X & X & \text { ST }\end{array}$

42 QUINACEAE

144 Quina magalano-gomesii Schwacke

$\mathrm{X}$

ST 
Tabela 3. Espécies arbóreas amostradas em 320 pontos quadrantes, na floresta ombrófila densa no Parque Estadual "Carlos Botelho" - São Miguel Arcanjo, SP. I = estrato inferior; $\mathrm{M}=$ estrato médio; $\mathrm{D}=$ dossel; $\mathrm{E}=$ emergente; $\mathrm{GE}=$ grupo ecológico

Estrato

Família/Espécies

I M D E GE

43 ROSACEAE

145 Prunus myrtifolia (L.) Urb.

$\mathrm{X}$

SI

44 RUBIACEAE

146 Alibertia aff. myrciifolia (Spreng) K. Schum.

147 Alibertia sp.

148 Alseis floribunda Schott

$X \quad X$

ST

149 Amaioua intermedia Mart.

$X \quad X \quad N C$

150 Bathysa australis (A. St. Hil.) Hook

$\mathrm{X}$

SI

$X \quad X \quad X \quad$ SI

151 Coussarea sp.

$\begin{array}{lllll}X & X & X & \text { SI }\end{array}$

152 Ixora burchelliana Mull. Arg.

$X \quad X \quad X \quad$ SI

153 Posoqueria acutifolia Mart.

$X \quad X$

SI

154 Psychotria suterella Mull. Arg.

$X \quad X \quad X$

SI

155 Psychotria velloziana Benth.

$\mathrm{X}$

$\mathrm{X} X \quad \mathrm{ST}$

156 Rudgea jasminoides (Cham.) Mull. Arg.

$\mathrm{X} X \mathrm{X}$

SI

45 RUTACEAE

157 Esenbeckia grandiflora Mart.

158 Zanthoxylum rhoifolium Lam.

$\begin{array}{llll}X & X & & \text { SI } \\ & X & \text { SI }\end{array}$

46 SABIACEAE

159 Meliosma sellowii Urban.

160 Meliosma sinuata Urban.

$\begin{array}{llll}X & X & S I \\ X & X & S I\end{array}$

47 SAPINDACEAE

161 Allophylus edulis (A.St Hil.) Radlk.

162 Cupania oblongifolia Cambess.

163 Cupania vernalis Cambess.

$\begin{array}{lllll} & \text { X } & & & \text { P } \\ \text { X } & \text { X } & \text { X } & & \text { SI } \\ & \text { X } & \text { X } & & \text { SI } \\ & \text { X } & \text { X } & \text { X } & \text { SI } \\ \text { X } & \text { X } & \text { X } & & \text { SI }\end{array}$

165 Matayba juglandifolia (Cambess.) Radlk. 
Tabela 3. Espécies arbóreas amostradas em 320 pontos quadrantes, na floresta ombrófila densa no Parque Estadual "Carlos Botelho" - São Miguel Arcanjo, SP. I = estrato inferior; $\mathrm{M}=$ estrato médio; $\mathrm{D}=$ dossel; $\mathrm{E}=$ emergente; $\mathrm{GE}$ = grupo ecológico

\section{Estrato}

Família/Espécies

I $\quad$ M D $\mathbf{D}$ E GE

\section{SAPOTACEAE}

166 Chrysophyllum viride Mart. \& Eichler ex Miq

167 Diploon cuspidatum (Hoehne) Cronquist

168 Ecclinusa ramiflora Mart.

169 Micropholis crassipedicellata (Mart. \& Eichler) Pierre

$\begin{array}{llllll} & & \text { X } & & \text { ST } \\ \text { X } & \text { X } & \text { X } & & \text { ST } \\ & \text { X } & & & \text { ST } \\ & \text { X } & & & \text { ST } \\ \text { X } & \text { X } & \text { X } & \text { X } & \text { ST } \\ \text { X } & \text { X } & \text { X } & \text { X } & \text { ST }\end{array}$

170 Pouteria bullata (S. Moore) Baehni
171 Pouteria caimito (Ruiz \& Pavon) Radlk.

$X \quad X \quad X \quad X \quad S T$

\section{SOLANACEAE}

172 Solanum pseudoquina A.St.Hil

X P

50 SYMPLOCACEAE

173 Symplocos falcata Brand.

174 Symplocos variabilis Mart. Ex Miq.

$\begin{array}{llll}X & X & X & S T\end{array}$

$X X \quad$ ST

51 VERBENACEAE

175 Aegiphila sellowiana Cham.

X P

52 VOCHYSIACEAE

176 Vochysia sp.1

$\mathrm{X} \quad \mathrm{NC}$

53 WINTERACEAE

177 Drymis winteri J.R. Forst.

$\mathrm{X} X$

ST

Considerando-se os métodos aplicados, observou-se, através dos pontos quadrantes, que a riqueza de comunidade foi representativa, significando $70,24 \%$ do total de espécies levantadas pelo método de parcelas, em menor espaços de tempo. Notou-se que a riqueza de espécies foi superior pelo método de parcelas. Há que se considerar que o resultado obtido por este método corresponde à amostragem de 5,76 ha, ou seja, área cerca de 5,5 vezes maior do que a avaliada nos quadrantes. 
Gorenstein (2002) comparando o método de quadrantes a outros dois (Bitterlich e parcela de área fixa) na floresta da Estação Ecológica de Caetetus, ao estimar a diversidade alfa da comunidade arbórea e esforço amostral, observou superioridade do método de quadrantes em relação à riqueza de espécies apresentada pelos demais. Da mesma maneira Rocha (2003) ao estudar outra área, na mesma floresta, analisou e comparou dois métodos de amostragem de vegetação florestal (parcelas de área fixa e ponto quadrantes), concluiu ser os quadrantes eficiente na amostragem florística, como também fez uso dos dados da composição florística e estrutura do componente arbóreo, a fim de subsidiar laudos de desapropriação ambiental e determinação de preço da propriedade.

$\mathrm{Na}$ Figura 7 são apresentadas as curvas do coletor para os dois métodos considerando o acréscimo de novas espécies à medida que se aumenta o número de árvores amostradas. Comparando-se essas curvas, nota-se que são semelhantes.

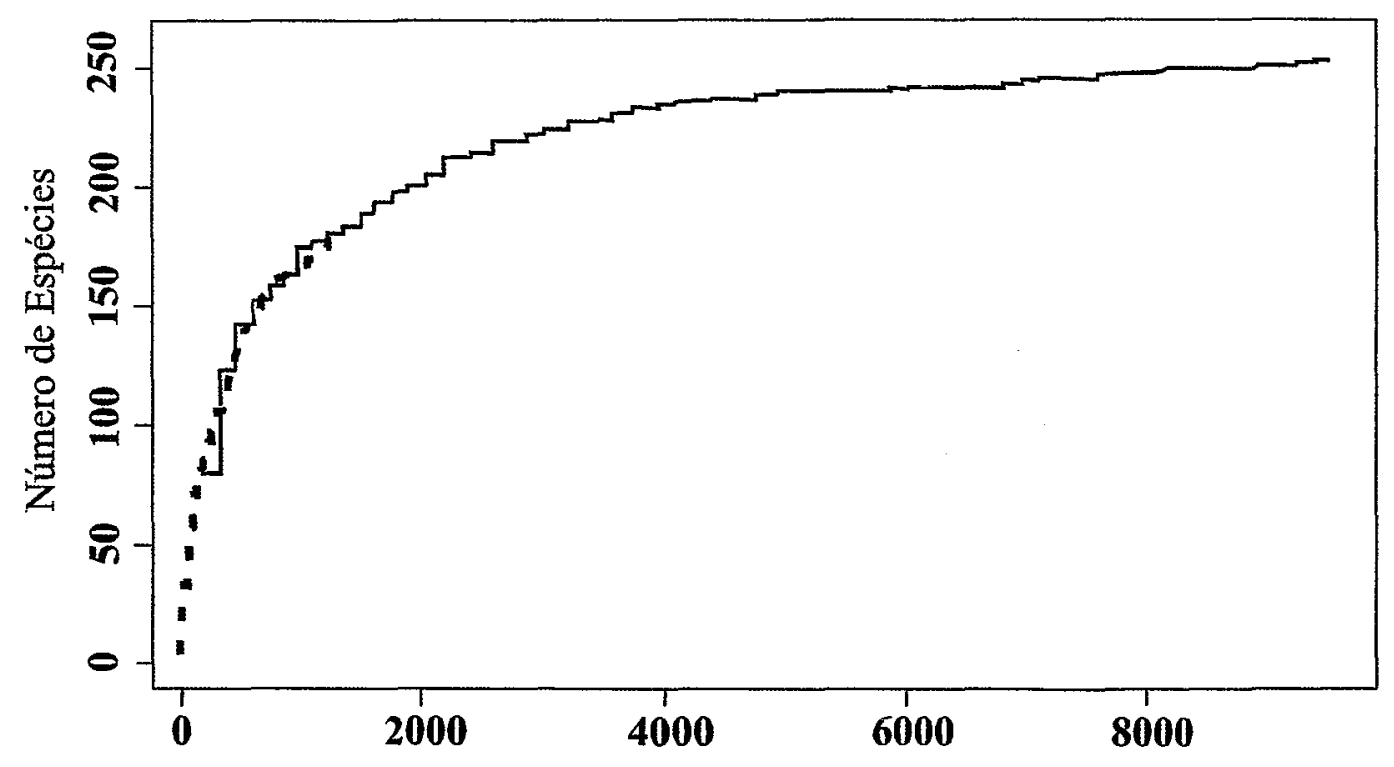

Número de Árvores Amostradas

Figura 7 - Curva do coletor do número de espécies em função do número de árvores amostradas 
Entretanto, na avaliação por parcelas, o desgaste físico para amostrar a mesma quantidade de árvores analisadas pelo método de quadrantes é muito maior. Deve-se ressaltar, que para amostrar os indivíduos de uma parcela, a equipe permaneceu por mais tempo em um ambiente acidentado, com grande número de paradas, caminhando em direções variadas. Ao passo que, para serem avaliados os indivíduos arbóreos pelo método de quadrantes, as caminhadas foram mais longas, porém, menos desgastantes, com menor quantidade de paradas e poucos desvios de direção.

A Figura 8 apresenta as curvas do coletor tomando-se por base o número de espécies encontradas pela quantidade de unidades amostrais. Considerou-se para cada unidade amostral da figura, cinco pontos quadrantes, correspondente a quantidade de pontos dentro de cada parcela. Assim, para a curva dos quadrantes, a unidade amostral 1 corresponde ao acúmulo de espécies até o ponto 5, na unidade 2 corresponde ao acúmulo até o ponto 10 e assim sucessivamente, até os últimos cinco pontos que correspondem à parcela 64 . Verifica-se que, enquanto para os quadrantes a curva apresentou-se mais acentuada até a unidade 26, estabilizando-se posteriormente, para as parcelas observa-se que a curva estabilizou-se após a unidade 35. O método de parcelas amostrou mais espécies, refletindo a quantidade bem maior de indivíduos amostrados. Não são observados sobressaltos nas curvas. Isto pode ser interpretado como uma característica de homogeneidade da vegetação estudada.

No método de parcelas, as famílias com maior número de gêneros foram: Myrtaceae com 12 (9,6\% do total), seguida por Lauraceae com $10(8,0 \%)$, Rubiaceae com 10 (8,0\%), Fabaceae $7(5,6 \%)$, Sapotaceae 5 (4,0\%) e Euphorbiaceae 4 (3,2\%). A Figura 9 mostra a contribuição percentual, em número de gêneros, das famílias identificadas por este método. 


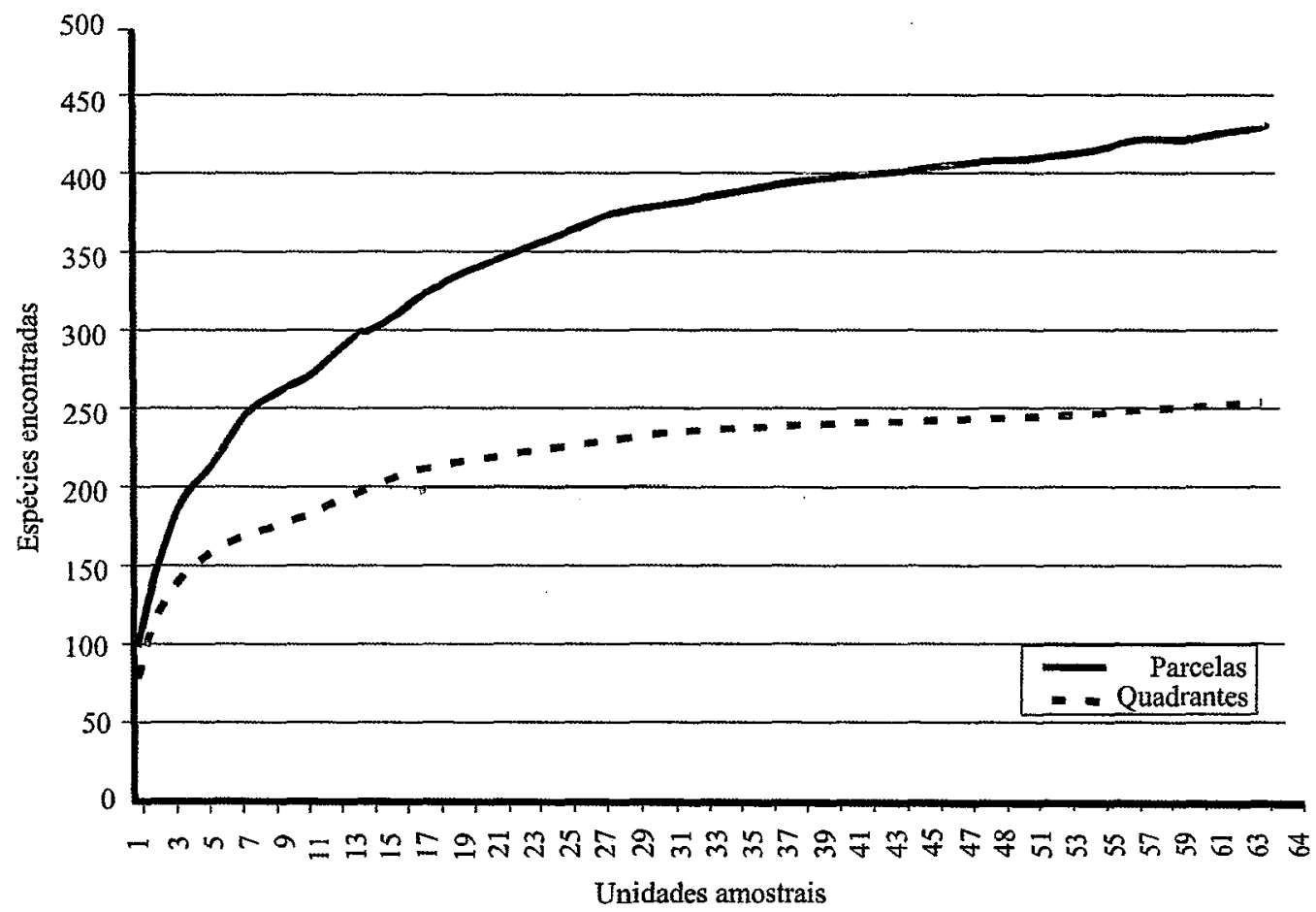

Figura 8 - Curva do coletor do número de espécies em função do número de pontos amostrais 


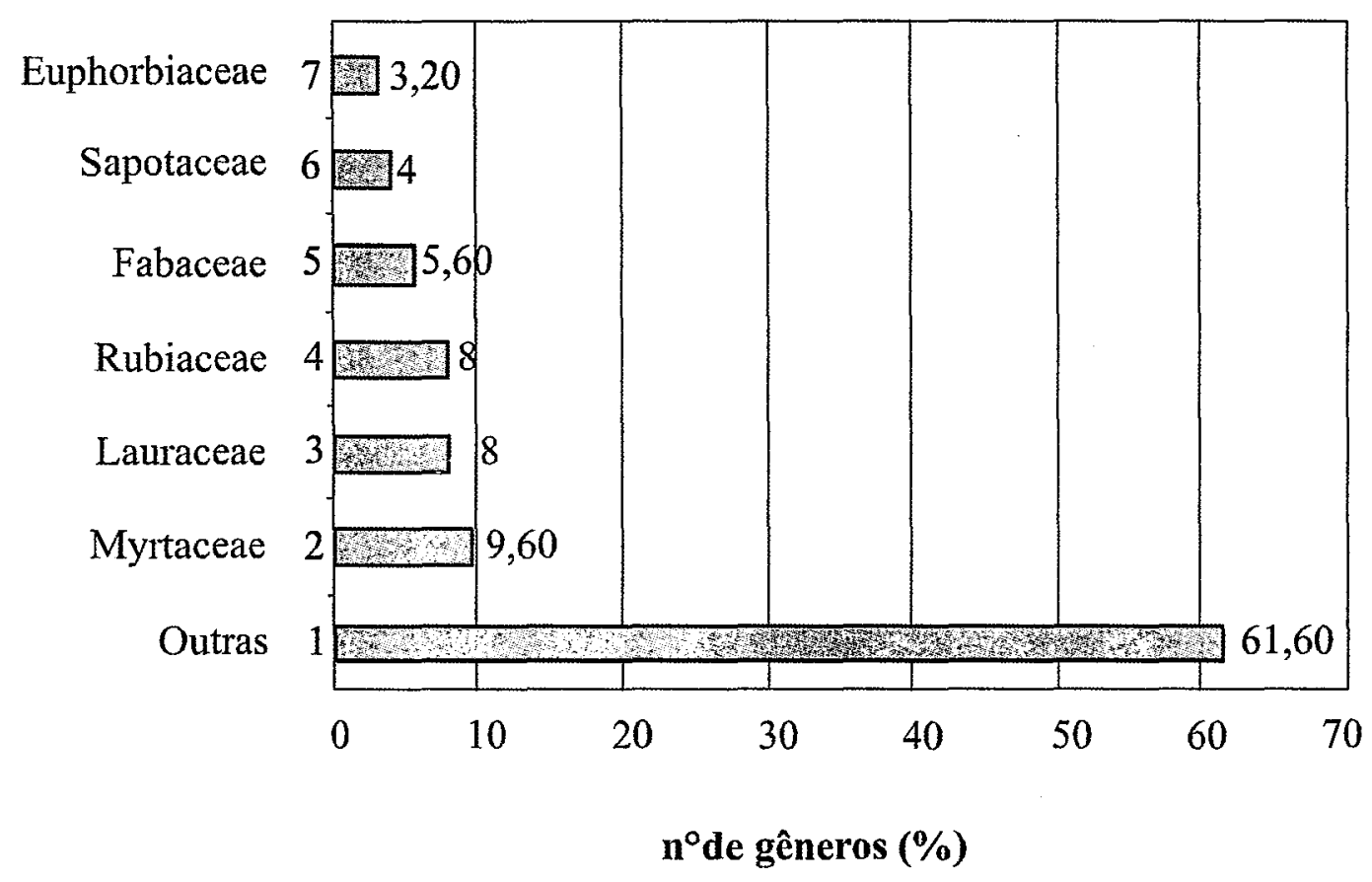

Figura 9 - Contribuição das principais famílias em percentuais de número de gênero na composição florística da floresta ombrófila densa do Parque Estadual "Carlos Botelho" - São Miguel Arcanjo, SP. Amostragem pelo método de parcelas

No método quadrantes, destacaram-se, em número de gêneros as familias Myrtaceae com 12 (11,32\% do total), Rubiaceae 9 (8,49\%), Lauraceae 7 $(6,60 \%)$, Fabaceae $5(4,71 \%)$, Sapotaceae $5(4,71 \%)$ e Euphorbiaceae $3(2,83 \%)$. Essas famílias contribuíram com $38,66 \%$ do total de gêneros amostrados, enquanto as 47 outras dividem entre si os $61,34 \%$ dos gêneros restantes. A Figura 10 mostra a contribuição das famílias, em percentagem do número de gêneros, pelo método de quadrantes. 


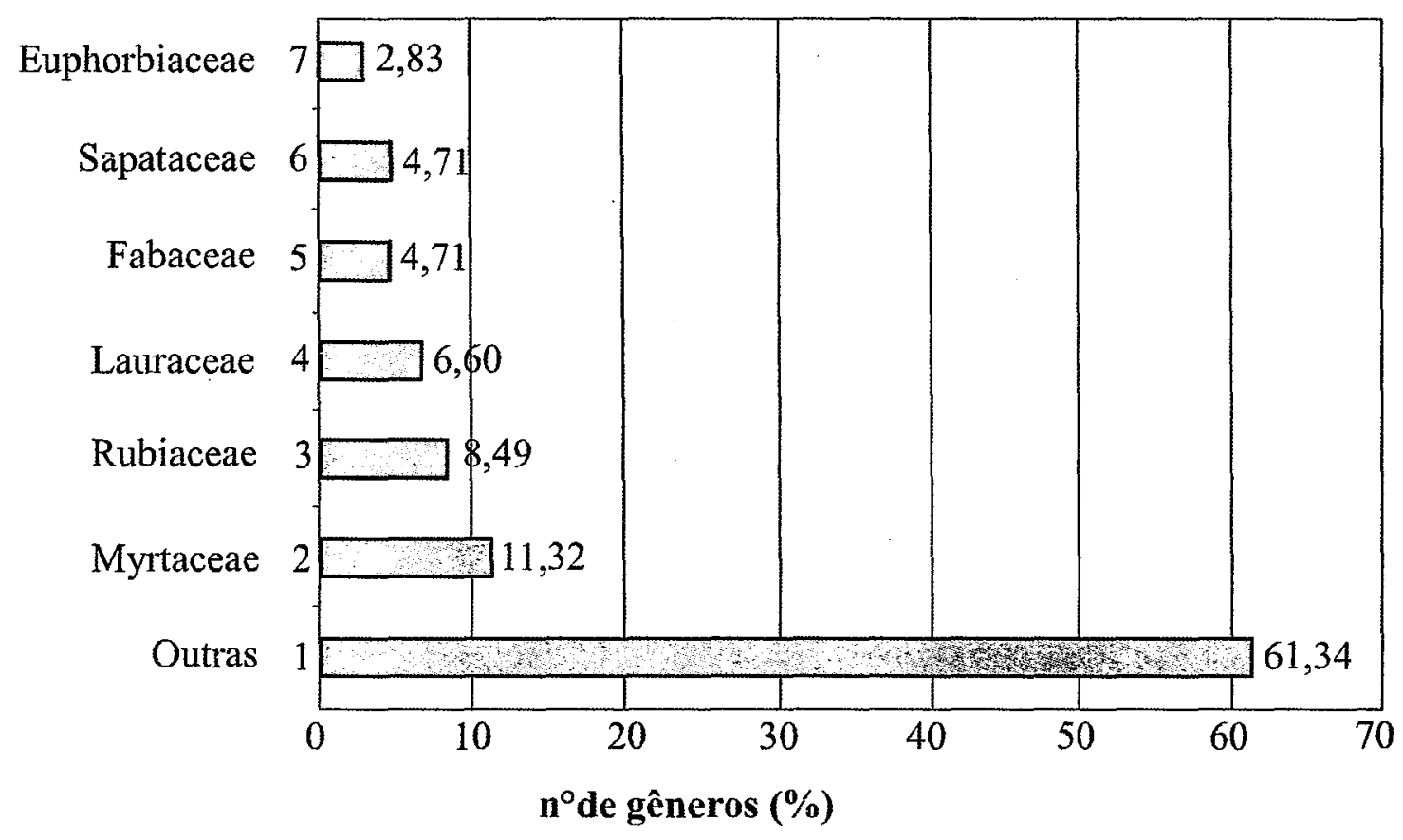

Figura 10 - Contribuição das principais famílias em percentuais de número de gênero, na composição florística da floresta ombrófila densa no Parque Estadual "Carlos Botelho" - São Miguel Arcanjo, SP. Amostragem pelo método de quadrantes

Observou-se que as principais famílias foram, exatamente, as mesmas para os dois métodos, apenas Rubiaceae e Lauraceae trocaram posição.

Os gêneros mais representados, nas parcelas, foram: Eugenia (Myrtaceae) e Ocotea (Lauraceae) ambos com 21 espécies, seguidos por Myrcia (Myrtaceae) com 10 espécies, Miconia (Melastomataceae) com 7 espécies, Mollinedia (Monimiaceae) e Myrceugenia (Myrtaceae), cada um com 6 espécies e Inga, Rapanea, 
Marlierea e Ilex, respectivamente, pertencentes às famílias Mimosaceae, Myrsinaceae, Myrtaceae e Aquifoliaceae com 4 espécies cada um.

Nos quadrantes, os gêneros que mais se destacaram foram: Eugenia (Myrtaceae) com 17 espécies, Ocotea (Lauraceae) com 13 espécies, Myrcia (Myrtaceae) com 6 espécies Miconia (Melastomataceae) com 5 espécies e Rapanea (Myrsinaceae), Marlierea (Myrtaceae) e Myrceugenia (Myrtaceae), com 4 espécies cada.

Nota-se que há coincidência entre os gêneros, nos dois métodos, e verifica-se o predomínio de gêneros que são caracterizados por espécies que preferem os estratos inferiores da floresta.

Segundo Mantovani (1993), as espécies encontradas como típicas de sub-bosque apresentam síndrome de dispersão por animais seja, através de frutos carnosos ou de sementes com estruturas que favoreçam sua dispersão, o que ressalta a importância da fauna em florestas pluviais tropicais.

Na Figura 11 é apresentada a distribuição do número de espécies na amostragem por parcelas. As famílias mais importantes foram: Myrtaceae, com 58 espécies $(23,02 \%)$ do total amostrado, logo a seguir Lauraceae com $36(14,28 \%)$. Rubiaceae e Melastomataceae 12 espécies (4,76\%) cada, Fabaceae 8 espécies $(3,17 \%)$, Monimiaceae, Sapotaceae e Sapindaceae 6 espécies( 2,38\%) cada, Myrsinaceae, Mimosaceae e Aquifoliaceae 5 espécies (1,98\%) cada uma e Annonaceae, Euphorbiaceae e Flacourtiaceae 4 espécies $(1,58 \%)$ cada. Essas 14 famílias totalizam $67,81 \%$ das espécies, 27 famílias equivalentes a $10,71 \%$ do total foram amostradas, apenas com uma espécie cada. 
Flocourtiaceae Euphorbiaceae Annonaceae Aquifoliaceae Mimosaceae Myrsinoceae Sapindaceae Sapotaceae Monimiaceae Fabaceae Melastomaceae Rubiaceae Lauraceae Myrtaceae Outras

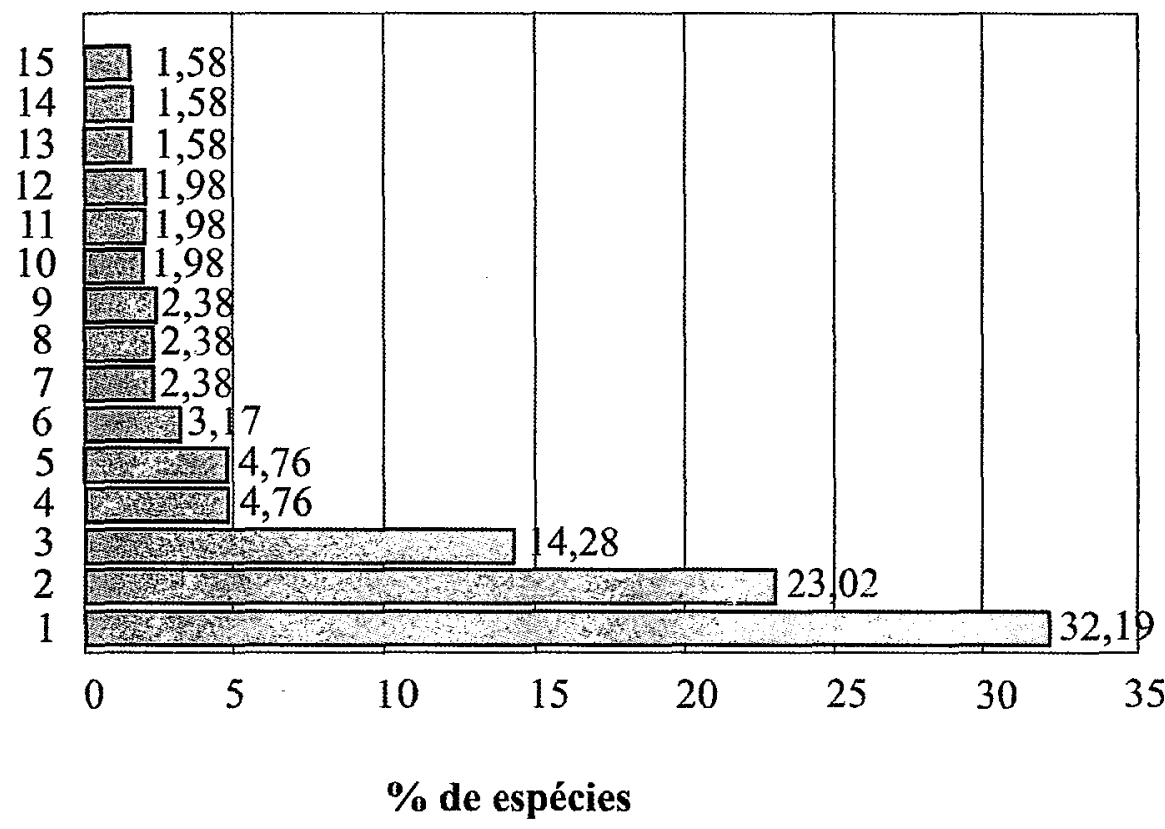

Figura 11 - Contribuição das principais famílias em percentuais de número de espécies, na composição florística da floresta ombrófila densa no Parque Estadual "Carlos Botelho" - São Miguel Arcanjo, SP. Amostragem pelo método de parcelas

Nos quadrantes, as famílias com maior riqueza em espécies foram: Myrtaceae com 42 espécies, 23,72\% do total amostrado, Lauraceae com 20 (11,29\%) espécies, Rubiaceae com 11 (6,21\%), Melastomataceae com 7 (3,95\%), Fabaceae e Sapotaceae com $6(3,38 \%)$ espécies cada uma, Sapindaceae com $5(2,82 \%)$ e Annonaceae, Mimosaceae e Myrsinaceae com 4 ou 2,25\% de espécies cada uma (Figura 12). Essas 10 famílias foram responsáveis por $61,50 \%$ do total de espécies encontradas, sendo que $5,64 \%$ correspondem a 10 outras famílias com apenas uma espécie. 


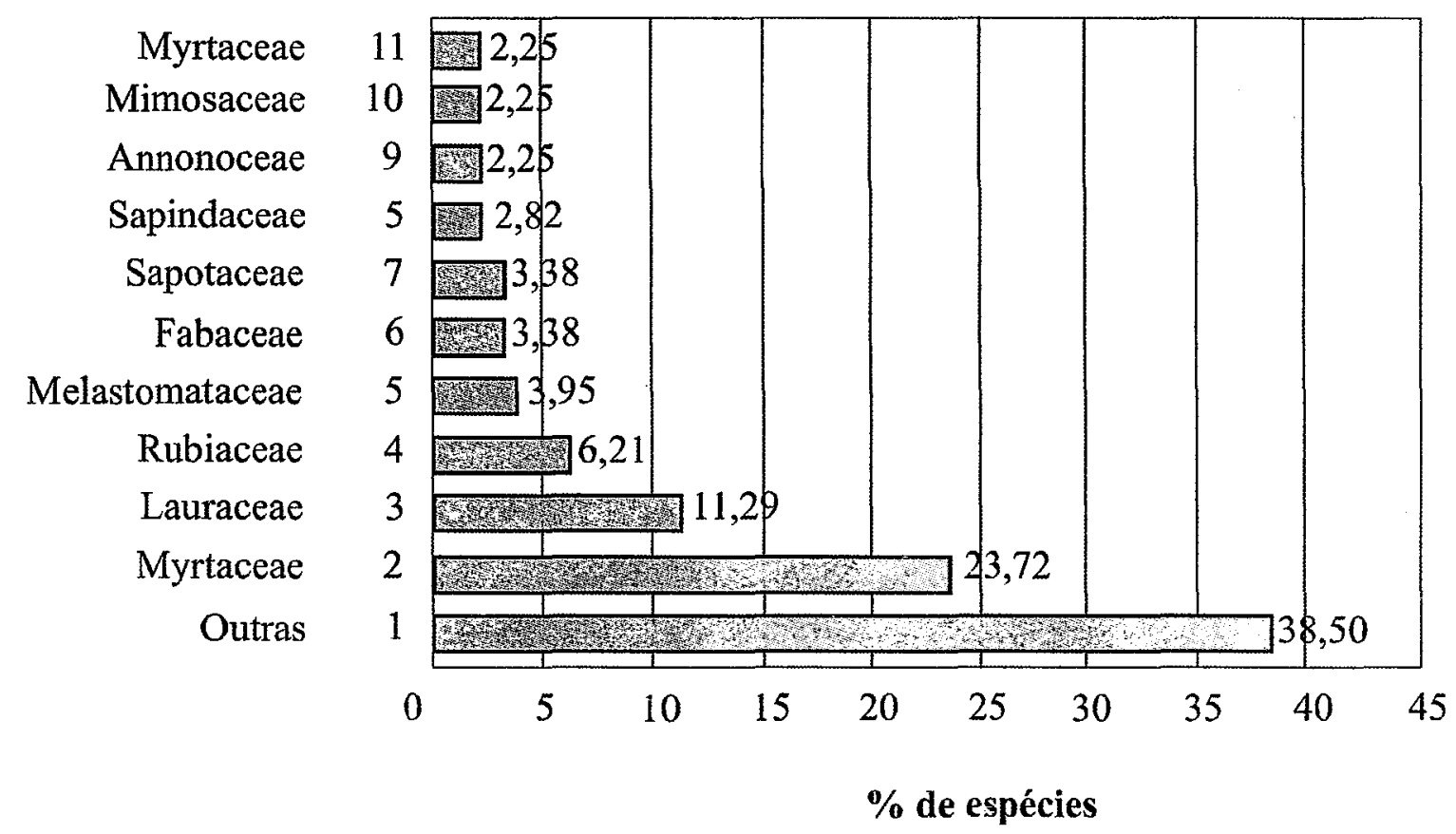

Figura 12 - Contribuição das principais famílias em percentagem de número de espécies na composição florística da floresta ombrófila densa do Parque Estadual "Carlos Botelho" - São Miguel Arcanjo, SP. Amostragem pelo método de quadrantes

Considerando os aspectos abordados as famílias, os gêneros e as espécies que mais se destacaram são similares aos encontrados em outros estudos.

Para as famílias, dependendo da região do planalto atlântico, já foram mencionadas como de maior riqueza em levantamentos citados por Aragaki e Mantovani (1993), Baitello et al. (1992), De Vuono (1985), Gandolffi (1991), Gomes (1992), nas zonas de serrania costeira com Leitão Filho et al. (1993), Mantovani (1990), Sanches (1994), Silva \& Leitão Filho (1982) e baixada litorânea Mantovani (1993). As famílias Leguminosae e Myrtaceae foram detectadas com maior riqueza florística na floresta estacional decidual em Piracicaba (Ivanauskas \& Rodrigues 2000), já Ivanauskas et al. 
(2000), em um remanescente de floresta estacional semidecidual em Itatinga, obtiveram maior riqueza também para Myrtaceae, Lauraceae e Leguminosae.

Na Figura 13, pode-se constatar que $71,6 \%$ dos indivíduos amostrados pelo método de parcela são representados por apenas 10 famílias. Myrtaceae apresentou o maior número de indivíduos (1393), o que corresponde a $14,59 \%$ do total. A família seguinte foi Rubiaceae com 1201 indivíduos (12,58\%). Lauraceae foi a terceira colocada, com 1173 indivíduos (12,29\%), vindo posteriormente Arecaceae com 1087 indivíduos ou (11,38\%), Sapotaceae com 508 indivíduos ou (5,32\%), após Monimiaceae com 427 indivíduos ou (4,47\%), Melastomataceae com 318 indivíduos (3,33\%), Fabaceae com 298 indivíduos ou (3,12\%), Sapindaceae com 233 indivíduos $(2,44 \%)$ e Malpighiaceae 199 indivíduos (2,08\%). Os demais indivíduos correspondem à 28,40\% pertencentes à outras 50 famílias.

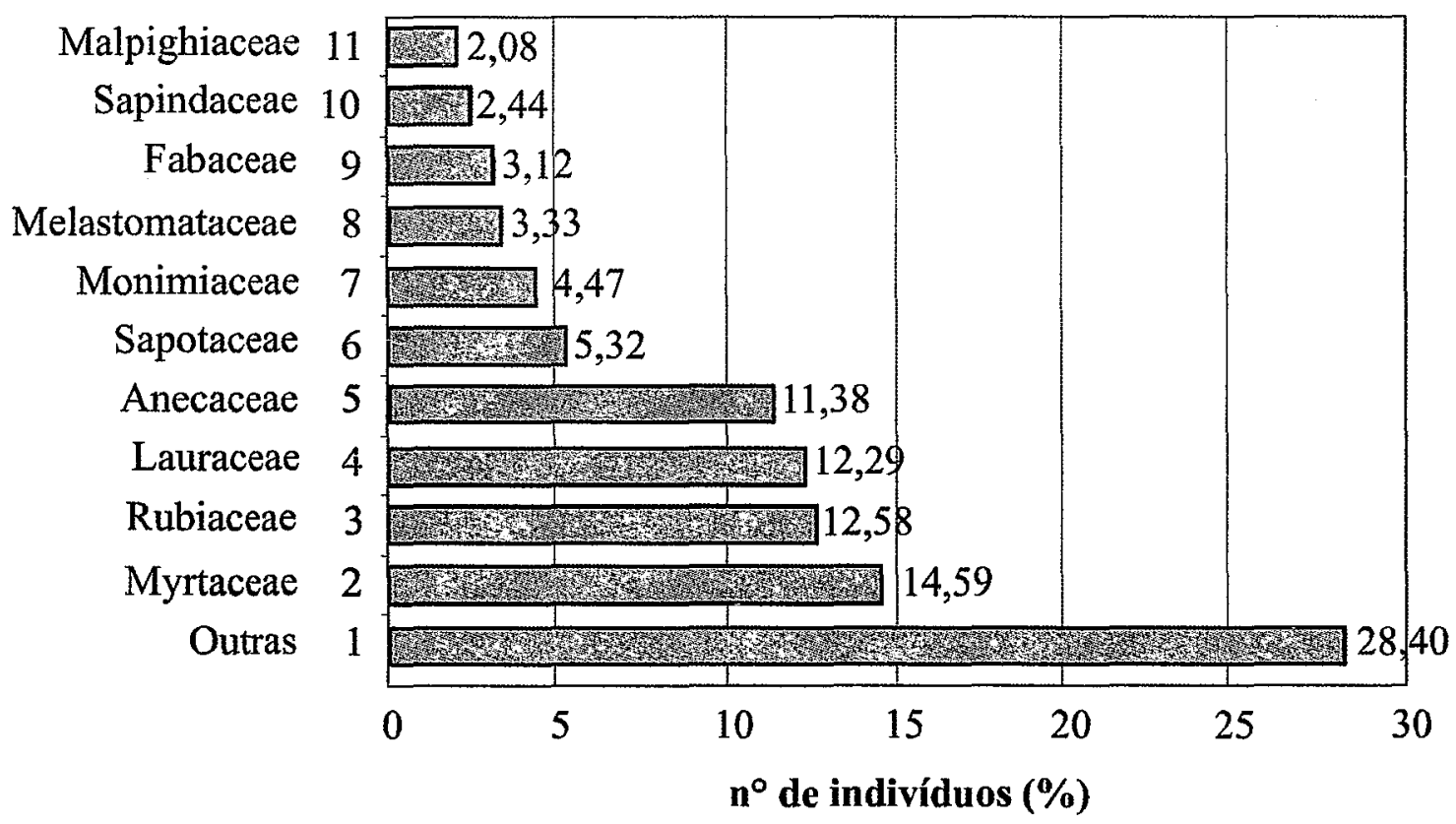

Figura 13 - Contribuição das principais famílias em porcentagem de número de indivíduos, na composição florística da floresta ombrófila densa no Parque Estadual "Carlos Botelho" - São Miguel Arcanjo, SP. Amostragem pelo método de parcelas 
A espécie com maior número de indivíduos, no método de parcelas, foi Euterpe edulis, com 1084 exemplares, (11,35\%), seguida por Alibertia sp com 310 (3,24\%), Micropholis crassipedicellata 258 (2,70\%), Bathysa australis, com 234 (2,45\%), Ocotea catharinensis, com 227 (2,37\%), Coussarea sp. com 203 (2,12\%), Pouteria bullata com 167 (1,74\%), Eugenia stictosepala, com 160 (1,67\%) e Guapira opposita, com 146 indivíduos ou $(1,52 \%)$. Juntas as 10 espécies mais representativas somam $32,19 \%$ dos indivíduos estudados.

Nos quadrantes 10 famílias foram responsáveis por $73,38 \%$ dos indivíduos amostrados. Myrtaceae apresentou o maior número de indivíduos (183), correspondendo a 14,29\%, seguida por Arecaceae com 162 indivíduos, (12,65\%), Rubiaceae com 157 (12,26\%), Lauraceae com 135 (10,54\%), Sapotaceae com 90 (7,03\%), Monimiaceae com 62 (4,84\%), Fabaceae 50 (3,90\%), Melastomataceae 43 (3,35\%), Sapindaceae $34(2,65 \%)$ e Annonaceae com 24 indivíduos, que correspondeu a $1,87 \%$ do total amostrado. Os $26,62 \%$ restantes são representados por indivíduos pertencentes a outras 43 famílias. Esses números são apresentados na Figura 14. Cerca de $26 \%$ das espécies (46) foram amostradas por apenas um indivíduo.

Os dois métodos amostraram a composição florística da vegetação estudada, de maneira semelhante. Este fato fica ainda mais ressaltado, quando considera-se as principais famílias, gêneros e espécies. 


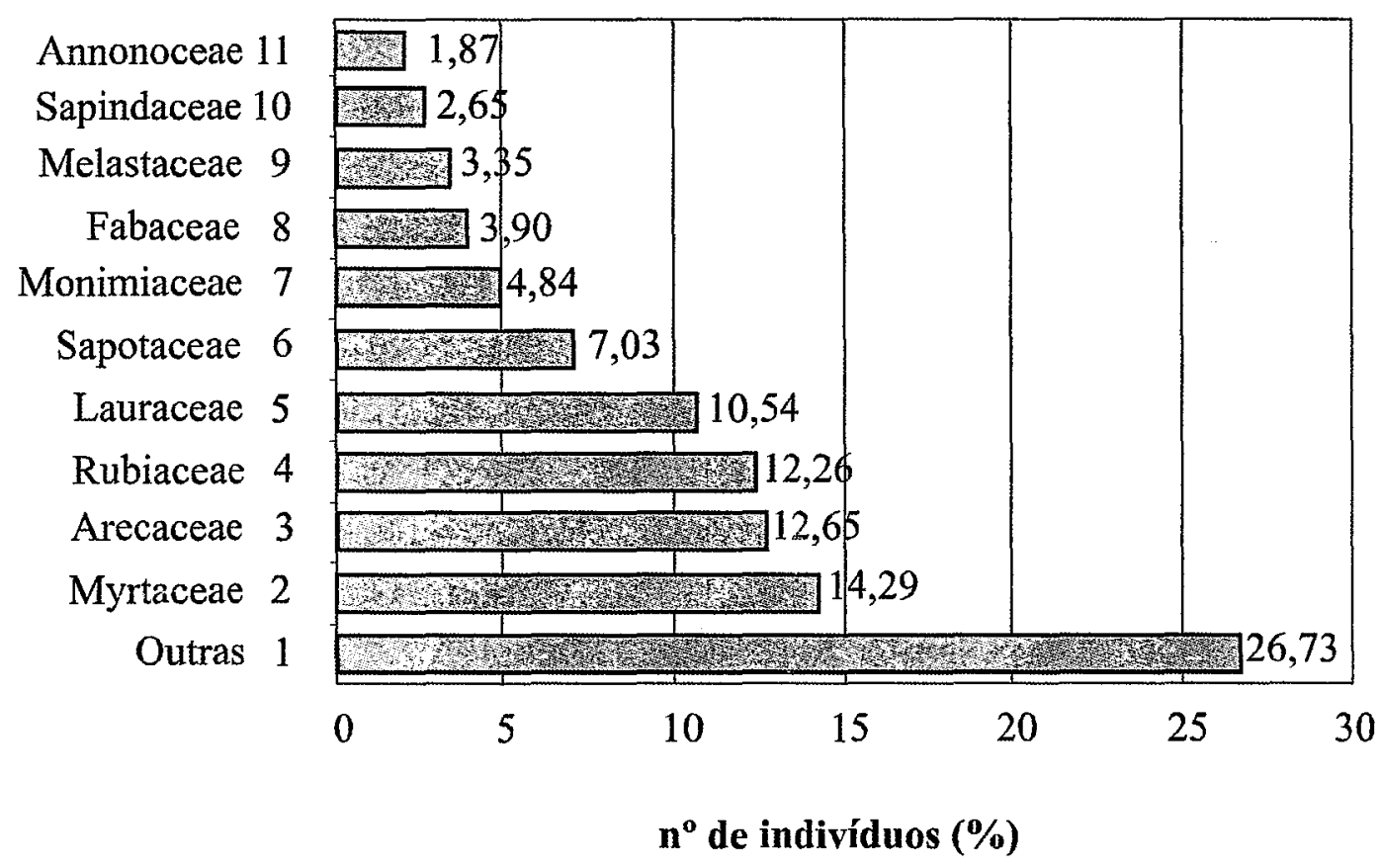

Figura 14 - Contribuição das principais famílias em porcentagem de número de indivíduos, na composição florística da floresta ombrófila densa no Parque Estadual "Carlos Botelho" - São Miguel Arcanjo, SP. Amostragem pelo método de quadrantes

\subsection{Fitossociologia}

Na Tabela 4 estão listadas as 252 espécies amostradas no levantamento pelo método de parcelas, com seus respectivos parâmetros fitossociológicos classificados por ordem decrescente do Índice de Valor de Importância (IVI). 
Tabela 4. Espécies em ordem decrescente de índice de valor de importância (IVI) encontradas através de levantamento pelo método de parcelas no Parque Estadual "Carlos Botelho" - São Miguel Arcanjo, SP, onde $\mathrm{n}=$ número de indivíduos; fr.a = freqüência absoluta; fr.r = freqüência relativa; de. $a=$ densidade absoluta; de. $r=$ densidade relativa; do. $a=$ dominância absoluta; do.r = dominância relativa; ivi = índice de valor de importância e ivc $=$ índice de valor de cobertura

\begin{tabular}{|c|c|c|c|c|c|c|c|}
\hline Espécies & $\mathbf{n}$ & Fr.a fr.r & de.a & de.r do.a & do.r & ivi & ive \\
\hline Micropholis crassipedicellata & 258 & $85,941,33$ & 44,79 & $2,705,82$ & 13,05 & 17,081 & $\overline{15,75}$ \\
\hline Euterpe edulis & 1084 & $100,001,55$ & 188,19 & $11,361,18$ & 2,66 & 15,561 & 14,01 \\
\hline Ocotea catharinensis & 227 & $87,501,35$ & 39,41 & $2,382,90$ & 6,51 & 10,25 & 8,89 \\
\hline Pouteria bullata & 167 & $89,061,38$ & 28,99 & $1,751,85$ & 4,16 & 7,29 & 5,91 \\
\hline Alchornea triplinervia & 114 & $71,881,11$ & 19,79 & $1,191,75$ & 3,92 & 6,22 & 5,11 \\
\hline Mollinedia oligantha & 290 & $90,631,40$ & 50,35 & $3,040,56$ & 1,26 & 5,70 & 4,29 \\
\hline Alibertia sp. & 310 & $90,631,40$ & 53,82 & $3,250,41$ & 0,92 & 5,57 & 4,17 \\
\hline Vantanea compacta & 128 & $76,561,19$ & 22,22 & $1,341,34$ & 3,01 & 5,53 & 4,35 \\
\hline Bathysa australis & 234 & $68,751,06$ & 40,63 & $2,450,82$ & 1,83 & 5,35 & 4,28 \\
\hline Cabralea canjerana & 104 & $78,131,21$ & 18,06 & $1,091,18$ & 2,64 & 4,94 & 3,73 \\
\hline Ocotea bicolor & 140 & $64,060,99$ & 24,31 & $1,470,93$ & 2,09 & 4,55 & 3,56 \\
\hline Guapira opposita & 146 & $78,131,21$ & 25,35 & $1,530,64$ & 1,43 & 4,17 & 2,96 \\
\hline Coussarea sp. & 203 & $82,811,28$ & 35,24 & $2,130,31$ & 0,71 & 4,11 & 2,83 \\
\hline Ocotea elegans & 111 & $75,001,16$ & 19,27 & $1,160,73$ & 1,64 & 3,96 & 2,80 \\
\hline Ormosia dasycarpa & 142 & $56,250,87$ & 24,65 & $1,490,62$ & 1,38 & 3,74 & 2,87 \\
\hline Chionanthus filiformis & 134 & $68,751,06$ & 23,26 & $1,400,43$ & 0,96 & 3,42 & 2,36 \\
\hline Eugenia stictosepala & 160 & $82,811,28$ & 27,78 & $1,680,16$ & 0,37 & 3,33 & 2,04 \\
\hline Matayba juglandifolia & 107 & $73,441,14$ & 18,58 & $1,120,47$ & 1,06 & 3,32 & 2,18 \\
\hline Mollinedia schottiana & 118 & $89,061,38$ & 20,49 & $1,240,31$ & 0,69 & 3,30 & 1,93 \\
\hline Amaioua intermedia & 128 & $70,311,09$ & 22,22 & $1,340,29$ & 0,64 & 3,07 & 1,98 \\
\hline Cryptocarya sp. 1 & 64 & $53,130,82$ & 11,11 & $0,670,65$ & 1,45 & 2,95 & 2,12 \\
\hline Byrsonima ligustrifolia & 120 & $59,380,92$ & 20,83 & $1,260,33$ & 0,73 & 2,91 & 1,99 \\
\hline Ocotea pulchra & 105 & $65,631,02$ & 18,23 & $1,100,35$ & 0,79 & 2,90 & 1,89 \\
\hline Ocotea odorifera & 87 & $56,250,87$ & 15,10 & $0,910,49$ & 1,11 & 2,89 & 2,02 \\
\hline Myrcia pubipetala & 83 & $73,441,14$ & 14,41 & $0,870,35$ & 0,78 & 2,79 & 1,65 \\
\hline Tapirira guianensis & 67 & $57,810,89$ & 11,63 & $0,700,52$ & 1,17 & 2,76 & 1,87 \\
\hline Rudgea jasminoides & 128 & $71,881,11$ & 22,22 & $1,340,14$ & 0,31 & 2,76 & 1,65 \\
\hline
\end{tabular}


Tabela 4. Espécies em ordem decrescente de índice de valor de importância (IVI) encontradas através de levantamento pelo método de parcelas no Parque Estadual "Carlos Botelho" - São Miguel Arcanjo, SP, onde $\mathrm{n}=$ número de indivíduos; fr.a $=$ freqüência absoluta; fr.r = freqüência relativa; de. $\mathrm{a}=$ densidade absoluta; de. $\mathrm{r}=$ densidade relativa; do. $\mathrm{a}=$ dominância absoluta; do.r = dominância relativa; ivi = índice de valor de importância e ivc = índice de valor de cobertura

\begin{tabular}{|c|c|c|c|c|c|c|c|}
\hline Espécies & $\mathbf{n}$ & Fr.a fr.r & de.a & de.r do.a & do.r & ivi & ive \\
\hline Ocotea aciphylla & 74 & $46,880,73$ & 12,85 & $0,780,55$ & 1,24 & 2,74 & 2,02 \\
\hline Esenbeckia grandiflora & 104 & $65,631,02$ & 18,06 & $1,090,17$ & 0,38 & 2,49 & 1,47 \\
\hline Myrocarpus frondosus & 79 & $57,810,89$ & 13,72 & $0,830,33$ & 0,75 & 2,47 & 1,58 \\
\hline Pouteria caimito & 50 & $50,000,77$ & 8,68 & $0,520,51$ & 1,15 & 2,45 & 1,67 \\
\hline Tibouchina pulchra & 77 & $43,750,68$ & 13,37 & $0,810,42$ & 0,95 & 2,44 & 1,76 \\
\hline Xylopia langsdorffiana & 98 & $56,250,87$ & 17,01 & $1,030,23$ & 0,52 & 2,42 & 1,55 \\
\hline Parinari excelsa & 62 & $48,440,75$ & 10,76 & $0,650,43$ & 0,96 & 2,36 & 1,61 \\
\hline Matayba guianensis & 57 & $50,000,77$ & 9,90 & $0,600,42$ & 0,94 & 2,31 & 1,53 \\
\hline Rapanea umbellata & 75 & $67,191,04$ & 13,02 & $0,790,20$ & 0,45 & 2,28 & 1,24 \\
\hline Copaifera trapezifolia & 50 & $48,440,75$ & 8,68 & $0,520,44$ & 0,99 & 2,27 & 1,52 \\
\hline Byrsonima myricifolia & 79 & $56,250,87$ & 13,72 & $0,830,23$ & 0,52 & 2,21 & 1,34 \\
\hline Guatteria australis & 65 & $60,940,94$ & 11,28 & $0,680,25$ & 0,56 & 2,19 & 1,24 \\
\hline Cryptocarya moschata & 40 & $37,500,58$ & 6,94 & $0,420,52$ & 1,18 & 2,18 & 1,60 \\
\hline Aniba viridis & 64 & $57,810,89$ & 11,11 & $0,670,21$ & 0,48 & 2,05 & 1,15 \\
\hline Posoqueria acutifolia & 70 & $56,250,87$ & 12,15 & $0,730,16$ & 0,36 & 1,97 & 1,10 \\
\hline Myrcia fallax & 83 & $46,880,73$ & 14,41 & $0,870,15$ & 0,35 & 1,94 & 1,22 \\
\hline Cordia sellowiana & 62 & $53,130,82$ & 10,76 & $0,650,20$ & 0,45 & 1,92 & 1,10 \\
\hline Didymopanax navarroi & 30 & $35,940,56$ & 5,21 & $0,310,47$ & 1,05 & 1,92 & 1,36 \\
\hline Pterocarpus rohrii & 50 & $42,190,65$ & 8,68 & $0,520,33$ & 0,73 & 1,91 & 1,26 \\
\hline Symplocos falcata & 36 & $42,190,65$ & 6,25 & $0,380,35$ & 0,79 & 1,82 & 1,17 \\
\hline Maytenus robusta & 43 & $45,310,70$ & 7,47 & $0,450,28$ & 0,63 & 1,78 & 1,08 \\
\hline Siphoneugena densiflora & 56 & $51,560,80$ & 9,72 & $0,590,17$ & 0,38 & 1,76 & 0,97 \\
\hline Copaifera langsdorffii & 54 & $51,560,80$ & 9,38 & $0,570,17$ & 0,39 & 1,76 & 0,96 \\
\hline Hirtella hebeclada & 48 & $48,440,75$ & 8,33 & $0,500,22$ & 0,50 & 1,75 & 1,00 \\
\hline Miconia cabucu & 58 & $48,440,75$ & 10,07 & $0,610,17$ & 0,38 & 1,74 & 0,99 \\
\hline Aspidosperma olivaceum & 45 & $42,190,65$ & 7,81 & $0,470,26$ & 0,58 & 1,70 & 1,05 \\
\hline Sorocea bonplandii & 61 & $54,690,85$ & 10,59 & $0,640,08$ & 0,18 & 1,66 & 0,82 \\
\hline
\end{tabular}


Tabela 4. Espécies em ordem decrescente de índice de valor de importância (IVI) encontradas através de levantamento pelo método de parcelas no Parque Estadual "Carlos Botelho" - São Miguel Arcanjo, SP, onde $\mathbf{n}=$ número de indivíduos; fr.a = freqüência absoluta; fr.r = freqüência relativa; de. $\mathrm{a}=$ densidade absoluta; de. $\mathrm{r}=$ densidade relativa; do. $\mathrm{a}=$ dominância absoluta; do.r = dominância relativa; ivi = índice de valor de importância e ivc $=$ índice de valor de cobertura

\begin{tabular}{lcccccccc}
\hline \multicolumn{1}{c}{ Espécies } & n & Fr.a & fr.r & de.a & de.r do.a & do.r & ivi & ivc \\
\hline Buchenavia kleinii & 11 & $17,190,27$ & 1,91 & $0,120,54$ & 1,21 & 1,60 & 1,33 \\
Eugenia subavenia & 69 & $50,000,77$ & 11,98 & $0,720,04$ & 0,10 & 1,59 & 0,82 \\
Sclerolobium denudatum & 44 & $35,940,56$ & 7,64 & $0,460,26$ & 0,58 & 1,59 & 1,04 \\
Andira anthelmia & 47 & $51,560,80$ & 8,16 & $0,490,13$ & 0,30 & 1,59 & 0,79 \\
Miconia pusilliflora & 61 & $50,000,77$ & 10,59 & $0,640,07$ & 0,15 & 1,56 & 0,79 \\
Meliosma sinuata & 44 & $32,810,51$ & 7,64 & $0,460,26$ & 0,57 & 1,54 & 1,03 \\
Myrceugenia sp. 1 & 46 & $53,130,82$ & 7,99 & $0,480,10$ & 0,22 & 1,52 & 0,70 \\
Miconia petropolitana & 57 & $48,440,75$ & 9,90 & $0,600,07$ & 0,16 & 1,50 & 0,75 \\
Eugenia handroana & 49 & $51,560,80$ & 8,51 & $0,510,08$ & 0,17 & 1,48 & 0,69 \\
Alibertia aff. myrciifolia & 61 & $40,630,63$ & 10,59 & $0,640,09$ & 0,20 & 1,47 & 0,84 \\
Eugenia sp. 1 & 42 & $50,000,77$ & 7,29 & $0,440,11$ & 0,24 & 1,45 & 0,68 \\
Lamanonia ternata & 29 & $28,130,44$ & 5,03 & $0,300,31$ & 0,70 & 1,44 & 1,01 \\
Pithecellobium langsdorffi & 53 & $39,060,60$ & 9,20 & $0,560,12$ & 0,27 & 1,43 & 0,83 \\
Cupania oblongifolia & 40 & $39,060,60$ & 6,94 & 0,42 & 0,18 & 0,40 & 1,42 & 0,82 \\
Protium heptaphyllum & 41 & $34,380,53$ & 7,12 & $0,430,20$ & 0,46 & 1,42 & 0,89 \\
Prunus myrtifolia & 35 & $35,940,56$ & 6,08 & $0,370,22$ & 0,49 & 1,41 & 0,85 \\
Marlierea parviflora & 50 & $43,750,68$ & 8,68 & 0,52 & 0,09 & 0,20 & 1,40 & 0,73 \\
Eugenia sp. 5 & 34 & $35,940,56$ & 5,90 & $0,360,20$ & 0,44 & 1,35 & 0,79 \\
Inga sellowiana & 46 & $45,310,70$ & 7,99 & 0,48 & 0,07 & 0,15 & 1,34 & 0,63 \\
Plinia pauciflora & 35 & $43,750,68$ & 6,08 & $0,370,11$ & 0,26 & 1,30 & 0,62 \\
Ocotea dispersa & 40 & $40,630,63$ & 6,94 & $0,420,11$ & 0,25 & 1,30 & 0,67 \\
Myrtaceae 3 & 24 & $31,250,48$ & 4,17 & $0,250,23$ & 0,51 & 1,24 & 0,76 \\
Weinmannia paulliniifolia & 27 & $32,810,51$ & 4,69 & $0,280,19$ & 0,44 & 1,23 & 0,72 \\
Eugenia involucrata & 41 & $42,190,65$ & 7,12 & $0,430,06$ & 0,14 & 1,22 & 0,57 \\
Gomidesia tijucensis & 39 & $40,630,63$ & 6,77 & $0,410,08$ & 0,17 & 1,21 & 0,58 \\
Ouratea parviflora & 43 & $34,380,53$ & 7,47 & $0,450,10$ & 0,22 & 1,20 & 0,67 \\
Hieronyma alchorneoides & 40 & $21,880,34$ & 6,94 & $0,420,17$ & 0,38 & 1,14 & 0,80
\end{tabular}


Tabela 4. Espécies em ordem decrescente de índice de valor de importância (IVI) encontradas através de levantamento pelo método de parcelas no Parque Estadual "Carlos Botelho" - São Miguel Arcanjo, SP, onde $\mathrm{n}=$ número de indivíduos; fr.a = freqüência absoluta; fr.r = freqüência relativa; de. $\mathbf{a}=$ densidade absoluta; de. $\mathbf{r}=$ densidade relativa; do. $\mathbf{a}=$ dominância absoluta; do.r = dominância relativa; ivi = índice de valor de importância e ivc = índice de valor de cobertura

\begin{tabular}{llllllllll}
\hline \multicolumn{1}{c}{ Espécies } & n & Fr.a & fr.r & de.a & de.r & do.a & do.r & ivi & ivc \\
\hline Myrceugenia myrcioides & 40 & $40,630,63$ & 6,94 & $0,420,04$ & 0,08 & 1,13 & 0,50 \\
Myrcia sp. 1 & 31 & $35,940,56$ & 5,38 & $0,320,09$ & 0,20 & 1,08 & 0,53 \\
Sloanea monosperma & 25 & $31,250,48$ & 4,34 & $0,260,15$ & 0,33 & 1,07 & 0,59 \\
Aiouea acarodomatifera & 26 & $23,440,36$ & 4,51 & $0,270,18$ & 0,41 & 1,04 & 0,68 \\
Ixora burcheliana & 35 & $29,690,46$ & 6,08 & $0,370,08$ & 0,19 & 1,02 & 0,56 \\
Tibouchina sellowiana & 32 & $20,310,31$ & 5,56 & $0,340,16$ & 0,36 & 1,00 & 0,69 \\
Drymis winteri & 35 & $32,810,51$ & 6,08 & $0,370,05$ & 0,12 & 0,99 & 0,48 \\
Myrceugenia glaucescens & 34 & $29,690,46$ & 5,90 & $0,360,08$ & 0,18 & 0,99 & 0,53 \\
Eugenia mosenii & 35 & $26,560,41$ & 6,08 & $0,370,07$ & 0,16 & 0,94 & 0,53 \\
Ocotea pulchella & 20 & $23,440,36$ & 3,47 & $0,210,16$ & 0,36 & 0,94 & 0,57 \\
Cupania vernalis & 24 & $28,130,44$ & 4,17 & $0,250,11$ & 0,25 & 0,94 & 0,50 \\
Capsicodendron dinisii & 22 & $25,000,39$ & 3,82 & $0,230,14$ & 0,32 & 0,94 & 0,55 \\
Eugenia capitulifera & 33 & $31,250,48$ & 5,73 & $0,350,05$ & 0,11 & 0,94 & 0,45 \\
Eugenia beaurepaireana & 23 & $31,250,48$ & 3,99 & $0,240,09$ & 0,21 & 0,93 & 0,45 \\
Ilex amara & 30 & $28,130,44$ & 5,21 & $0,310,07$ & 0,15 & 0,90 & 0,46 \\
Jacaranda puberula & 25 & $23,440,36$ & 4,34 & $0,260,12$ & 0,26 & 0,88 & 0,52 \\
Campomanesia guaviroba & 17 & $21,880,34$ & 2,95 & $0,180,15$ & 0,35 & 0,86 & 0,52 \\
Eugenia sp. 2 & 24 & $29,690,46$ & 4,17 & $0,250,05$ & 0,10 & 0,81 & 0,36 \\
Calyptranthes aff. lucida & 26 & $28,130,44$ & 4,51 & $0,270,04$ & 0,10 & 0,80 & 0,37 \\
Psychotria velloziana & 17 & $20,310,31$ & 2,95 & $0,180,14$ & 0,31 & 0,80 & 0,49 \\
Ocotea teleiandra & 25 & $26,560,41$ & 4,34 & $0,260,05$ & 0,11 & 0,78 & 0,37 \\
Diploon cuspidatum & 18 & $18,750,29$ & 3,13 & $0,190,13$ & 0,30 & 0,77 & 0,48 \\
Symplocos variabilis & 20 & $20,310,31$ & 3,47 & $0,210,10$ & 0,22 & 0,75 & 0,43 \\
Eugenia cerasiflora & 21 & $26,560,41$ & 3,65 & $0,220,05$ & 0,11 & 0,74 & 0,33 \\
Casearia decandra & 21 & $23,440,36$ & 3,65 & $0,220,07$ & 0,15 & 0,73 & 0,37 \\
Marlierea tomentosa & 19 & $21,880,34$ & 3,30 & $0,200,08$ & 0,18 & 0,71 & 0,38 \\
Coccoloba aff.latifolia & 16 & $18,750,29$ & 2,78 & $0,170,11$ & 0,24 & 0,70 & 0,41
\end{tabular}


Tabela 4. Espécies em ordem decrescente de índice de valor de importância (IVI) encontradas através de levantamento pelo método de parcelas no Parque Estadual "Carlos Botelho" - São Miguel Arcanjo, SP, onde $\mathrm{n}=$ número de indivíduos; fr.a = freqüência absoluta; fr.r = freqüência relativa; de. $\mathbf{a}=$ densidade absoluta; de. $\mathbf{r}=$ densidade relativa; do. $\mathbf{a}=$ dominância absoluta; do.r = dominância relativa; ivi = índice de valor de importância e ivc $=$ índice de valor de cobertura

\begin{tabular}{|c|c|c|c|c|c|c|c|}
\hline Espécies & $\mathbf{n}$ & Fr.a fr.r & de.a & de.l & do.r & ivi & ive \\
\hline Eugenia riedeliana & 20 & $26,560,41$ & 3,47 & $0,210,03$ & 0,07 & 0,69 & 0,28 \\
\hline Ilex paraguariensis & 19 & $20,310,31$ & 3,30 & $0,200,08$ & 0,17 & 0,68 & 0,37 \\
\hline Heisteria silvianii & 19 & $25,000,39$ & 3,30 & $0,200,04$ & 0,09 & 0,68 & 0,29 \\
\hline Rollinia sericea & 19 & $23,440,36$ & 3,30 & $0,200,05$ & 0,12 & 0,68 & 0,31 \\
\hline Endlicheria paniculata & 21 & $20,310,31$ & 3,65 & $0,220,05$ & 0,12 & 0,65 & 0,34 \\
\hline Ilex theezans & 18 & $20,310,31$ & 3,13 & $0,190,05$ & 0,12 & 0,62 & 0,31 \\
\hline Ocotea silvestris & 18 & $21,880,34$ & 3,13 & $0,190,04$ & 0,09 & 0,62 & 0,28 \\
\hline Didymopanax angustissimum & 14 & $18,750,29$ & 2,43 & $0,150,08$ & 0,17 & 0,61 & 0,32 \\
\hline Eugenia melanogina & 17 & $20,310,31$ & 2,95 & $0,180,05$ & 0,11 & 0,60 & 0,29 \\
\hline Ocotea glaziovii & 16 & $18,750,29$ & 2,78 & $0,170,06$ & 0,14 & 0,60 & 0,31 \\
\hline Myrtaceae 2 & 20 & $21,880,34$ & 3,47 & $0,210,02$ & 0,04 & 0,58 & 0,25 \\
\hline Quina magalano-gomesii & 18 & $18,750,29$ & 3,13 & $0,190,05$ & 0,10 & 0,58 & 0,29 \\
\hline Pera glabrata & 11 & $15,630,24$ & 1,91 & $0,120,09$ & 0,20 & 0,56 & 0,32 \\
\hline Clethra scabra & 10 & $14,060,22$ & 1,74 & $0,100,10$ & 0,23 & 0,55 & 0,34 \\
\hline Coussapoa microcarpa & 13 & $17,190,27$ & 2,26 & $0,140,07$ & 0,15 & 0,55 & 0,29 \\
\hline Casearia obliqua & 23 & $15,630,24$ & 3,99 & $0,240,03$ & 0,07 & 0,55 & 0,31 \\
\hline Persea pyrifolia & 12 & $17,190,27$ & 2,08 & $0,130,07$ & 0,15 & 0,54 & 0,28 \\
\hline Myrcia aff. glabra & 11 & $15,630,24$ & 1,91 & $0,120,08$ & 0,18 & 0,54 & 0,30 \\
\hline Eugenia sp. 3 & 14 & $17,190,27$ & 2,43 & $0,150,06$ & 0,13 & 0,54 & 0,27 \\
\hline Citronella paniculata & 13 & $14,060,22$ & 2,26 & $0,140,08$ & 0,18 & 0,53 & 0,32 \\
\hline Ilex taubertiana & 12 & $17,190,27$ & 2,08 & $0,130,06$ & 0,14 & 0,53 & 0,26 \\
\hline Eugenia cambucarana & 14 & $15,630,24$ & 2,43 & $0,150,06$ & 0,13 & 0,52 & 0,28 \\
\hline Clusia criuva & 6 & $9,380,15$ & 1,04 & $0,060,13$ & 0,30 & 0,51 & 0,36 \\
\hline Inga sessilis & 14 & $18,750,29$ & 2,43 & $0,150,02$ & 0,04 & 0,47 & 0,18 \\
\hline Garcinia gardneriana & 13 & $20,310,31$ & 2,26 & $0,140,01$ & 0,02 & 0,47 & 0,16 \\
\hline Casearia sylvestris & 14 & $17,190,27$ & 2,43 & $0,150,02$ & 0,05 & 0,47 & 0,20 \\
\hline Rapanea hermogenesii & 14 & $18,750,29$ & 2,43 & $0,150,01$ & 0,03 & 0,46 & 0,17 \\
\hline
\end{tabular}


Tabela 4. Espécies em ordem decrescente de índice de valor de importância (IVI) encontradas através de levantamento pelo método de parcelas no Parque Estadual "Carlos Botelho" - São Miguel Arcanjo, SP, onde $\mathrm{n}=$ número de indivíduos; fr.a = freqüência absoluta; fr.r = freqüência relativa; de. $a=$ densidade absoluta; de. $r=$ densidade relativa; do. $a=$ dominância absoluta; do. $\mathrm{r}=$ dominância relativa; ivi $=$ índice de valor de importância $\mathrm{e}$ ivc $=$ índice de valor de cobertura

\begin{tabular}{lrrrrrrrr}
\hline \multicolumn{1}{c}{ Espécies } & n & Fr.a & fr.r & de.a & de.r do.a & do.r & ivi & ivc \\
\hline Podocarpus sellowii & 9 & $10,940,17$ & 1,56 & $0,090,09$ & 0,20 & 0,46 & 0,29 \\
Myrtaceae 4 & 12 & $15,630,24$ & 2,08 & $0,130,04$ & 0,09 & 0,45 & 0,21 \\
Eugenia neoglomerata & 13 & $18,750,29$ & 2,26 & $0,140,01$ & 0,03 & 0,45 & 0,16 \\
Eugenia pruinosa & 8 & $10,940,17$ & 1,39 & $0,080,09$ & 0,19 & 0,45 & 0,28 \\
Calycorectes australis & 11 & $14,060,22$ & 1,91 & $0,120,05$ & 0,11 & 0,45 & 0,23 \\
Ocotea brachybotra & 13 & $17,190,27$ & 2,26 & $0,140,02$ & 0,04 & 0,44 & 0,17 \\
Eugenia sp. 4 & 12 & $17,190,27$ & 2,08 & $0,130,02$ & 0,04 & 0,44 & 0,17 \\
Weinmannia discolor & 10 & $10,940,17$ & 1,74 & $0,100,06$ & 0,14 & 0,41 & 0,24 \\
Rapanea ferruginea & 12 & $12,500,19$ & 2,08 & $0,130,04$ & 0,09 & 0,41 & 0,21 \\
Calyptranthes sp. & 12 & $12,500,19$ & 2,08 & $0,130,04$ & 0,08 & 0,40 & 0,21 \\
Marlierea reitzii & 10 & $14,060,22$ & 1,74 & $0,100,03$ & 0,07 & 0,39 & 0,17 \\
Zollernia ilicifolia & 11 & $14,060,22$ & 1,91 & $0,120,03$ & 0,06 & 0,39 & 0,17 \\
Chrysophyllum viride & 8 & $12,500,19$ & 1,39 & $0,080,05$ & 0,11 & 0,39 & 0,19 \\
Miconia vatherii & 11 & $15,630,24$ & 1,91 & $0,120,01$ & 0,03 & 0,38 & 0,14 \\
Ecclinusa ramiflora & 7 & $9,380,15$ & 1,22 & $0,070,07$ & 0,16 & 0,38 & 0,24 \\
Neomitranthes glomerata & 13 & $12,500,19$ & 2,26 & $0,140,02$ & 0,05 & 0,38 & 0,19 \\
Cedrela fissilis & 7 & $9,380,15$ & 1,22 & $0,070,07$ & 0,16 & 0,38 & 0,23 \\
Beilschmiedia emarginata & 9 & $9,380,15$ & 1,56 & $0,090,06$ & 0,13 & 0,37 & 0,22 \\
Solanum excelsum & 9 & $6,250,10$ & 1,56 & $0,090,07$ & 0,17 & 0,36 & 0,26 \\
Myrtaceae 1 & 9 & $12,500,19$ & 1,56 & $0,090,03$ & 0,06 & 0,35 & 0,16 \\
Fabaceae 1 & 9 & $12,500,19$ & 1,56 & $0,090,02$ & 0,04 & 0,33 & 0,14 \\
Piptocarpha macropoda & 10 & $9,380,15$ & 1,74 & $0,100,03$ & 0,08 & 0,33 & 0,18 \\
Miconia cubatanensis & 9 & $14,060,22$ & 1,56 & $0,090,00$ & 0,01 & 0,32 & 0,10 \\
Talauma ovata & 6 & $6,250,10$ & 1,04 & $0,060,07$ & 0,16 & 0,32 & 0,22 \\
Myrceugenia kleinii & 8 & $10,940,17$ & 1,39 & $0,080,03$ & 0,06 & 0,31 & 0,14 \\
Alseis floribunda & 9 & $10,940,17$ & 1,56 & $0,090,02$ & 0,04 & 0,31 & 0,14 \\
Vochysia sp. 1 & 6 & $7,810,12$ & 1,04 & $0,060,05$ & 0,12 & 0,31 & 0,19 \\
& & & & & & &
\end{tabular}


Tabela 4. Espécies em ordem decrescente de índice de valor de importância (IVI) encontradas através de levantamento pelo método de parcelas no Parque Estadual "Carlos Botelho" - São Miguel Arcanjo, SP, onde $\mathbf{n}=$ número de indivíduos; fr.a = freqüência absoluta; fr.r = freqüência relativa; de. $\mathrm{a}=$ densidade absoluta; de. $\mathrm{r}=$ densidade relativa; do. $\mathrm{a}=$ dominância absoluta; do.r = dominância relativa; ivi = índice de valor de importância e ivc = índice de valor de cobertura

\begin{tabular}{lrrrrrrrr}
\hline \multicolumn{1}{c}{ Espécies } & n & fr.a & fr.r & de.a & de.r do.a & do.r & ivi & ivc \\
\hline Gomidesia schaueriana & 7 & $9,380,15$ & 1,22 & $0,070,04$ & 0,09 & 0,31 & 0,16 \\
Sapium glandulatum & 7 & $7,810,12$ & 1,22 & $0,070,05$ & 0,11 & 0,31 & 0,19 \\
Calyptranthes sp. & 7 & $9,380,15$ & 1,22 & $0,070,03$ & 0,07 & 0,29 & 0,14 \\
Eugenia umbelliflora & 4 & $6,250,10$ & 0,69 & $0,040,06$ & 0,14 & 0,28 & 0,18 \\
Mollinedia aff. uleana & 8 & $10,940,17$ & 1,39 & $0,080,01$ & 0,02 & 0,27 & 0,10 \\
Zanthoxyllum rhoifolium & 9 & $7,810,12$ & 1,56 & $0,090,02$ & 0,05 & 0,27 & 0,15 \\
Ocotea tabacifolia & 7 & $10,940,17$ & 1,22 & $0,070,01$ & 0,02 & 0,26 & 0,09 \\
Marlierea eugeniopsoides & 6 & $9,380,15$ & 1,04 & $0,060,02$ & 0,05 & 0,26 & 0,11 \\
Tabebuia heptaphylla & 6 & $9,380,15$ & 1,04 & $0,060,02$ & 0,04 & 0,25 & 0,10 \\
Mollinedia sp. 1 & 7 & $9,380,15$ & 1,22 & $0,070,01$ & 0,03 & 0,25 & 0,10 \\
Guarea macrophylla & 8 & $7,810,12$ & 1,39 & $0,080,02$ & 0,04 & 0,24 & 0,12 \\
Persea sp. 1 & 5 & $6,250,10$ & 0,87 & $0,050,04$ & 0,09 & 0,23 & 0,14 \\
Ocotea daphnifolia & 7 & $9,380,15$ & 1,22 & $0,070,01$ & 0,01 & 0,23 & 0,09 \\
Ocotea vaccinioides & 5 & $7,810,12$ & 0,87 & $0,050,02$ & 0,05 & 0,22 & 0,10 \\
Allophylus edulis & 4 & $6,250,10$ & 0,69 & $0,040,03$ & 0,08 & 0,22 & 0,12 \\
Miconia sellowiana & 7 & $7,810,12$ & 1,22 & $0,070,01$ & 0,02 & 0,21 & 0,09 \\
Meliosma sellowii & 5 & $7,810,12$ & 0,87 & $0,050,01$ & 0,03 & 0,20 & 0,08 \\
Nectandra oppositifolia & 4 & $4,690,07$ & 0,69 & 0,04 & 0,04 & 0,08 & 0,20 & 0,13 \\
Ocotea sp. 2 & 3 & $3,130,05$ & 0,52 & $0,030,05$ & 0,12 & 0,20 & 0,15 \\
Roupala sp. 1 & 5 & $7,810,12$ & 0,87 & $0,050,01$ & 0,01 & 0,19 & 0,07 \\
Ocotea velloziana & 4 & $6,250,10$ & 0,69 & $0,040,01$ & 0,03 & 0,17 & 0,07 \\
Solanum bullatum & 5 & $6,250,10$ & 0,87 & $0,050,01$ & 0,02 & 0,17 & 0,07 \\
Plinia complanata & 5 & $6,250,10$ & 0,87 & $0,050,01$ & 0,02 & 0,17 & 0,07 \\
Dalbergia frutescens & 4 & $6,250,10$ & 0,69 & 0,04 & 0,01 & 0,02 & 0,16 & 0,07 \\
Vernonia diffusa & 3 & $3,130,05$ & 0,52 & $0,030,04$ & 0,08 & 0,16 & 0,11 \\
Eugenia cereja & 4 & $4,690,07$ & 0,69 & 0,04 & 0,02 & 0,04 & 0,16 & 0,09 \\
Inga marginata & 5 & $6,250,10$ & 0,87 & $0,050,00$ & 0,01 & 0,16 & 0,06 \\
& & & & & & &
\end{tabular}


Tabela 4. Espécies em ordem decrescente de índice de valor de importância (IVI) encontradas através de levantamento pelo método de parcelas no Parque Estadual "Carlos Botelho" - São Miguel Arcanjo, SP, onde $\mathbf{n}=$ número de indivíduos; fr.a = freqüência absoluta; fr.r = freqüência relativa; de. $\mathrm{a}=$ densidade absoluta; de. $\mathrm{r}=$ densidade relativa; do. $\mathrm{a}=$ dominância absoluta; do.r = dominância relativa; ivi = índice de valor de importância e ivc $=$ índice de valor de cobertura

\begin{tabular}{lrrrrrrrrr}
\hline \multicolumn{1}{c}{ Espécies } & n & fr.a & fr.r & de.a & de.r & do.a & do.r & ivi & ivc \\
\hline Ocotea nectandrifolia & 3 & $4,690,07$ & 0,52 & $0,030,02$ & 0,05 & 0,16 & 0,08 \\
Cariniana estrellensis & 1 & $1,560,02$ & 0,17 & $0,010,05$ & 0,12 & 0,16 & 0,13 \\
Myrceugenia campestris & 5 & $6,250,10$ & 0,87 & 0,05 & 0,00 & 0,01 & 0,16 & 0,06 \\
Solanum pseudoquina & 4 & $6,250,10$ & 0,69 & 0,04 & 0,01 & 0,02 & 0,16 & 0,06 \\
Myrciaria sp. 1 & 4 & $6,250,10$ & 0,69 & 0,04 & 0,01 & 0,02 & 0,16 & 0,06 \\
Inga laurina & 4 & $6,250,10$ & 0,69 & $0,040,01$ & 0,01 & 0,15 & 0,06 \\
Attalea dubia & 3 & $3,130,05$ & 0,52 & $0,030,03$ & 0,07 & 0,15 & 0,10 \\
Myrcia hatschbachii & 7 & $3,130,05$ & 1,22 & $0,070,01$ & 0,03 & 0,15 & 0,10 \\
Styrax acuminatus & 4 & $4,690,07$ & 0,69 & $0,040,01$ & 0,03 & 0,14 & 0,07 \\
Lauraceae Indet. 2 & 3 & $4,690,07$ & 0,52 & $0,030,02$ & 0,04 & 0,14 & 0,07 \\
Cordia sp. 1 & 7 & $3,130,05$ & 1,22 & $0,070,00$ & 0,01 & 0,13 & 0,08 \\
Myrceugenia aff. pilotantha & 4 & $4,690,07$ & 0,69 & 0,04 & 0,01 & 0,01 & 0,13 & 0,06 \\
Leandra sp. & 3 & $4,690,07$ & 0,52 & $0,030,01$ & 0,02 & 0,13 & 0,06 \\
Piptocarpha sp. 1 & 3 & $4,690,07$ & 0,52 & 0,03 & 0,01 & 0,02 & 0,13 & 0,05 \\
Aniba firmula & 2 & $3,130,05$ & 0,35 & 0,02 & 0,02 & 0,05 & 0,12 & 0,08 \\
Lauraceae Indet. 3 & 2 & $3,130,05$ & 0,35 & 0,02 & 0,02 & 0,05 & 0,12 & 0,07 \\
Chomelia sp. & 4 & $4,690,07$ & 0,69 & 0,04 & 0,00 & 0,00 & 0,12 & 0,05 \\
Daphnopsis gemmiflora & 3 & $4,690,07$ & 0,52 & 0,03 & 0,01 & 0,01 & 0,12 & 0,04 \\
Marlierea sp. 1 & 2 & $3,130,05$ & 0,35 & 0,02 & 0,02 & 0,04 & 0,11 & 0,06 \\
Lauraceae Indet. 1 & 3 & $4,690,07$ & 0,52 & 0,03 & 0,00 & 0,01 & 0,11 & 0,04 \\
Eugenia prasina & 3 & $4,690,07$ & 0,52 & 0,03 & 0,00 & 0,01 & 0,11 & 0,04 \\
Aiouea saligna & 3 & $4,690,07$ & 0,52 & 0,03 & 0,00 & 0,00 & 0,11 & 0,04 \\
Myrcia aff. obtecta & 2 & $3,130,05$ & 0,35 & 0,02 & 0,02 & 0,04 & 0,11 & 0,06 \\
Myrcia sp. 2 & 3 & $4,690,07$ & 0,52 & 0,03 & 0,00 & 0,00 & 0,11 & 0,03 \\
Symplocos celastrinea & 2 & $1,560,02$ & 0,35 & 0,02 & 0,03 & 0,06 & 0,10 & 0,08 \\
Calyptranthes sp. 3 & 2 & $3,130,05$ & 0,35 & 0,02 & 0,01 & 0,03 & 0,10 & 0,05 \\
Campomanesia schlechtendaliana & 2 & $3,130,05$ & 0,35 & 0,02 & 0,01 & 0,03 & 0,10 & 0,05
\end{tabular}


Tabela 4. Espécies em ordem decrescente de índice de valor de importância (IVI) encontradas através de levantamento pelo método de parcelas no Parque Estadual "Carlos Botelho" - São Miguel Arcanjo, SP, onde n = número de indivíduos; fr.a = freqüência absoluta; fr.r = freqüência relativa; de. $\mathrm{a}=$ densidade absoluta; de. $\mathrm{r}=$ densidade relativa; do. $\mathrm{a}=$ dominância absoluta; do.r = dominância relativa; ivi = índice de valor de importância e ivc $=$ índice de valor de cobertura

\begin{tabular}{|c|c|c|c|c|c|c|c|}
\hline Espécies & $\mathbf{n}$ & fr.a fr.r & de.a & de.r do.a & do.r & ivi & ive \\
\hline Rhodostemonodaphine macrocalyx & 2 & $3,130,05$ & 0,35 & $0,020,01$ & 0,03 & 0,09 & $\overline{0,05}$ \\
\hline Myrcia tenuivenosa & 3 & $3,130,05$ & 0,52 & $0,030,01$ & 0,01 & 0,09 & 0,04 \\
\hline Aegiphila sellowiana & 2 & $3,130,05$ & 0,35 & $0,020,01$ & 0,02 & 0,09 & 0,04 \\
\hline Dalbergia brasiliensis & 3 & $3,130,05$ & 0,52 & $0,030,00$ & 0,01 & 0,09 & 0,04 \\
\hline Ocotea sp. 1 & 2 & $3,130,05$ & 0,35 & $0,020,01$ & 0,01 & 0,08 & 0,04 \\
\hline Miconia sp. 1 & 1 & $1,560,02$ & 0,17 & $0,010,02$ & 0,05 & 0,08 & 0,06 \\
\hline Ocotea venulosa & 2 & $3,130,05$ & 0,35 & $0,020,00$ & 0,01 & 0,08 & 0,03 \\
\hline Mollinedia oligotricha & 2 & $3,130,05$ & 0,35 & $0,020,00$ & 0,01 & 0,08 & 0,03 \\
\hline Cleiloclinium cognatum & 2 & $3,130,05$ & 0,35 & $0,020,00$ & 0,01 & 0,08 & 0,03 \\
\hline Myrcia richardiana & 2 & $3,130,05$ & 0,35 & $0,020,00$ & 0,01 & 0,08 & 0,03 \\
\hline Psychotria suterella & 2 & $3,130,05$ & 0,35 & $0,020,00$ & 0,01 & 0,07 & 0,03 \\
\hline Rapanea gardneriana & 2 & $3,130,05$ & 0,35 & $0,020,00$ & 0,00 & 0,07 & 0,02 \\
\hline Rollinia parviflora & 2 & $3,130,05$ & 0,35 & $0,020,00$ & 0,00 & 0,07 & 0,02 \\
\hline Mollinedia aff. elegans & 2 & $3,130,05$ & 0,35 & $0,020,00$ & 0,00 & 0,07 & 0,02 \\
\hline Nectandra membranacea & 1 & $1,560,02$ & 0,17 & $0,010,01$ & 0,02 & 0,06 & 0,03 \\
\hline Ocotea aff. lancifolia & 1 & $1,560,02$ & 0,17 & $0,010,01$ & 0,02 & 0,06 & 0,03 \\
\hline Vochysia selloi & 1 & $1,560,02$ & 0,17 & $0,010,01$ & 0,02 & 0,05 & 0,03 \\
\hline Machaerium sp. 1 & 1 & $1,560,02$ & 0,17 & $0,010,01$ & 0,01 & 0,05 & 0,02 \\
\hline Cecropia glaziowii & 1 & $1,560,02$ & 0,17 & $0,010,01$ & 0,01 & 0,05 & 0,02 \\
\hline Calycorectes aff. psidiiflorus & 1 & $1,560,02$ & 0,17 & $0,010,00$ & 0,01 & 0,04 & 0,02 \\
\hline Xylosma glaberrima & 1 & $1,560,02$ & 0,17 & $0,010,00$ & 0,01 & 0,04 & 0,02 \\
\hline Leandra dasytricha & 1 & $1,560,02$ & 0,17 & $0,010,00$ & 0,00 & 0,04 & 0,02 \\
\hline Cinnamomum hirsutum & 1 & $1,560,02$ & 0,17 & $0,010,00$ & 0,00 & 0,04 & 0,01 \\
\hline Aegiphila sp. & 1 & $1,560,02$ & 0,17 & $0,010,00$ & 0,00 & 0,04 & 0,01 \\
\hline Allophylus petiolulatus & 1 & $1,560,02$ & 0,17 & $0,010,00$ & 0,00 & 0,04 & 0,01 \\
\hline Machaerium nictitans & 1 & $1,560,02$ & 0,17 & $0,010,00$ & 0,00 & 0,04 & 0,01 \\
\hline Verbenaceae 1 & 1 & $1,560,02$ & 0,17 & $0,010,00$ & 0,00 & 0,04 & 0,01 \\
\hline
\end{tabular}


Tabela 4. Espécies em ordem decrescente de índice de valor de importância (IVI) encontradas através de levantamento pelo método de parcelas no Parque Estadual "Carlos Botelho" - São Miguel Arcanjo, SP, onde n = número de indivíduos; fr.a = freqüência absoluta; fr.r = freqüência relativa; de. $a=$ densidade absoluta; de.r $=$ densidade relativa; do. $a=$ dominância absoluta; do.r = dominância relativa; ivi = índice de valor de importância e ivc $=$ índice de valor de cobertura

\begin{tabular}{lccccccccc}
\hline \multicolumn{1}{c}{ Espécies } & n & fr.a & fr.r & de.a & de.r do.a do.r & ivi & ive \\
\hline Piper arboreum & 1 & $1,560,02$ & 0,17 & 0,01 & 0,00 & 0,00 & 0,04 & 0,01 \\
Stylogine laevigata & 1 & $1,560,02$ & 0,17 & $0,010,00$ & 0,00 & 0,04 & 0,01 \\
Vitex aff. polygama & 1 & $1,560,02$ & 0,17 & $0,010,00$ & 0,00 & 0,04 & 0,01 \\
Calyptranthes lanceolata & 1 & $1,560,02$ & 0,17 & 0,01 & 0,00 & 0,00 & 0,04 & 0,01 \\
Salacia elliptica & 1 & $1,560,02$ & 0,17 & $0,010,00$ & 0,00 & 0,04 & 0,01 \\
Myrcia heringii & 1 & $1,560,02$ & 0,17 & $0,010,00$ & 0,00 & 0,04 & 0,01 \\
Meriania clausenii & 1 & $1,560,02$ & 0,17 & $0,010,00$ & 0,00 & 0,04 & 0,01 \\
Nectandra debilis & 1 & $1,560,02$ & 0,17 & 0,01 & 0,00 & 0,00 & 0,04 & 0,01 \\
Erythroxylum sp. 1 & 1 & $1,560,02$ & 0,17 & 0,01 & 0,00 & 0,00 & 0,04 & 0,01 \\
\hline
\end{tabular}

A Figura 15 demonstra as respectivas densidade, dominância e frequência relativa obtidas nas parcelas, referentes à distribuição das dez principais espécies em IVI, que são: Micropholis crassipedicellata $(17,08)$, Euterpe edulis $(15,56)$, Ocotea catharinensis (10,25), Pouteria bullata (7,28), Alchornea triplinervia $(6,22)$, Mollinedia oligantha $(5,69)$, Alibertia sp. $(5,57)$, Vantanea compacta $(5,53)$, Bathysa australis $(5,34)$ e Cabralea canjerana $(4,93)$. Essas espécies representam 27,8\% do IVI total. Das 242 espécies restantes, 163 possuem IVI menor do que 1, correspondendo a $64,80 \%$ das espécies amostradas e $54,3 \%$ do IVI total.

Analisando-se a influência dos parâmetros, que compõem o IVI das duas principais espécies, verifica-se que $M$. crassipedicelata se destacou pela sua alta dominância, refletindo o grande porte e DAPs avantajado na maioria dos 258 indivíduos amostrados. Por outro lado, E. edulis foi amostrada com grande quantidade de indivíduos espalhados regularmente por toda a área estudada, proporcionando a esta espécie maior densidade, porém, com indivíduos de pequenos diâmetros. 
C. canjerana

B. australis

V. compacta

Alibertia sp.

M. oligantha

A. triplinervia

P. bullata

O. catharinensis

E. edulis

M. crassipedicellata

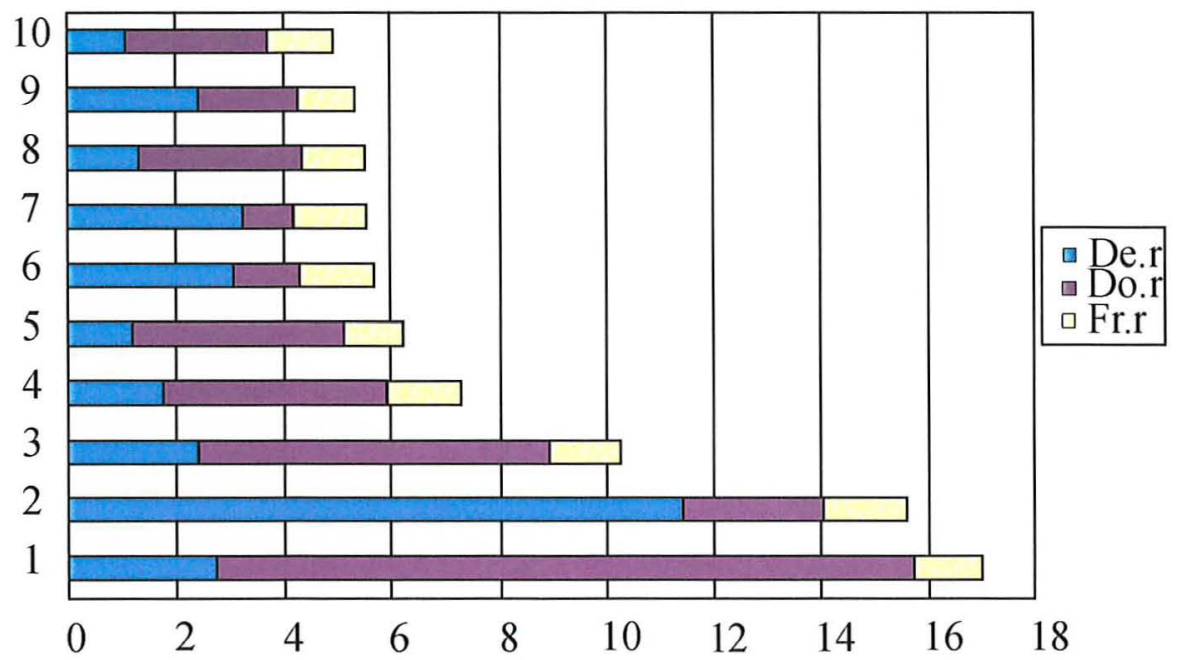

Índices de Valor de Importância

Figura 15 - Distribuição das 10 principais espécies em IVI e suas respectivas densidade relativa (De.r), dominância relativa (Do.r) e freqüência relativa (Fr.r) na floresta ombrófila densa no Parque Estadual "Carlos Botelho" - São Miguel Arcanjo, SP. Amostragem pelo método de parcelas

Com relação às freqüências relativas observadas, que variaram de 1,06 à 1,55 , em mais de $69 \%$ das unidades amostradas, constatou-se que não foram determinantes para algumas das principais espécies classificadas pelo IVI. Euterpe edulis foi detectada em todas as unidades amostrais, apresentou freqüência absoluta de 100\%. Mollinedia oligantha e Alibertia sp. tiveram, $91 \%$ de freqüência absoluta cada uma Pouteria bullata $89 \%$, Ocotea catharinensis 88\%, Micropholis crassipedicellata 86\%, Cabralea canjerana $78 \%$, Alchornea triplinervia $72 \%$ e Bathysa australis $69 \%$.

A densidade absoluta total obtida foi de 1657 indivíduos por hectare. As espécies que apresentaram as maiores densidades absolutas foram: E. edulis (188ind.ha ${ }^{-1}$ ), Alibertia sp. (54ind.ha $\left.{ }^{-1}\right)$, M. oligantha $\left(50\right.$ ind.ha $\left.^{-1}\right)$, M. crassipedicellata $\left(45\right.$ ind.ha $\left.^{-1}\right), B$. 
australis (41 ind.ha $\left.{ }^{-1}\right), O$. catharinensis (39ind.ha $\left.{ }^{-1}\right)$, Coussarea sp. $\left(35,2\right.$ ind.ha $\left.^{-1}\right), P$. bullata (29ind.ha $\left.{ }^{-1}\right)$, E. stictosepala $\left(27,8\right.$ ind.ha $\left.^{-1}\right)$ e C. canjerana $\left(25,3\right.$ ind.ha $\left.^{-1}\right)$.

Analisando-se as dez espécies com maior dominância absoluta, observase que a espécie Micropholis crassipedicellata aparece na primeira posição com $\left(5,8 \mathrm{~m}^{2} \cdot \mathrm{ha}^{-1}\right)$, seguida por Ocotea catharinensis $\left(2,90\right.$ ind.ha $\left.^{-1}\right)$, Pouteria bullata $\left(1,85\right.$ ind.ha $\left.^{-1}\right)$, Alchornea triplinervia $\left(1,75\right.$ ind.ha $\left.^{-1}\right)$, Vantanea compacta $\left(1,34\right.$ ind.ha $\left.^{-1}\right)$, Euterpe edulis $\left(1,18\right.$ ind.ha $\left.^{-1}\right)$ e Cabralea canjerana $\left(1,18\right.$ ind.ha $\left.^{-1}\right)$. Quanto às outras 245 espécies amostradas, a dominância absoluta apresentada por cada uma delas, foi menor do que (1ind.ha ${ }^{-1}$ ). A área basal total obtida foi de 44,6ind.ha ${ }^{-1}$.

Observando-se as espécies que mais se destacaram, com altos valores de Índice de Valor de Cobertura (IVC), constatou-se que são as mesmas que se destacaram em IVI, evidenciando a troca de algumas posições. Nota-se que Alchornea triplinervia e Cabralea canjerana apresentam os menores valores em número de indivíduos quando comparada estas dez espécies. Entretanto, a presença de ambas em posições de destaque, deve-se à estratégia de ocupação da área adotada por elas, com poucos indivíduos em relação às demais, porém, com portes elevados.

A Figura 16 mostra a distribuição das dez principais espécies em IVI com as respectivas densidades, dominâncias e freqüências relativas conseguidas por quadrantes. Na Tabela 5, são apresentadas as 177 espécies, em ordem decrescente de IVI, com seus respectivos parâmetros fitossociológicos, detectadas pelo método de quadrantes. $\mathrm{O}$ maior Índice de Valor de Importância foi registrado por Euterpe edulis (24,97), seguido de Micropholis crassipedicellata $(23,67)$, Bathysa australis $(12,49)$, Guapira opposita $(8,68)$, Mollinedia oligantha $(8,40)$, Ocotea catharinensis $(8,08)$, Pouteria bullata (7,15), Vantanea compacta (6,31), Eugenia melanogina $(5,74)$, Coussarea sp. $(5,39)$. Essas espécies representam 36,96\% do IVI total e as 167 espécies restantes assinalam $63,04 \%$ do IVI total. Os IVIs menores do que 1 estão representados por 101 espécies, ou seja, 57,06\% do total de espécies amostradas. 
Coussarea sp.

E. melanogina

V. compacta

P. bullata

$O$. catharinensis

M. oligantha

G. opposita

B. australis

M. crassipedicellata

E. edulis

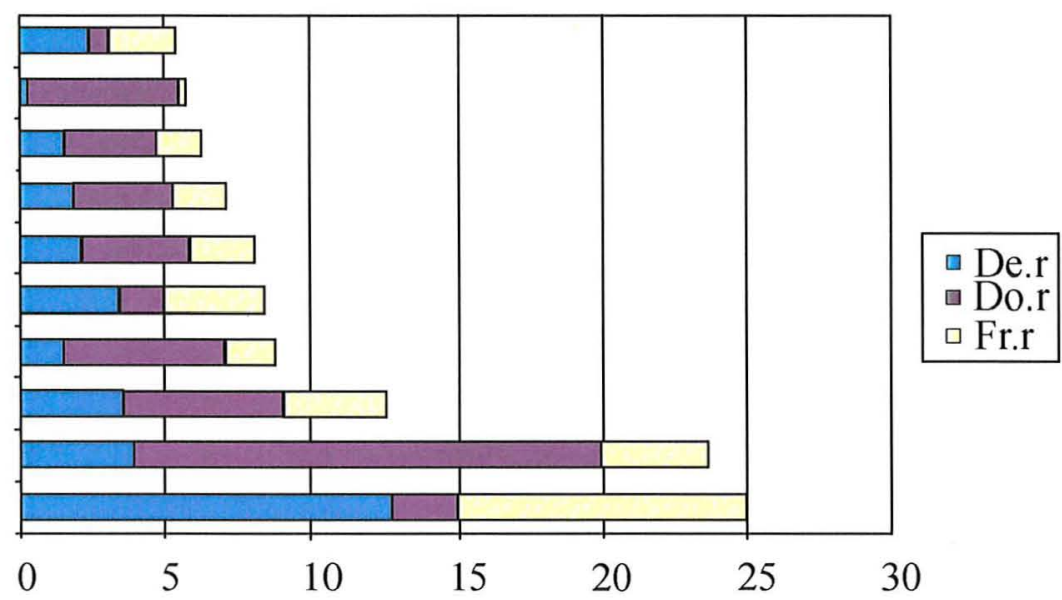

Índices de Valor de Importância

Figura 16 - Distribuição das 10 principais espécies em IVI e suas respectivas densidade relativa (De.r), dominância relativa (Do.r) e freqüência relativa (Fr.r) na floresta ombrófila densa no Parque Estadual "Carlos Botelho" - São Miguel Arcanjo, SP. Amostragem pelo método de quadrantes 
Tabela 5. Espécies em ordem decrescente de índice de valor de importância (IVI) encontradas através de levantamento pelo método de quadrantes no Parque Estadual "Carlos Botelho" - São Miguel Arcanjo, SP, onde $\mathrm{n}$ = número de indivíduos; fr.a = freqüência absoluta; fr.r $=$ freqüência relativa; de. $\mathbf{r}=$ densidade relativa; de. $\mathrm{a}=$ densidade absoluta; do. $\mathbf{r}=$ dominância relativa; do.a = dominância absoluta; ivi $=$ índice de valor de importância e ivc $=$ índice de valor de cobertura

\begin{tabular}{|c|c|c|c|c|c|c|c|c|}
\hline Espécie & $\mathbf{n}$ & fr.a & fr.r & de.r & de.a & do.r do.a & ivi & ive \\
\hline Euterpe edulis & \multicolumn{5}{|c|}{$16237,8110,1212,66198,30$} & \multicolumn{3}{|c|}{$2,201,2224,9714,85$} \\
\hline Micropholis crassipedicellata & & 14,06 & 3,76 & 3,91 & 61,201 & $16,008,892$ & 23,671 & 19,91 \\
\hline Bathysa australis & & 12,81 & 3,43 & 3,52 & 55,08 & $5,553,081$ & 12,49 & 9,06 \\
\hline Guapira opposita & 19 & 5,94 & 1,59 & 1,48 & 23,26 & $5,613,12$ & 8,68 & 7,09 \\
\hline Mollinedia oligantha & & 12,81 & 3,43 & 3,44 & 53,86 & $1,540,86$ & 8,41 & 4,98 \\
\hline Ocotea catharinensis & 27 & 8,44 & 2,26 & 2,11 & 33,05 & $3,712,06$ & 8,08 & 5,82 \\
\hline Pouteria bullata & 24 & 7,19 & 1,92 & 1,88 & 29,38 & $3,361,87$ & 7,15 & 5,23 \\
\hline Vantanea compacta & 19 & 5,94 & 1,59 & 1,48 & 23,26 & $3,251,80$ & 6,32 & 4,73 \\
\hline Eugenia melanogina & 3 & 0,94 & 0,25 & 0,23 & 3,67 & $5,262,92$ & 5,74 & 5,49 \\
\hline Coussarea sp. & 31 & 8,75 & 2,34 & 2,42 & 37,95 & $0,630,35$ & 5,39 & 3,05 \\
\hline Alchornea triplinervia & 16 & 5,00 & 1,34 & 1,25 & 19,59 & $2,631,46$ & 5,21 & 3,88 \\
\hline Cabralea canjerana & 19 & 5,00 & 1,34 & 1,48 & 23,26 & $2,11 \quad 1,17$ & 4,94 & 3,60 \\
\hline Pouteria caimito & 9 & 2,81 & 0,75 & 0,70 & 11,02 & $3,131,74$ & 4,58 & 3,83 \\
\hline Alibertia sp. & 25 & 7,50 & 2,01 & 1,95 & 30,60 & $0,330,18$ & 4,29 & 2,28 \\
\hline Byrsonima ligustrifolia & 18 & 5,31 & 1,42 & 1,41 & 22,03 & $0,900,50$ & 3,73 & 2,31 \\
\hline Eugenia stictosepala & 22 & 6,25 & 1,67 & 1,72 & 26,93 & $0,220,12$ & 3,61 & 1,94 \\
\hline Ocotea elegans & 10 & 3,13 & 0,84 & 0,78 & 12,24 & $1,901,05$ & 3,51 & 2,68 \\
\hline Ocotea bicolor & 15 & 4,69 & 1,25 & 1,17 & 18,36 & $1,08 \quad 0,60$ & 3,51 & 2,25 \\
\hline Ormosia dasycarpa & 20 & 4,69 & 1,25 & 1,56 & 24,48 & $0,550,30$ & 3,36 & 2,11 \\
\hline Diploon cuspidatum & 5 & 1,56 & 0,42 & 0,39 & 6,12 & $2,441,35$ & 3,25 & 2,83 \\
\hline Mollinedia schottiana & 16 & 5,00 & 1,34 & 1,25 & 19,59 & $0,320,18$ & 2,91 & 1,57 \\
\hline Myrocarpus frondosus & 13 & 4,06 & 1,09 & 1,02 & 15,91 & $0,790,44$ & 2,89 & 1,80 \\
\hline Matayba juglandifolia & 14 & 4,06 & 1,09 & 1,09 & 17,14 & $0,660,37$ & 2,84 & 1,75 \\
\hline Ocotea odorifera & 13 & 4,06 & 1,09 & 1,02 & 15,91 & $0,670,37$ & 2,77 & 1,68 \\
\hline Cryptocarya sp. 1 & 10 & 3,13 & 0,84 & 0,78 & 12,24 & $1,150,64$ & 2,77 & 1,93 \\
\hline Ocotea aciphylla & 8 & 2,50 & 0,67 & 0,63 & 9,79 & $1,280,71$ & 2,58 & 1,91 \\
\hline Xylopia langsdorffiana & 12 & 3,44 & 0,92 & 0,94 & 14,69 & $0,640,36$ & 2,50 & 1,58 \\
\hline
\end{tabular}


Tabela 5. Espécies em ordem decrescente de índice de valor de importância (IVI) encontradas através de levantamento pelo método de quadrantes no Parque Estadual "Carlos Botelho" - São Miguel Arcanjo, SP, onde $\mathrm{n}=$ número de indivíduos; fr.a = freqüência absoluta; fr.r $=$ freqüência relativa; de. $\mathrm{r}=$ densidade relativa; de. $\mathrm{a}=$ densidade absoluta; do. $\mathrm{r}=$ dominância relativa; do.a = dominância absoluta; ivi = índice de valor de importância e ivc = índice de valor de cobertura

\begin{tabular}{lrrrrrrrrrr}
\hline \multicolumn{1}{c}{ Espécie } & n & fr.a & fr.r & de.r & de.a & do.r & do.a & ivi & ivc \\
\hline Amaioua intermedia & 12 & 3,75 & 1,00 & 0,94 & 14,69 & 0,51 & 0,28 & 2,45 & 1,44 \\
Rudgea jasminoides & 14 & 4,38 & 1,17 & 1,09 & 17,14 & 0,16 & 0,09 & 2,42 & 1,25 \\
Ocotea pulchra & 12 & 3,75 & 1,00 & 0,94 & 14,69 & 0,44 & 0,24 & 2,38 & 1,38 \\
Meliosma sinuata & 5 & 1,56 & 0,42 & 0,39 & 6,12 & 1,52 & 0,84 & 2,33 & 1,91 \\
Tibouchina pulchra & 9 & 2,81 & 0,75 & 0,70 & 11,02 & 0,80 & 0,44 & 2,25 & 1,50 \\
Alibertia aff. myrciifolia & 12 & 3,75 & 1,00 & 0,94 & 14,69 & 0,27 & 0,15 & 2,21 & 1,20 \\
Miconia cabucu & 12 & 3,44 & 0,92 & 0,94 & 14,69 & 0,30 & 0,17 & 2,16 & 1,24 \\
Matayba guianensis & 9 & 2,81 & 0,75 & 0,70 & 11,02 & 0,64 & 0,35 & 2,09 & 1,34 \\
Copaifera trapezifolia & 9 & 2,50 & 0,67 & 0,70 & 11,02 & 0,72 & 0,40 & 2,09 & 1,42 \\
Cordia sellowiana & 10 & 2,81 & 0,75 & 0,78 & 12,24 & 0,55 & 0,30 & 2,08 & 1,33 \\
Ilex amara & 2 & 0,63 & 0,17 & 0,16 & 2,45 & 1,75 & 0,97 & 2,07 & 1,90 \\
Didymopanax navarroi & 7 & 2,19 & 0,59 & 0,55 & 8,57 & 0,93 & 0,52 & 2,06 & 1,47 \\
Symplocos falcata & 7 & 2,19 & 0,59 & 0,55 & 8,57 & 0,90 & 0,50 & 2,03 & 1,44 \\
Marlierea parviflora & 10 & 3,13 & 0,84 & 0,78 & 12,24 & 0,32 & 0,18 & 1,93 & 1,10 \\
Sorocea bonplandii & 10 & 3,13 & 0,84 & 0,78 & 12,24 & 0,28 & 0,15 & 1,89 & 1,06 \\
Miconia pusilliflora & 11 & 3,44 & 0,92 & 0,86 & 13,46 & 0,11 & 0,06 & 1,89 & 0,97 \\
Esenbeckia grandiflora & 10 & 3,13 & 0,84 & 0,78 & 12,24 & 0,25 & 0,14 & 1,87 & 1,03 \\
Cryptocarya moschata & 7 & 2,19 & 0,59 & 0,55 & 8,57 & 0,73 & 0,41 & 1,86 & 1,28 \\
Aniba viridis & 8 & 2,50 & 0,67 & 0,63 & 9,79 & 0,54 & 0,30 & 1,83 & 1,16 \\
Parinari excelsa & 6 & 1,88 & 0,50 & 0,47 & 7,34 & 0,86 & 0,48 & 1,83 & 1,33 \\
Andira anthelmia & 10 & 3,13 & 0,84 & 0,78 & 12,24 & 0,18 & 0,10 & 1,80 & 0,97 \\
Lamanonia ternata & 7 & 2,19 & 0,59 & 0,55 & 8,57 & 0,61 & 0,34 & 1,74 & 1,15 \\
Copaifera langsdorffii & 4 & 1,25 & 0,33 & 0,31 & 4,90 & 1,07 & 0,59 & 1,72 & 1,38 \\
Chionanthus filiformis & 9 & 2,81 & 0,75 & 0,70 & 11,02 & 0,23 & 0,13 & 1,69 & 0,94 \\
Myrcia fallax & 9 & 2,81 & 0,75 & 0,70 & 11,02 & 0,23 & 0,13 & 1,68 & 0,93 \\
Myrcia pubipetala & 8 & 2,50 & 0,67 & 0,63 & 9,79 & 0,34 & 0,19 & 1,64 & 0,97 \\
Posoqueria acutifolia & 8 & 2,50 & 0,67 & 0,63 & 9,79 & 0,28 & 0,16 & 1,58 & 0,91
\end{tabular}


Tabela 5. Espécies em ordem decrescente de índice de valor de importância (IVI) encontradas através de levantamento pelo método de quadrantes no Parque Estadual "Carlos Botelho" - São Miguel Arcanjo, SP, onde $\mathrm{n}$ = número de indivíduos; fr.a = freqüência absoluta; fr.r $=$ freqüência relativa; de. $\mathrm{r}=$ densidade relativa; de. $\mathrm{a}=$ densidade absoluta; do. $\mathrm{r}=$ dominância relativa; do.a = dominância absoluta; ivi = índice de valor de importância e ivc $=$ indice de valor de cobertura

\begin{tabular}{|c|c|c|c|c|c|c|c|c|}
\hline Espécie & $\mathbf{n}$ & fr.a & fr.r & de.r & de.a & do.r do.a & ivi & ive \\
\hline Aspidosperma olivaceum & 6 & 1,88 & 0,50 & 0,47 & 7,34 & $0,590,33$ & 1,56 & 1,06 \\
\hline Eugenia mosenii & 9 & 2,50 & 0,67 & 0,70 & 11,02 & $0,160,09$ & 1,53 & 0,86 \\
\hline Eugenia handroana & 7 & 2,19 & 0,59 & 0,55 & 8,57 & $0,370,21$ & 1,50 & 0,92 \\
\hline Cupania oblogifolia & 7 & 2,19 & 0,59 & 0,55 & 8,57 & $0,350,20$ & 1,49 & 0,90 \\
\hline Eugenia sp. 2 & 7 & 2,19 & 0,59 & 0,55 & 8,57 & $0,350,20$ & 1,48 & 0,90 \\
\hline Myrtaceae 2 & 5 & 1,56 & 0,42 & 0,39 & 6,12 & $0,600,33$ & 1,41 & 0,99 \\
\hline Guatteria australis & 8 & 2,19 & 0,59 & 0,63 & 9,79 & $0,160,09$ & 1,37 & 0,79 \\
\hline Ouratea parviflora & 7 & 2,19 & 0,59 & 0,55 & 8,57 & $0,170,09$ & 1,30 & 0,71 \\
\hline Maytenus robusta & 5 & 1,56 & 0,42 & 0,39 & 6,12 & $0,480,27$ & 1,29 & 0,87 \\
\hline Hirtella hebeclada & 6 & 1,88 & 0,50 & 0,47 & 7,34 & $0,300,17$ & 1,27 & 0,77 \\
\hline Inga sellowiana & 7 & 2,19 & 0,59 & 0,55 & 8,57 & $0,110,06$ & 1,24 & 0,66 \\
\hline Casearia obliqua & 8 & 1,88 & 0,50 & 0,63 & 9,79 & $0,090,05$ & 1,21 & 0,71 \\
\hline Eugenia subavenia & 7 & 2,19 & 0,59 & 0,55 & 8,57 & $0,060,04$ & 1,20 & 0,61 \\
\hline Eugenia beaurepaireana & 6 & 1,88 & 0,50 & 0,47 & 7,34 & $0,210,12$ & 1,18 & 0,68 \\
\hline Coccoloba aff. latifolia & 5 & 1,56 & 0,42 & 0,39 & 6,12 & $0,360,20$ & 1,17 & 0,75 \\
\hline Myrceugenia glaucescens & 6 & 1,88 & 0,50 & 0,47 & 7,34 & $0,180,10$ & 1,15 & 0,65 \\
\hline Casearia decandra & 6 & 1,88 & 0,50 & 0,47 & 7,34 & $0,180,10$ & 1,15 & 0,65 \\
\hline Ocotea teleiandra & 7 & 1,88 & 0,50 & 0,55 & 8,57 & $0,090,05$ & 1,14 & 0,64 \\
\hline Rapanea umbellata & 6 & 1,88 & 0,50 & 0,47 & 7,34 & $0,160,09$ & 1,13 & 0,63 \\
\hline Eugenia sp. 1 & 6 & 1,88 & 0,50 & 0,47 & 7,34 & $0,130,07$ & 1,10 & 0,60 \\
\hline Siphoneugena densiflora & 6 & 1,88 & 0,50 & 0,47 & 7,34 & $0,080,05$ & 1,05 & 0,55 \\
\hline Sclerolobium denudatum & 5 & 1,56 & 0,42 & 0,39 & 6,12 & $0,210,12$ & 1,02 & 0,60 \\
\hline Pithecellobium langsdorffii & 5 & 1,56 & 0,42 & 0,39 & 6,12 & $0,180,10$ & 0,99 & 0,58 \\
\hline Hieronyma alchorneoides & 5 & 1,25 & 0,33 & 0,39 & 6,12 & $0,260,15$ & 0,99 & 0,65 \\
\hline Miconia petropolitana & 6 & 1,56 & 0,42 & 0,47 & 7,34 & $0,090,05$ & 0,98 & 0,56 \\
\hline Myrceugenia myrcioides & 6 & 1,56 & 0,42 & 0,47 & 7,34 & $0,060,03$ & 0,95 & 0,53 \\
\hline Gomidesia tijucensis & 5 & 1,56 & 0,42 & 0,39 & 6,12 & $0,140,08$ & 0,94 & 0,53 \\
\hline
\end{tabular}


Tabela 5. Espécies em ordem decrescente de índice de valor de importância (IVI) encontradas através de levantamento pelo método de quadrantes no Parque Estadual "Carlos Botelho" - São Miguel Arcanjo, SP, onde $\mathrm{n}$ = número de indivíduos; fr.a = freqüência absoluta; fr.r $=$ freqüência relativa; de. $\mathrm{r}=$ densidade relativa; de. $\mathrm{a}=$ densidade absoluta; do. $\mathrm{r}=$ dominância relativa; do.a $=$ dominância absoluta; ivi $=$ índice de valor de importância e ivc $=$ índice de valor de cobertura

\begin{tabular}{|c|c|c|c|c|c|c|c|c|}
\hline Espécie & $\mathbf{n}$ & fr.a & fr.r & de.r & de.a & do.r do.a & ivi & ive \\
\hline$\overline{\text { Sloanea monosperma }}$ & 5 & 1,56 & 0,42 & 0,39 & 6,12 & $0,100,06$ & 0,91 & $\overline{0,50}$ \\
\hline Ocotea glaziovii & 3 & 0,94 & 0,25 & 0,23 & 3,67 & $0,430,24$ & 0,91 & 0,66 \\
\hline Inga sessilis & 5 & 1,56 & 0,42 & 0,39 & 6,12 & $0,090,05$ & 0,90 & 0,48 \\
\hline Eugenia riedeliana & 5 & 1,56 & 0,42 & 0,39 & 6,12 & $0,08 \quad 0,04$ & 0,88 & 0,47 \\
\hline Calyptranthes aff. lucida & 4 & 1,25 & 0,33 & 0,31 & 4,90 & $0,230,13$ & 0,88 & 0,54 \\
\hline Heisteria silvianii & 5 & 1,56 & 0,42 & 0,39 & 6,12 & $0,060,04$ & 0,87 & 0,45 \\
\hline Drymis winteri & 5 & 1,56 & 0,42 & 0,39 & 6,12 & $0,05 \quad 0,03$ & 0,85 & 0,44 \\
\hline Pterocarpus rohrii & 4 & 1,25 & 0,33 & 0,31 & 4,90 & $0,200,11$ & 0,85 & 0,52 \\
\hline Garcinia gardneriana & 5 & 1,56 & 0,42 & 0,39 & 6,12 & $0,04 \quad 0,02$ & 0,85 & 0,43 \\
\hline Ocotea dispersa & 4 & 1,25 & 0,33 & 0,31 & 4,90 & $0,20 \quad 0,11$ & 0,85 & 0,51 \\
\hline Cupania vernalis & 3 & 0,94 & 0,25 & 0,23 & 3,67 & $0,360,20$ & 0,84 & 0,59 \\
\hline Eugenia involucrata & 4 & 1,25 & 0,33 & 0,31 & 4,90 & $0,190,11$ & 0,84 & 0,51 \\
\hline Sapium glandulatum & 2 & 0,63 & 0,17 & 0,16 & 2,45 & $0,500,28$ & 0,82 & 0,65 \\
\hline Marlierea tomentosa & 3 & 0,94 & 0,25 & 0,23 & 3,67 & $0,330,18$ & 0,82 & 0,57 \\
\hline Myrcia sp. 1 & 4 & 1,25 & 0,33 & 0,31 & 4,90 & $0,170,09$ & 0,81 & 0,48 \\
\hline Weinmannia paulliniifolia & 1 & 0,31 & 0,08 & 0,08 & 1,22 & $0,600,34$ & 0,77 & 0,68 \\
\hline Eugenia sp. 3 & 4 & 1,25 & 0,33 & 0,31 & 4,90 & $0,080,05$ & 0,73 & 0,40 \\
\hline Rapanea hermogenesii & 4 & 1,25 & 0,33 & 0,31 & 4,90 & $0,08 \quad 0,04$ & 0,72 & 0,39 \\
\hline Ixora burcheliana & 4 & 1,25 & 0,33 & 0,31 & 4,90 & $0,060,03$ & 0,71 & 0,38 \\
\hline Tapirira guianensis & 3 & 0,94 & 0,25 & 0,23 & 3,67 & $0,200,11$ & 0,69 & 0,43 \\
\hline Jacaranda puberula & 4 & 1,25 & 0,33 & 0,31 & 4,90 & $0,03 \quad 0,02$ & 0,68 & 0,34 \\
\hline Eugenia sp. 5 & 3 & 0,94 & 0,25 & 0,23 & 3,67 & $0,18 \quad 0,10$ & 0,66 & 0,41 \\
\hline Capsicodendron dinisii & 3 & 0,94 & 0,25 & 0,23 & 3,67 & $0,160,09$ & 0,65 & 0,40 \\
\hline Calyptranthes sp. 2 & 3 & 0,94 & 0,25 & 0,23 & 3,67 & $0,150,08$ & 0,64 & 0,39 \\
\hline Psychotria velloziana & 2 & 0,63 & 0,17 & 0,16 & 2,45 & $0,31 \quad 0,17$ & 0,63 & 0,46 \\
\hline Myrceugenia kleinii & 3 & 0,94 & 0,25 & 0,23 & 3,67 & $0,130,07$ & 0,61 & 0,36 \\
\hline Ocotea brachybotra & 2 & 0,63 & 0,17 & 0,16 & 2,45 & $0,280,16$ & 0,61 & 0,44 \\
\hline
\end{tabular}


Tabela 5. Espécies em ordem decrescente de índice de valor de importância (IVI) encontradas através de levantamento pelo método de quadrantes no Parque Estadual "Carlos Botelho" - São Miguel Arcanjo, SP, onde $\mathrm{n}=$ número de indivíduos; fr.a $=$ freqüência absoluta; fr.r $=$ freqüência relativa; de. $\mathrm{r}=$ densidade relativa; de. $\mathrm{a}=$ densidade absoluta; do. $\mathrm{r}=$ dominância relativa; do.a $=$ dominância absoluta; ivi $=$ índice de valor de importância e ivc $=$ índice de valor de cobertura

Espécie

Protium heptaphyllum

Weinmannia discolor

Eugenia cambucarana

Chrysophyllum viride

Rollinea sericea

Myrcia aff.obtecta

Didymopanax angustissimum

Vochysia sp1

Tibouchina sellowiana

Buckenavia kleinii

Zollernia ilicifolia

Ocotea silvestris

Calycorectes australis

Symplocos variabilis

Ilex paraguariensis

Neomitranthes glomerata

Marlierea sp. 1

Eugenia cereja

Myrtaceae 4

Myrtaceae 1

Mollinedia oligotricha

Eugenia cerasiflora

Miconia sellowiana

Rapanea ferruginea

Meliosma sellowi

Myrceugenia sp. 1

Marlierea reitzii n fr.a fr.r de.r de.a do.r do.a ivi ive

$\begin{array}{lllllllll}2 & 0,63 & 0,17 & 0,16 & 2,45 & 0,28 & 0,15 & 0,60 & 0,43 \\ 3 & 0,94 & 0,25 & 0,23 & 3,67 & 0,09 & 0,05 & 0,57 & 0,32 \\ 3 & 0,94 & 0,25 & 0,23 & 3,67 & 0,08 & 0,04 & 0,56 & 0,31 \\ 1 & 0,31 & 0,08 & 0,08 & 1,22 & 0,40 & 0,22 & 0,56 & 0,47 \\ 3 & 0,94 & 0,25 & 0,23 & 3,67 & 0,07 & 0,04 & 0,55 & 0,30 \\ 2 & 0,63 & 0,17 & 0,16 & 2,45 & 0,22 & 0,12 & 0,54 & 0,37 \\ 1 & 0,31 & 0,08 & 0,08 & 1,22 & 0,37 & 0,20 & 0,53 & 0,44 \\ 1 & 0,31 & 0,08 & 0,08 & 1,22 & 0,34 & 0,19 & 0,50 & 0,42 \\ 2 & 0,63 & 0,17 & 0,16 & 2,45 & 0,17 & 0,10 & 0,50 & 0,33 \\ 1 & 0,31 & 0,08 & 0,08 & 1,22 & 0,33 & 0,19 & 0,50 & 0,41 \\ 2 & 0,63 & 0,17 & 0,16 & 2,45 & 0,12 & 0,07 & 0,44 & 0,27 \\ 2 & 0,63 & 0,17 & 0,16 & 2,45 & 0,11 & 0,06 & 0,43 & 0,27 \\ 1 & 0,31 & 0,08 & 0,08 & 1,22 & 0,26 & 0,15 & 0,42 & 0,34 \\ 2 & 0,63 & 0,17 & 0,16 & 2,45 & 0,09 & 0,05 & 0,41 & 0,24 \\ 2 & 0,63 & 0,17 & 0,16 & 2,45 & 0,08 & 0,04 & 0,40 & 0,24 \\ 2 & 0,63 & 0,17 & 0,16 & 2,45 & 0,08 & 0,04 & 0,40 & 0,23 \\ 1 & 0,31 & 0,08 & 0,08 & 1,22 & 0,23 & 0,13 & 0,39 & 0,31 \\ 2 & 0,63 & 0,17 & 0,16 & 2,45 & 0,07 & 0,04 & 0,39 & 0,22 \\ 2 & 0,63 & 0,17 & 0,16 & 2,45 & 0,06 & 0,03 & 0,38 & 0,22 \\ 2 & 0,63 & 0,17 & 0,16 & 2,45 & 0,05 & 0,03 & 0,37 & 0,20 \\ 2 & 0,63 & 0,17 & 0,16 & 2,45 & 0,04 & 0,02 & 0,37 & 0,20 \\ 2 & 0,63 & 0,17 & 0,16 & 2,45 & 0,04 & 0,02 & 0,36 & 0,20 \\ 2 & 0,63 & 0,17 & 0,16 & 2,45 & 0,04 & 0,02 & 0,36 & 0,20 \\ 2 & 0,63 & 0,17 & 0,16 & 2,45 & 0,03 & 0,02 & 0,35 & 0,18 \\ 2 & 0,63 & 0,17 & 0,16 & 2,45 & 0,03 & 0,02 & 0,35 & 0,18 \\ 2 & 0,63 & 0,17 & 0,16 & 2,45 & 0,02 & 0,01 & 0,35 & 0,18 \\ 2 & 0,63 & 0,17 & 0,16 & 2,45 & 0,02 & 0,01 & 0,35 & 0,18\end{array}$


Tabela 5. Espécies em ordem decrescente de índice de valor de importância (IVI) encontradas através de levantamento pelo método de quadrantes no Parque Estadual "Carlos Botelho" - São Miguel Arcanjo, SP, onde $\mathrm{n}=$ número de indivíduos; fr.a = freqüência absoluta; fr.r $=$ freqüência relativa; de. $\mathrm{r}=$ densidade relativa; de. $\mathrm{a}=$ densidade absoluta; do. $\mathrm{r}=$ dominância relativa; do.a $=$ dominância absoluta; ivi $=$ índice de valor de importância e ivc $=$ índice de valor de cobertura

\begin{tabular}{lccccccccc}
\hline \multicolumn{1}{c}{ Espécie } & n & fr.a & fr.r & de.r & de.a & do.r & do.a & ivi & ivc \\
\hline Alseis floribunda & 2 & 0,63 & 0,17 & 0,16 & 2,45 & 0,02 & 0,01 & 0,35 & 0,18 \\
Ilex taubertiana & 2 & 0,63 & 0,17 & 0,16 & 2,45 & 0,02 & 0,01 & 0,34 & 0,17 \\
Prunus myrtifolia & 2 & 0,63 & 0,17 & 0,16 & 2,45 & 0,01 & 0,01 & 0,34 & 0,17 \\
Citronella paniculata & 1 & 0,31 & 0,08 & 0,08 & 1,22 & 0,15 & 0,08 & 0,31 & 0,23 \\
Campomanesia guaviroba & 1 & 0,31 & 0,08 & 0,08 & 1,22 & 0,13 & 0,07 & 0,29 & 0,20 \\
Cecropia glaziowii & 1 & 0,31 & 0,08 & 0,08 & 1,22 & 0,06 & 0,04 & 0,23 & 0,14 \\
Zanthoxyllum rhoifolium & 1 & 0,31 & 0,08 & 0,08 & 1,22 & 0,06 & 0,03 & 0,22 & 0,13 \\
Chlethra scabra & 1 & 0,31 & 0,08 & 0,08 & 1,22 & 0,05 & 0,03 & 0,22 & 0,13 \\
Talauma ovata & 1 & 0,31 & 0,08 & 0,08 & 1,22 & 0,05 & 0,03 & 0,21 & 0,13 \\
Aegiphila sellowiana & 1 & 0,31 & 0,08 & 0,08 & 1,22 & 0,05 & 0,03 & 0,21 & 0,13 \\
Beilschmiedia emarginata & 1 & 0,31 & 0,08 & 0,08 & 1,22 & 0,04 & 0,02 & 0,21 & 0,12 \\
Rhodostemonodaphine macrocalyx & 1 & 0,31 & 0,08 & 0,08 & 1,22 & 0,04 & 0,02 & 0,20 & 0,12 \\
Coussapoa microcarpa & 1 & 0,31 & 0,08 & 0,08 & 1,22 & 0,04 & 0,02 & 0,20 & 0,12 \\
Piptocarpha macropoda & 1 & 0,31 & 0,08 & 0,08 & 1,22 & 0,03 & 0,02 & 0,20 & 0,11 \\
Eugenia sp. 4 & 1 & 0,31 & 0,08 & 0,08 & 1,22 & 0,03 & 0,02 & 0,19 & 0,11 \\
Vernonia diffusa & 1 & 0,31 & 0,08 & 0,08 & 1,22 & 0,03 & 0,02 & 0,19 & 0,11 \\
Calyptranthes sp. 3 & 1 & 0,31 & 0,08 & 0,08 & 1,22 & 0,03 & 0,02 & 0,19 & 0,11 \\
Eugenia capitulifera & 1 & 0,31 & 0,08 & 0,08 & 1,22 & 0,02 & 0,01 & 0,19 & 0,10 \\
Ocotea vaccinioides & 1 & 0,31 & 0,08 & 0,08 & 1,22 & 0,02 & 0,01 & 0,18 & 0,10 \\
Myrciaria sp. 1 & 1 & 0,31 & 0,08 & 0,08 & 1,22 & 0,02 & 0,01 & 0,18 & 0,10 \\
Piptocarpha sp. & 1 & 0,31 & 0,08 & 0,08 & 1,22 & 0,02 & 0,01 & 0,18 & 0,10 \\
Fabaceae 1 & 1 & 0,31 & 0,08 & 0,08 & 1,22 & 0,02 & 0,01 & 0,18 & 0,10 \\
Guarea macrophylla & 1 & 0,31 & 0,08 & 0,08 & 1,22 & 0,02 & 0,01 & 0,18 & 0,10 \\
Solanum pseudoquina & 1 & 0,31 & 0,08 & 0,08 & 1,22 & 0,01 & 0,01 & 0,18 & 0,09 \\
Ecclinusa ramiflora & 1 & 0,31 & 0,08 & 0,08 & 1,22 & 0,01 & 0,01 & 0,18 & 0,09 \\
Psychotria suterella & 1 & 0,31 & 0,08 & 0,08 & 1,22 & 0,01 & 0,01 & 0,17 & 0,09 \\
Miconia cubatanensis & 1 & 0,31 & 0,08 & 0,08 & 1,22 & 0,01 & 0,01 & 0,17 & 0,09
\end{tabular}


Tabela 5. Espécies em ordem decrescente de índice de valor de importância (IVI) encontradas através de levantamento pelo método de quadrantes no Parque Estadual "Carlos Botelho" - São Miguel Arcanjo, SP, onde $\mathrm{n}$ = número de indivíduos; fr.a = freqüência absoluta; fr.r = freqüência relativa; de. $\mathbf{r}=$ densidade relativa; de. $\mathbf{a}=$ densidade absoluta; do. $\mathbf{r}=$ dominância relativa; do.a = dominância absoluta; ivi = índice de valor de importância e ivc $=$ índice de valor de cobertura

\begin{tabular}{lccccccccc}
\hline \multicolumn{1}{c}{ Espécie } & n & fr.a & fr.r & de.r & de.a & do.r do.a & ivi & ive \\
\hline Plinia pauciflora & 1 & 0,31 & 0,08 & 0,08 & 1,22 & 0,01 & 0,01 & 0,17 & 0,09 \\
Endlicheria paniculata & 1 & 0,31 & 0,08 & 0,08 & 1,22 & 0,01 & 0,01 & 0,17 & 0,09 \\
Aiouea acarodomatifera & 1 & 0,31 & 0,08 & 0,08 & 1,22 & 0,01 & 0,00 & 0,17 & 0,09 \\
Ocotea velloziana & 1 & 0,31 & 0,08 & 0,08 & 1,22 & 0,01 & 0,00 & 0,17 & 0,09 \\
Allophylus edulis & 1 & 0,31 & 0,08 & 0,08 & 1,22 & 0,01 & 0,00 & 0,17 & 0,09 \\
Piper arboreum & 1 & 0,31 & 0,08 & 0,08 & 1,22 & 0,01 & 0,00 & 0,17 & 0,09 \\
Inga marginata & 1 & 0,31 & 0,08 & 0,08 & 1,22 & 0,01 & 0,00 & 0,17 & 0,09 \\
Cordia sp. & 1 & 0,31 & 0,08 & 0,08 & 1,22 & 0,01 & 0,00 & 0,17 & 0,08 \\
Cedrela fissilis & 1 & 0,31 & 0,08 & 0,08 & 1,22 & 0,01 & 0,00 & 0,17 & 0,08 \\
Quina magalano-gomesii & 1 & 0,31 & 0,08 & 0,08 & 1,22 & 0,01 & 0,00 & 0,17 & 0,08 \\
Myrcia aff.glabra & 1 & 0,31 & 0,08 & 0,08 & 1,22 & 0,01 & 0,00 & 0,17 & 0,08 \\
Plinia complanata & 1 & 0,31 & 0,08 & 0,08 & 1,22 & 0,01 & 0,00 & 0,17 & 0,08 \\
Myrcia heringii & 1 & 0,31 & 0,08 & 0,08 & 1,22 & 0,00 & 0,00 & 0,17 & 0,08 \\
Rollinea parviflora & 1 & 0,31 & 0,08 & 0,08 & 1,22 & 0,00 & 0,00 & 0,17 & 0,08 \\
Rapanea gardneriana & 1 & 0,31 & 0,08 & 0,08 & 1,22 & 0,00 & 0,00 & 0,17 & 0,08 \\
\hline
\end{tabular}

As duas principais espécies conforme o IVI Euterpe edulis e Micropholis crassipedicellata, atingiram tais posições devido à fatores diferentes. Enquanto Euterpe edulis apresenta densidade elevada (162ind.ha. ${ }^{-1}$ ) e freqüência relativa de $10,1 \%$, Micropholis crassipedicellata se beneficia com a presença de indivíduos de maior porte e com diâmetros maiores.

Comparando-se $M$. crassipedicellata com $B$. australis $\left(2^{\mathrm{a}}\right.$ e $3^{\mathrm{a}}$ em IVI), observa-se que as duas espécies apresentaram frequências e densidades relativas praticamente iguais, contudo, novamente fica ressaltada a presença de indivíduos de 
maior porte de $M$. crassipedicelata, favorecendo o caráter dominância relativa dessa espécie.

A maior freqüência absoluta coube a Euterpe edulis $(37,8 \%)$ e, posterirmente, Micropholis crassipedicellata (14,16\%), Bathysa australis e Mollinedia oligantha, com (12,8\%), Coussarea sp. (8,75\%), Ocotea catharinensis $(8,44 \%)$, Alibertia sp. (7,5\%), Pouteria bullata (7,19\%), Eugenia stictosepala (6,25\%) e Guapira opposita com $(5,94 \%)$.

A densidade absoluta total foi de 1567 indivíduos por hectare. A maior contribuição para este valor coube às espécies, Euterpe edulis (198ind.ha $\left.{ }^{-1}\right)$, Micropholis crassipedicellata $\left(61,2\right.$ ind.ha $\left.^{-1}\right)$, Bathysa australis (55.1 ind.ha $\left.{ }^{-1}\right)$, Guapira opposita $\left(23,3\right.$ ind.ha $\left.^{-1}\right)$ Mollinedia oligantha $\left(53,9\right.$ ind.ha $\left.^{-1}\right)$, Ocotea catharinensis $\left(33,1\right.$ ind.ha $\left.{ }^{-1}\right)$, Pouteria bullata $\left(29,4\right.$ ind.ha $\left.^{-1}\right)$, Vantanea compacta $\left(23,3\right.$ ind.ha $\left.^{-1}\right)$, Eugenia melanogina $\left(3,67\right.$ ind.ha $\left.^{-1}\right)$ Coussarea sp.(37,9ind.ha $\left.{ }^{-1}\right)$. Representam 518,87ind.ha ${ }^{-1}$, ou seja, quase um terço da densidade absoluta total.

Quanto à dominância absoluta, os maiores valores ficaram com Micropholis crassipedicellata $\left(8,89 \mathrm{~m}^{2} \cdot \mathrm{ha}^{-1}\right)$, Guapira opposita $\left(3,12 \mathrm{~m}^{2} \cdot \mathrm{ha}^{-1}\right)$, Bathysa australis $\left(3,08 \mathrm{~m}^{2} \cdot \mathrm{ha}^{-1}\right)$, Eugenia melanogina $\left(2,92 \mathrm{~m}^{2} \cdot \mathrm{ha}^{-1}\right)$, Ocotea catharinensis $\left(2,06 \mathrm{~m}^{2} \cdot \mathrm{ha}^{-1}\right)$, Pouteria bullata $\left(1,86 \mathrm{~m}^{2} \cdot \mathrm{ha}^{-1}\right)$, Vantanea compacta $\left(1,80 \mathrm{~m}^{2} \cdot \mathrm{ha}^{-1}\right)$, Pouteria caimito $\left(1,73 \mathrm{~m}^{2} \cdot \mathrm{ha}^{-1}\right)$, Alchornea triplinervia $\left(1,46 \mathrm{~m}^{2} \cdot \mathrm{ha}^{-1}\right)$, Diploon cuspidatum $\left(1,35 \mathrm{~m}^{2} \cdot \mathrm{ha}^{-1}\right)$. Estes totalizaram $28,27 \mathrm{~m}^{2} \cdot \mathrm{ha}^{-1}$, um pouco mais da metade do valor de $55,6 \mathrm{~m}^{2}$.há, ${ }^{-1}$ referente à dominância absoluta total.

Considerando as dez espécies que se destacaram em termos dos Índices de Valor de Valor de Cobertura, nota-se que são praticamente as mesmas espécies com maiores IVIs, porém, com posições invertidas. Micropholis crassipedicellata (ivc 19,9), Euterpe edulis (ivc 14,9), Bathysa australis (ivc 9,06), Guapira opposita (ivc 7,09), Ocotea catharinensis (ivc 5,82), Eugenia melanogina (ivc 5,49), Pouteria bullata (ivc 5,23) Mollinedia oligantha (ivc 4,98), Vantanea compacta (ivc 4,73), Alchornea trplinervia (ivc 3,88). Juntas essas espécies representam 40,54\% do IVC total. Cabe chamar atenção para duas exceções: Coussarea sp. é a décima espécie referenciada pelo IVI e Alchornea triplinervia é a décima referenciada pelo IVC. Quanto a espécie 
Eugenia melanogina, apesar de três indivíduos apenas, obteve a terceira maior dominância relativa que possibilitou estar entre as dez que mais se destacaram.

Comparando-se os dois métodos constatou-se que entre as dez principais espécies em IVI, sete são coincidentes, porém, não necessariamente na mesma ordem.

$\mathrm{Na}$ Tabela 6 são apresentados os parâmetros fitossociológicos das sete espécies em comum entre os dez maiores IVIs nos dois métodos de amostragem deste estudo, ondel se observa, que o método de quadrantes superestimou a maioria dos valores de densidade relativa e todos os valores de frequência relativa. Entretanto, essas diferenças não ultrapassaram 3,5 pontos percentuais, excetuando-se a frequência relativa de E. Edulis. Provavelmente essa maior diferença deve-se ao fato desta espécie estar regularmente distribuída pela área de amostragem, c assim, ter maior probabilidade de ser capturada nas unidades amostrais do método de pontos quadrantes.

Os altos valores de densidade e frequência de $E$. edulis podem evidenciar que os trabalhos de fiscalização e conscientização das comunidades de entorno do Parque Estadual Carlos Botelho estão alcançando seus objetivos. Entretanto, deve-se considerar que a área de estudo está localizada apenas há 4 quilômetros da Sede do referido Parque. Provavelmente, se a amostragem for repetida em uma área mais próxima do núcleo Sete Barras, os resultados poderão evidenciar outra realidade, ou seja, um extrativismo mais intenso.

Na Tabela 7 pode-se constatar que $56,18 \%$ dos indivíduos amostrados pelo método de parcelas são representados por apenas 5 famílias. Myrtaceae apresentou o maior número de indivíduos (1393), correspondendo a $14,59 \%$ do total. Rubiaceae veio em seguida, com 1201 ou 12,58\%, Lauraceae com 1673 indivíduos ou 12,29\%, Arecaceae com 1087 indivíduos ou 11,38\% e Sapotaceae com 508 indivíduos ou 5,32\%. Os 4182 indivíduos restantes ou $43,82 \%$ correspondem a outras 55 famílias. 
Tabela 6. Parâmetros fitossociológicos das sete espécies em comum entre os dez maiores IVIs, onde: De. $r=$ densidade relativa; Do.r $=$ dominância relativa; Fr.r $=$ freqüência relativa; IVI = índice de valor de importância

\begin{tabular}{lcccccccc}
\hline & \multicolumn{2}{c}{ De.r } & \multicolumn{2}{c}{ Do.r } & \multicolumn{2}{c}{ Fr.r } & \multicolumn{2}{c}{ IVI } \\
& $\mathrm{P}$ & $\mathrm{Q}$ & $\mathrm{P}$ & $\mathrm{Q}$ & $\mathrm{P}$ & $\mathrm{Q}$ & $\mathrm{P}$ & $\mathrm{Q}$ \\
\hline M. crassipedicelata & 2,7 & 3,91 & 13 & 16 & 1,33 & 3,76 & 17 & 23,7 \\
E. edulis & 11,4 & 12,7 & 2,65 & 2,19 & 1,55 & 10,1 & 16 & 25 \\
O. catharinensis & 2,38 & 2,11 & 6,51 & 3,71 & 1,35 & 2,26 & 10 & 8,08 \\
B. australis & 2,45 & 3,52 & 1,83 & 5,54 & 1,06 & 3,43 & 5,3 & 12,5 \\
P. bullata & 1,75 & 1,88 & 4,15 & 3,35 & 1,38 & 1,92 & 7,3 & 7,15 \\
V. compacta & 1,34 & 1,48 & 3 & 3,24 & 1,19 & 1,59 & 5,5 & 6,32 \\
M. oligantha & 3,04 & 3,44 & 1,25 & 1,54 & 1,4 & 3,43 & 5,7 & 8,41 \\
\hline
\end{tabular}

Tabela 7. Comparação do percentual de indivíduos das principais famílias

\begin{tabular}{lcc}
\hline \multicolumn{1}{c}{ Famílias } & Parcelas (\%) & Quadrantes (\%) \\
\hline Myrtaceae & 14,59 & 14,29 \\
Arecaceae & 11,38 & 12,65 \\
Rubiaceae & 12,58 & 12,26 \\
Lauraceae & 12,89 & 10,54 \\
Sapotaceae & 5,32 & 7,03 \\
\hline
\end{tabular}

A espécie com maior número de indivíduos no método de parcelas foi Euterpe edulis (1084) correspondendo a 11,35\%, seguida por Alibertia sp. com 310 indivíduos ou 3,24\%, Mollinedia oligantha com 290 indivíduos ou 3,03\%, Bathysa australis com 234 indivíduos ou 2,45\% e Micropholis crassipedicellata com 258 indivíduos ou $2,70 \%$. As cinco espécies representam 22,77\% dos indivíduos amostrados (Tabela 8). 
Tabela 8. Comparação do percentual das espécies com maior número de indivíduos

\begin{tabular}{lcc}
\hline \multicolumn{1}{c}{ Espécies } & Parcelas (\%) & Quadrantes (\%) \\
\hline Euterpe edulis & 11,35 & 12,65 \\
Alibertia sp. & 3,24 & - \\
Mollinedia oligantha & 3,03 & 3,43 \\
Bathysa australis & 2,45 & 3,51 \\
Microphollis & 2,70 & 3,90 \\
crassipedicellata & & \\
Coussarea sp. & - & 2,42 \\
\hline
\end{tabular}

Nos quadrantes, as 5 famílias mais representativas foram responsáveis por $56,77 \%$ dos indivíduos amostrados. Myrtaceae apresentou o maior número de indivíduos, 183, correspondendo a 14,29\% do total. Arecaceae com 162 indivíduos representou 12,65\%, Rubiaceae com 157 indivíduos correspondeu a 12,26\%, Lauraceae com 135 indivíduos representou 10,54\% e Sapotaceae com 90 indivíduos correspondeu a 7,03\% dos indivíduos amostrados. Os $43,23 \%$ representam o restante dos indivíduos pertencentes a outras 48 famílias. Esses números estão apresentados na Tabela 7. Salienta-se ainda, que 10 famílias $(18,86 \%$ do total) foram amostradas por uma única espécie.

As espécies foram praticamente as mesmas citadas acima no método de parcelas. Euterpe edulis (162 indivíduos) correspondendo a 12,65\%, seguida por Micropholis crassipedicellata com 50 indivíduos ou 3,90\%, Bathysa australis com 45 indivíduos ou 3,51\%, Mollinedia oligantha com 44 indivíduos ou 3,43\% e Coussarea sp. com 31 indivíduos ou 2,42\% (Tabela 8).

Do total de espécies amostradas, 39 ou 3,04\% foram representadas por apenas um indivíduo. 


\subsection{Distribuição da freqüência de árvores por classes de diâmetro}

No método de parcelas a distribuição de freqüência das classes de diâmetro representada na Figura 17. Assinala grande concentração de árvores nas classes de menor diâmetro, com $72,87 \%$ do total de indivíduos reunidos em apenas duas classes, cujos diâmetros são inferiores à $20 \mathrm{~cm}$. A freqüência das classes intermediárias é, relativamente, baixa e as classes superiores apresentam descontinuidade.

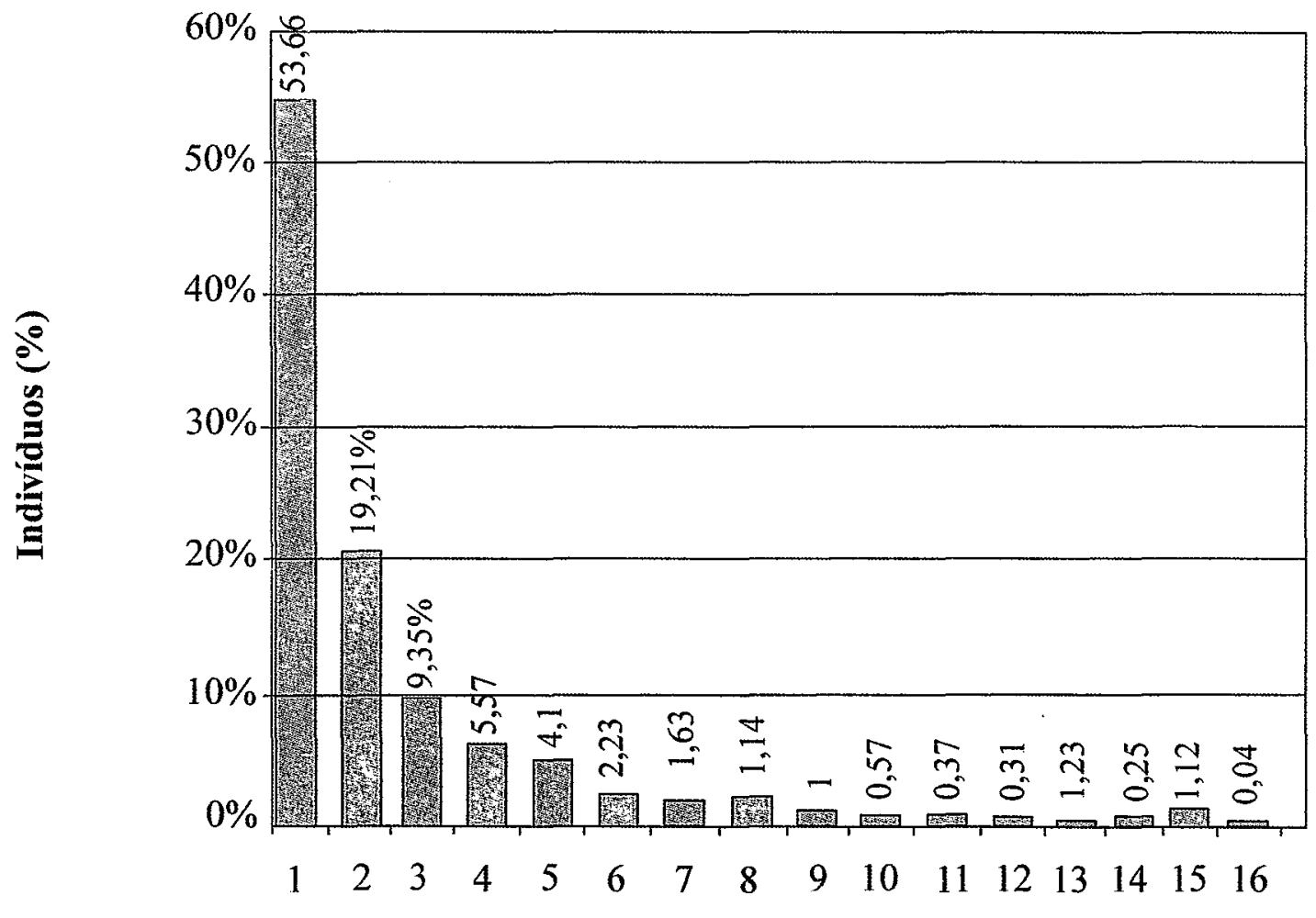

Classes de diâmetros

Figura 17 - Freqüência de árvores vivas (\%) por classes de diâmetro obtidas pelo método de parcelas, no Parque Estadual "Carlos Botelho" - São Miguel Arcanjo, SP. 1 = Classe de 5,0 a 10,0 cm, $2=$ Classe de 10,1 a $15 \mathrm{~cm}, 3=$ Classe de 15,1 a 20,0 cm, $4=$ Classe de 20,1 a 25,0 cm, $5=$ Classe de 25,1 a $20,0 \mathrm{~cm} \ldots 15=$ Classes maiores que $80,1 \mathrm{~cm}$ 
Esta distribuição com maior número de indivíduos nas classes de menor diâmetro e número reduzido nas classes médias e inferior mostra que a comunidade arbórea, analisada, é constituída, na sua maioria, de indivíduos de porte pouco elevado. Observa-se também, que da terceira á nona classe, onde estão concentrados $25,02 \%$ das árvores amostradas, ocorre uma diminuição gradual do número de indivíduos de $9 \%$ a $1 \%$, e a partir da décima classe até a última, compreende $2,11 \%$ do total amostrados.

Verifica-se a ocorrência de poucos representantes das espécies Alchornea triplinervia, Micropholis crassipedicellata, Didimopanax navarroi, Ocotea catharinensis, Matayba juglandifolia, Buchenavia kleinii e Euterpe edulis. Em Picinguaba, Ubatuba- SP, Sanchez (2001) encontrou Buchenavia Kleinii em diferentes altitudes, como segunda espécie mais importante por apresentar alto valor de dominância relativa

A Figura 18 apresenta a distribuição de freqüência de árvores por classe de diâmetro, detectada pelo método de quadrantes. Verifica-se, o predomínio de árvores nas classes de menor diâmetro, sendo que $70,10 \%$ do total de indivíduos amostrados, estão concentrados em apenas duas classes inferiores à $20 \mathrm{~cm}$ de diâmetro. Nota-se que da terceira à nona classe, onde estão reunidos $26,55 \%$ dos indivíduos arbóreos, ocorre uma diminuição gradual do número de indivíduos de $9 \%$ a $1 \%$ e a partir da décima classe até a última estão concentrados $3,17 \%$ do total de indivíduos amostrados. 


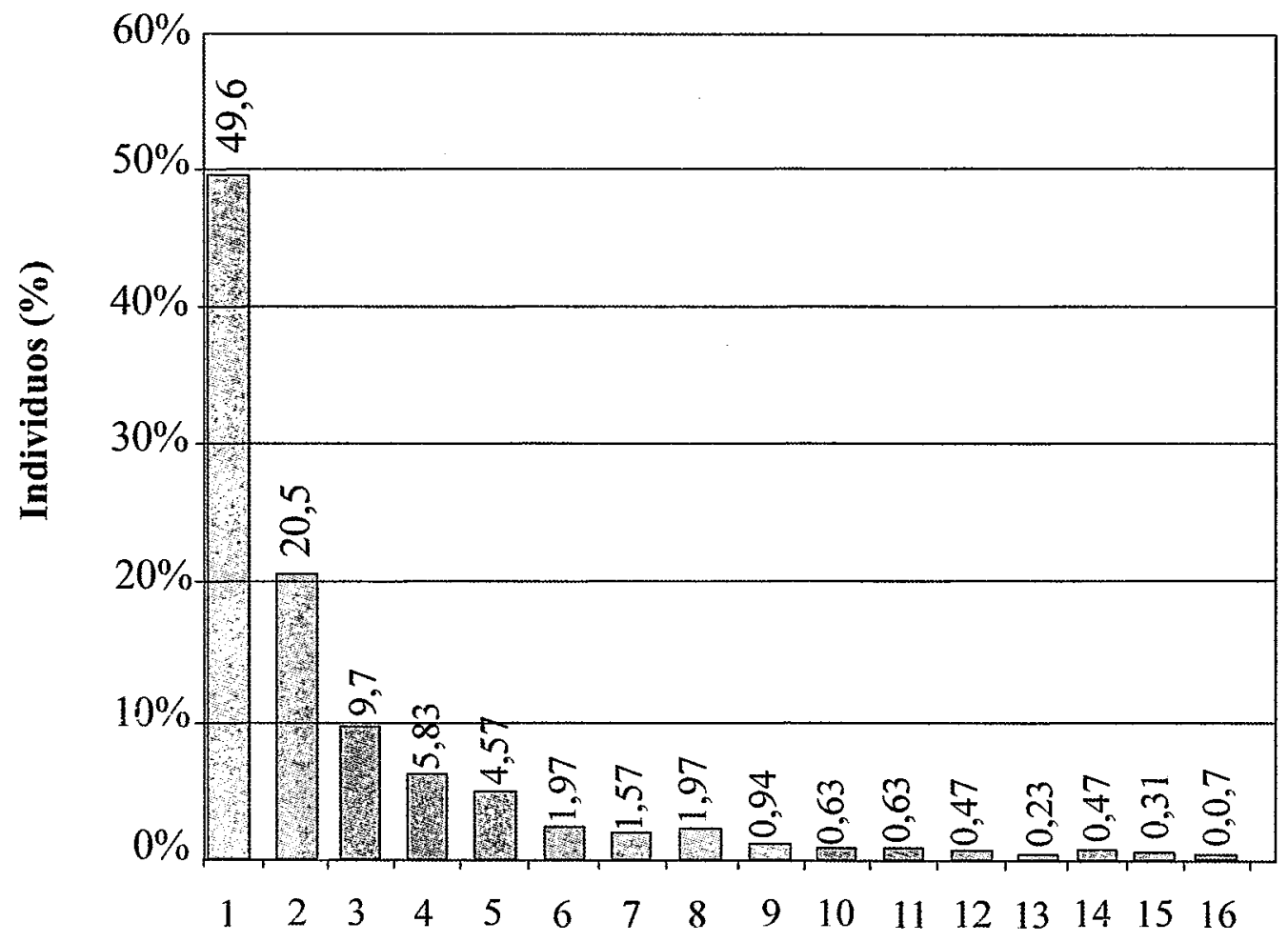

\section{Classes de diâmetros}

Figura 18 - Freqüência de árvores vivas (\%) por classes de diâmetro obtidas pelo método de quadrantes, no Parque Estadual "Carlos Botelho" - São Miguel Arcanjo, SP. $1=$ Classe de 5,0 a 10,0 cm, $2=$ Classe de 10,1 a $15 \mathrm{~cm}, 3=$ Classe de 15,1 a $20,0 \mathrm{~cm}, 4=$ Classe de 20,1 a $25,0 \mathrm{~cm}, 5=$ Classe de 25,1 a $20,0 \mathrm{~cm} \ldots$ $15=$ Classe de 75,1 a $80,0 \mathrm{~cm}$ e $16=$ Classes maiores que $80,1 \mathrm{~cm}$

Observa-se que, na distribuição diamétrica da comunidade estudada, tanto pelo método de parcelas como de quadrantes, há tendência ao " $\mathrm{J}$ " invertido, comum em floretas tropicais.

Segundo Batista (1989) as espécies com distribuição "J" invertido, tendem a ser substituídas por espécies com distribuição suavemente inclinada revelando, quase a uma reta. Acentua, ainda, que à forma " $J$ " invertido está relacionada à regeneração contínua e, a forma normal assimétrica, a um padrão de regeneração descontínuo. 
Cabe destacar, ainda, que tanto por parcelas, como por quadrantes, as populações mais abundantes, mais de 20 indivíduos, na área de amostragem, possuem maior número de indivíduos nas classes de tamanhos inferiores e poucos indivíduos nas classes superiores. Segundo Mantovani (1993) a distribuição dos indivíduos, predominante nas classes até $20 \mathrm{~cm}$, indica boa capacidade de regeneração na área. Este padrão de distribuição, que se assemelha a um " $\mathrm{"} \mathrm{invertido} \mathrm{indica} \mathrm{a} \mathrm{distribuição} \mathrm{dos}$ indivíduos em várias classes de diâmetro, com predominância nas iniciais.

$\mathrm{O}$ diâmetro do tronco é um bom indicador da idade da espécie e, conseqüentemente, fornece informações sobre o estádio sucessional da floresta (Baitello et al., 1993).

Comparando os dados das figuras de distribuição de freqüência de classes de diâmetro (Figuras 17 e 18), nota-se que são bem semelhantes. Tanto na amostragem pelo método de parcelas, como de quadrantes, o grande número de árvores nas classes iniciais pode significar que o trecho de mata estudado esteja em processo de crescimento. Segundo Martins (1991) as interrupções nas classes mais elevadas indicam um crescimento descontínuo, sugerindo que tais interrupções possam ter ocorrido devido a ação de algum fator.

\subsection{Perfilhamento}

Consiste na expansão lateral e a reprodução vegetativa, que atuam como estratégias vantajosas de competição, uma vez que as plântulas originadas por sementes têm pouca possibilidades de se estabelecer e competir. Entre os fatores apontados como capazes de favorecer as ramificações, está a abertura de clareiras, com mudanças no microclima, principalmente aumento da luminosidade (Mantovani, 1993).

Ainda Mantovani (1993) no estudo desenvolvido em um trecho de floresta atlântica na Estação Ecológica de Juréia-Itatins, no litoral sul do Estado de São Paulo, encontrou no componente dominante, $3,25 \%$ de indivíduos perfilhados. 
Ivanauskas e Rodrigues (2000) estudando dois remanescentes de floresta estacional decidual em Piracicaba, São Paulo, observaram 31\% de perfilhamento entre os indivíduos arbóreos.

No presente estudo, dos 9544 indivíduos amostrados nas parcelas, 835 árvores ou 8,74\% apresentaram perfilhamento, representados por 124 espécies ou 49,2\% do total de espécies. As espécies que apresentaram altos índices de perfilhamento foram: Guateria australis com 18 indivíduos ou 27,6\%; Maytenus robusta com 15 ou 34,8\%; Alchornea triplinervia com 30 ou 26,3\%; Ocotea aciphylla com 31 ou 41,8\%; Ocotea bicolor com 28 ou 20\%; Ocotea elegans com 75 ou 67,6\%; Ocotea odorifera com 24 ou 27,5\%; Ocotea teleiandra com 14 ou 56\%; Cabralea canjerana com 21 ou 20,1\%; Mollinedia oligantha com 73 ou 25,1\%; Mollinedia schottiana com 20 ou 16,.9\%; Guapira opposita com 24 ou 16,4\%; Alibertia sp. com 35 ou 11,3\%; Coussarea sp. com 18 ou $8,86 \%$; Rudgea jasminoides com 10 ou 7,81\%; Meliosma sinuata com 11 ou 25\%; Cupania oblongifolia com 11 ou 27,5\% e Matayba junglandifolia com 11 ou 10,2\%.

No método de quadrantes, dos 1280 indivíduos amostrados, 64 ou 5\% perfilharam. Os maiores índices de perfilhamento foram observados nas seguintes espécies: Ocotea catharinensis com 8 ou 29,6\%; Ocotea elegans com 5 ou 50\%; e Mollinedia oligantha com 6 ou 13,6\%.

As espécies Ocotea catharinensis e Mollinedia oligantha estão presentes nos dois métodos bem como entre as 10 espécies de maiores IVIs. Nos quadrantes o número de indivíduos por espécies que perfilharam foram poucos, muito provavelmente não tenham influenciado a dominância das espécies.

Nas parcelas o número de indivíduos perfilhados por espécie foi muito maior, podendo ter havido neste caso influência nos parâmetros de dominância. 


\section{CONCLUSÕES}

Os resultados referentes ao estudo da composição florística permitiram considerar que os dois métodos amostraram a vegetação estudada de maneira semelhante. Este fato fica ainda mais ressaltado, quando se considera as famílias, gêneros, espécies e percentual de indivíduos das dez espécies mais amostradas.

Através dos pontos quadrantes foi possível verificar que a riqueza da comunidade foi representativa, amostrando $70,24 \%$ do total de espécies levantadas pelo método de parcelas, em menor espaços de tempo. Há que se considerar que o resultado obtido por este método corresponde à amostragem de $1 / 5$ dos indivíduos amostrados pelo método de parcelas.

Os parâmetros fitossociolóigicos das sete espécies em comum entre os dez maiores IVIs nos dois métodos de amostragem deste estudo, permitiu verificar que o método de quadrantes superestimou a maioria dos valores de densidade relativa e todos os valores de frequência relativa. Entretanto, essas diferenças não ultrapassaram 3,5 pontos percentuais, excetuando-se a frequência relativa de $E$. Edulis. Provavelmente essa maior diferença deve-se ao fato desta espécie estar regularmente distribuída pela área de amostragem, e assim, ter maior probabilidade de ser capturada nas unidades amostrais do método de pontos quadrantes.

Os altos valores de densidade e frequência de $E$. edulis podem evidenciar que os trabalhos de fiscalização e conscientização das comunidades de entorno do Parque Estadual Carlos Botelho estão alcançando seus objetivos. Entretanto, deve-se considerar que a área de estudo está localizada apenas há 4 quilometros da Sede do referido Parque. Provavelmente, se a amostragem for repetida em uma área mais próxima do núcleo Sete Barras, os resultados poderão evidenciar outra realidade, ou seja, um extrativismo mais intenso. 
Os dois métodos amostraram a composição florística e a estrutura fitossociológica da comunidade estudada de maneira semelhante. Assim, considerandose o esforço físico e as dificuldades da topografia, recomenda-se aplicação do método de quadrantes para estudar a vegetação florestal em ambientes com as mesmas características de relevo.

A distribuição de frequiência de classes de diâmetro é semelhante entre os métodos aplicados; tem semelhança ao "J" invertido, indicando distribuição contínua e decrescente a partir das menores classes diamétricas. Provavelmente o grande número de árvores nas classes iniciais possa significar processo de crescimento, como as interrupções nas classes mais elevadas refletir limites de crescimento ou ações de caráter natural ou antrópico. 


\section{REFERÊNCIAS BIBLIOGRÁFICAS}

AGENDA 21 BRASILEIRA. Bases para discussão. Brasília: Ministério do Meio Ambiente/Programa das Nações Unidas para o Desenvolvimento, 2000. p.196.

AGUIAR, O.T. de; PASTORE, J.A.; ROCHA, F.T.; BAITELLO, J.B. Flora fanerogâmica de um trecho da floresta densa secundária no Parque Estadual da Serra do Mar - Núcleo Cunha Indaiá - S.P. Revista do Instituto Florestal, v.13, n.1, p.1$18,2001$.

ALMEIDA-SCABBIA, R.J. Fitossociologia de um trecho de floresta atlântica no Parque Estadual Intervales. Rio Claro, 1996. 122p. Dissertação (Mestrado) Instituto de Biociências, Universidade Estadual Paulista "Júlio de Mesquita Neto".

ARAGAKI, S.; MANTOVANI, W. Estudos estruturais e taxonômicos de trecho de remanescente de floresta no Parque Municipal Alfredo Volpi (São Paulo, SP). In: SIMPÓSIO DE ECOSSISTEMAS DA COSTA BRASILEIRA, 3., Serra Negra, 1993. Anais. São Paulo, ACIESP, 1993, 323p.

ASSIS, M.A. Florística e caracterização das comunidades vegetais da planície costeira de Picinguaba, Ubatuba - SP. Campinas, 1999. Tese (Doutorado) - Instituto de Biologia, Universidade Estadual de Campinas. 
BAITELLO, J.B.; AGUIAR, O.T. de; ROCHA, F.T.; PASTORE, J.A.; ESTEVES, R. Florística e fitossociologia do estrato arbóreo de um trecho da Serra da Cantareira (Núcleo Pinheirinho) - SP. In: CONGRESSO NACIONAL SOBRE ESSÊNCIAS NATIVAS, 2., São Paulo, 1992. Anais. São Paulo: UNIPRESS, 1992. p.291-297. Revista do Instituto Florestal, v.4, n. único, pt.1, 1992, Edição Especial/

BAITELLO, J.B.; AGUIAR, O.T. de; ROCHA, F.T.; PASTORE, J.A.; ESTEVES, R. Estrutura fitossociológica da vegetação árvores da Serra do Mar (SP) - Núcleo Pinheirinho. Revista do Instituto Florestal, v.5, n.2, p.133-161, 1993.

BATISTA, J.L.F. A função weibull como modelo para distribuição de diâmetros de espécies arbóreas tropicais. Piracicaba, 1989. 116p. Dissertação (Mestrado) Escola Superior de Agricultura "Luiz de Queiroz", Universidade de São Paulo.

BRAUN-BLANQUET, V. Fitosociología y bases para el estudio de las comunidades vegetales. Madrid: H. Blume, 1979. 820p.

CAMPOS, J.C.C.; HEINSDJIK, D.C. A floresta do Morro do Diabo. Silvicultura em São Paulo, v. 7, p. 43-58, 1970.

CASTRO, A.G. Levantamento florístico de um trecho de Mata Atlântica na Estação Ecológica de Bananal, Serra da Bocaina, Bananal, São Paulo. Rio de Janeiro, 2001. 61p. Dissertação (Mestrado) - Instituto de Florestas, Universidade Federal Rural do Rio de Janeiro.

CAVASSAN, O.; CESAR, O.; MARTINS, F.R. Fitossociologia da vegetação arbórea da Reserva Estadual de Bauru, Estado de São Paulo. Revista Brasileira de Botânica, n.7, p.91-106, 1984. 
CESAR, O. Composição florística, fitossociológica e e ciclagem de nutrientes em mata mesófila semidecídua (Fazenda Barreiro Rico, município de Anhembi, SP). Rio Claro, 1988. 233p. Tese (Doutorado) - Instituto de Biociências, Universidade Estadual Paulista "Julio de Mesquita Neto".

CHAPMAN, S.B. Methods in plant ecology. New York: John Wiley, 1976. 536p.

COTTAM, G.; CURTIS, J.T. The use of distance measures in phytosociological sampling. Ecology, v.37, n.3, p.451-460, 1956.

CRONQUIST, A. The evolution and classification of flowering plants. 2. ed. New York: New York Botanical Garden, 1988.

CUSTÓDIO FILHO, A. A floresta ombrófila densa em diferentes altitudes no Parque Estadual Carlos Botelho. São Paulo, Brasil. São Paulo, 2002. Tese (Doutorado) Instituto de Biociências, Universidade de São Paulo.

DAVIS, D.E. The annual life cycle of plants, mosquitos birds and mammals in two Brazilian Forests. Ecological Monographs, v.15, p. 243-295, 1945.

DE VUONO, Y.S. Fitossociologia do estrato arbóreo da floresta da Reserva do Instituto de Botânica (São Paulo). São Paulo, 1985. 213p. Tese (Doutorado) - Instituto de Biociências, Universidade de São Paulo.

DIAS, A.C. Composição florística, fitossociológica e diversidade em espécies do componente Arbóreo de um trecho de mata secundária. Parque Estadual de Carlos Botelho, SP. Piracicaba, 1993. 125p. Dissertação (Mestrado) - Escola de Agricultura "Luiz de Queiroz", Universidade de São Paulo. 
DIAS, A.C.; CUSTÓDIO FILHO, A.; FRANCO, G.A.D.C. Diversidade do componente arbórea em floresta pluvial atlântica secundária. São Paulo, Brasil. Revista do Instituto Florestal, v.12, n.2, p.127-53, 2000.

DIAS, A.C.; CUSTÓDIO FILHO, A.; FRANCO, G.A.D.C.; COUTO, H.T.Z. do. Estrutura do componente arbóreo em um trecho de floresta secundária no Parque Estadual de Carlos Botelho, S.P. Revista do Instituto Florestal, v.7, n.2, p.125-155, 1995.

DIAS, A.C.; NEGREIROS, O.C. de; VEIGA, A. A.; COUTO, H.T.Z. do. Comparação entre métodos empregados na amostragem de vegetação, desenvolvida em comunidades de Floresta Pluvial Tropical. Revista do Instituto Florestal., v.1, n.2, p.93-119, 1989.

DOMINGUES, E.N.; SILVA, D.A. Geomorfologia do Parque Estadual de Carlos Botelho. Boletim Técnico do Instituto Florestal, v.42, p.71-105, 1988.

DOMINGUES, E.N.; DIAS, A.C.; MOURA NETO, B. V. de. O meio biofísico da bacia do Ribeirão dos Fornos, no Parque Estadual de Carlos Botelho. S.P. Revista do Instituto Florestal, v.5, n.2, p.203-229, 1993.

DURIGAN, G.; SANTOS, J.D; GANDARA, F.B. Fitossociologia de dois fragmentos de floresta estacional semidecidual no Pontal do Paranapanema, SP. Revista do Instituto Florestal, v.14, n.1, p.13-26, 2002.

FIDALGO, O.; BONONI, V.L.R. (Coord.). Técnicas de coleta, preservação e herborização de material botânico. São Paulo: Instituto de Botânica, 1984. 62p. (Manual, 4). 
FUNDAÇÃO INSTITUTO BRASILEIRO DE GEOGRAFIA E ESTATÍSTICA. Manual técnico de vegetação brasileira. Rio de Janeiro, 1992. 92p

GANDOLFI, S. Estudo florístico e fitossociológico de uma floresta residual na área do Aeroporto Internacional de São Paulo, município de Guarulhos-SP. Campinas, 1991. Dissertação (Mestrado) - Universidade Estadual de Campinas.

GANDOLFI, S.; LEITÃO FILHO, H.F.; LINNEU, C.L.F. Levantamento florístico e caráter sucessional das espécies arbustivo-arbóreas de uma floresta semidecídua no município de Guarulho, SP. Revista Brasileira de Botânica, v.55, n.4, p.753-767, 1995.

GIBBS, P.E.; LEITÃO FILHO, H.F. Floristic composition of an area of gallery forest near Moji-Guaçu, state of São Paulo, SE, Brazil. Revista Brasileira de Botânica, v.1, p.151-156, 1978.

GIBBS, P.E.; LEITÃO FILHO, H.F.; ABBOT, R.J. Application of the point-centred quarter method in a floristic survey of an area of gallery forest at Mogi-Guaçu, SP, Brazil. Revista Brasileira de Botânica, n.1, p.151-156, 1980.

GIULIETTI, A.M. 1992 Biodiversidade da Região sudeste. Revista do Instituto Florestal, v.4 p. 125-30.

GORENSTEIN, M.R. Métodos de amostragem no levantamento da comunidade arbórea em floresta estacional semidecidual. Piracicaba, 2002. 92p. Dissertação (Mestrado)Escola Superior de Agricultura "Luiz de Queiroz", Universidade de São Paulo. 
GOMES, E.P.C. Fitossociologia do componente arbóreo de um trecho da mata em São Paulo-SP. São Paulo, 1992. Dissertação (Mestrado) - Instituto de Biociências, Universidade de São Paulo.

GUEDES-BRUNI, R.R.; LIMA, H.C. de. Mountain ranges of Rio de Janeiro - Southeastern Brazil. In: Word Wildlife Fund; International Union for Conservation of Nature. Centres of plant diversity. A guide and strategy for their conservation. Cambridge: IUCN Publications Unit, 1997. v.3. p.376-380.

GUEDES-BRUNI; R.R.; PESSOA, S. V.A.; KURTZ, B.C. Florística e estrutura do componente arbustivo arbóreo de um trecho preservado de Floresta Montana na Reserva Ecológica de Macaé de Cima. In: GUEDES, H. C. de; BRUNI, R.R. (Ed.). Serra de Macaé de Cima: diversidade florística e conservação em Mata Atlântica. Rio de Janeiro: Instituto de Pesquisas Jardim Botânico do Rio de Janeiro, 1997. p.127-145.

GUILLAUMON, J.R. Mudança do polo econômico do Nordeste para o Sudeste, no Brasil, e a destruição da floresta-mata atlântica. Revista do Instituto Florestal, v.1, n.2, p.13-41, 1989.

HEINSDJIK, D.C.; CAMPOS, J.C.C. Programa de manejo das florestas de produção Estaduais. Silvicultura em São Paulo, v.6, n.único, p.365-405, 1967.

IVANAUSKAS, N.M. Caracterização florística e fisionômica da floresta atlântica sobre a formação Pariquera-Açu na Zona Morraria Costeira do Estado de São Paulo. Campinas, 1997. Dissertação (Mestrado) - Instituto de Biologia, Universidade Estadual de Campinas. 
IVANAUSKAS, N.M.; RODRIGUES, R.R. Florística e fitossociologia de remanescentes de floresta estacional decidual em Piracicaba, São Paulo-Brasil. Revista Brasileira de Botânica., v.23, n.3, p.291-304, 2000.

JOLY, C.A.; AIDAR, M.P.M.; KLINK, C.A.; MCGRATH, D.G.; MOREIRA, A.G.; MOUTINHO, P.; NEPSTAD, D.C.; OLIVEIRA, A.A.; POTT, M.J.N.; SAMPAIO, E.V.S.B. Evolution of the Brazilian phytogeography classification systems: implications for biodiversity conservation. Ciência e Cultura, v.51, n.5/6, p.331$348,1999$.

KLEIN, R.M. Ecologia da flora e vegetação do Vale do Itajaí. Sellowia, v.32, p. 165 $389,1980$.

KOEPPEN, W. Climatologia. México: Fondo de Cultura Económica, 1948, 479p.

KRONKA, F.J.N.; MATSUKUMA, C.K.; NALON, M.A.; DEL CALI, I.H.; ROSSI, M.; MATTOS, I.F.A.; SHIN-IKE, M.S.; PONTINHA, A.A.S. Inventário florestal do Estado de São Paulo. São Paulo: Instituto Florestal, 1993. 199p.

LEITÃo FILHO, H. F. Aspectos taxonômicos das florestas do Estado de São Paulo. In: CONGRESSO NACIONAL SOBRE ESSÊNCIAS NATIVAS, Campos do Jordão, 1982. Anais. São Paulo: UNIPRESS, Silvicultura em São Paulo, v.16A, pt.1, p. 197-206, 1982. Edição Especial/

LEITÃo FILHO, H. F. Ecologia da Mata Atlântica em Cubatão. Campinas: Editora da Universidade Estadual de Campinas, 1993. 184p.

MANTOVANI, W. Estrutura e dinâmica da Floresta Atlântica na Juréia, Iguape-SP. São Paulo, 1993. Tese (Livre-Docência) - Instituição de Biociências, Universidade de São Paulo. 
MANTOVANI, W.; RODRIGUES, R.R.; ROSSI., L.; ROMANIUC-NETO, S.; CATHARINO, E.L.M.; CORDEIRO, J. A vegetação da Serra do Mar em Salesópolis, S.P. In: SIMPÓSIO DE ECOSSISTEMAS DE COSTA SUL E SUDESTE BRASILEIRA: ESTRUTURA, FUNÇÃO E MANEJO. Águas de Lindóia, 1990. Anais. /Publicação ACIESP, v.71, n.1, p.348-394, 1990/.

MARTINS, F.R. Critérios para avaliação de recursos vegetais. In: SIMPÓSIO SOBRE A COMUNIDADE VEGETAL COMO UNIDADE BIOLÓGICA, TURÍSTICA E ECONÔMICA, São Paulo, 1978. Anais. /Publicação ACIESP, v.15, p.136-149, $1978 /$.

MARTINS, F.R. O método de quadrantes e a fitossociologia de uma florestal residual do Estado de São Paulo: Parque Estadual de Vassununga. São Paulo, 1979. Tese (Doutorado) - Instituto Biociências, Universidade de São Paulo.

MARTINS, F.R. Fitossociologia de florestas do Brasil: um historio bibliográfico. Pesquisas, v.40, p.103-164, 1989. (Série Botânica).

MARTINS, F.R. Estrutura de uma floresta mesófila. 2.ed. Campinas: UNICAMP, 1993. 246p. /Série Teses/

MEGURO, M. Ciclagem de nutrientes minerais nos ecossistemas da Costa sul e sudeste brasileira: síntese dos conhecimentos. In: SIMPÓSIO SOBRE ECOSSISTEMAS DA COSTA SUL E SUDESTE BRASILEIRA. Cananéia. 1987. Anais. São Paulo: ACIESP, 1987. v.3.p. 98-122.

MELO, J.M.; OLIVEIRA FILHO, A.T.; SCOLFORO, J.R.S. Comparação entre procedimentos de amostragem para avaliação estrutural de um remanescente de floresta estacional semidecidual montana. Revista Cerne, v.2, n.2, p.1-15, 1996. 
MELO, M.M.R.F.; MANTOVANI, W. Composição florística e estrutura do trecho de Mata Atlântica de encosta na Ilha do Cardoso (Cananéia. S.P, Brasil). Boletim do Instituto de Botânica, v.9, p.107- 158, 1994.

MELO, M.M.R.F.; OLIVEIRA, R.J.; ROSSI, L.; MAMEDE, M.C.H.; CORDEIRO, I. Fitossociologia de trecho de mata atlântica na planície do rio Verde, Estação Ecológica de Juréia-Itatins, SP, Brasil. In: SIMPÓSIO DE ECOSSISTEMAS BRASILEIROS, 4., Águas de Lindóia, 1998. Anais. São Paulo: Academia de Ciências do Estado de São Paulo, 1998. p.49-50.

MONTEIRO, C.A.F. A dinâmica climática e as chuvas no Estado de São Paulo. São Paulo: Instituto de Geografia, 1973. 29p.

MORELLATO, L.P.C. The Brazilian Atlantic Forest. Biotropica, v.32, n.4b, p.786$792,2000$.

MORI, S.A. Eastern, extra - Amazonian Brazil. In: CAMPBELL. D.G.; HAMMOND, H.D. (Ed.). Floristic inventory of tropical countries: the status of plant systematics, collection, and vegetation, plus recommendations for the future. New York: New York Botanical Garden, 1989. p.427-454.

MORI, S.A.; SILVA, L.A.M.; LISBOA, G.; CORADIN, I. Manual de manejo de herbário fanerogâmico. Ilhéus: CEPLAC, Centro de Pesquisa do Cacau, 1985. $97 \mathrm{p}$.

MUELLER-DOMBOIS, D.; ELLEMBERG, H. Aims and methods of vegetations. Ecology. New York: John Wiley, 1974, 545p. 
NEGREIROS, O.C. de. Características fitossociológica de uma floresta latifoliada pluviosa tropical visando o manejo do palmito, Euterpe edulis Mart. Piracicaba, 1983. Dissertação (Mestrado) - Escola Superior de agricultura "Luiz de Queiroz", Universidade de São Paulo.

NEGREIROS, O.C. de. Análise estrutural de um trecho de floresta pluvial tropical, Parque Estadual de Carlos Botelho, Núcleo Sete Barras. Revista do Instituto Florestal, v.7, n.1, p.1-33, 1995.

OLIVEIRA-FILHO, A.T.; FONTES, M.A.L. Patterns of floristic differentation among Atlantic Forests in Southeastern Brazil and the influence of climate. Biotropica, v.32, n.4b, p.793-810, 2000.

PAGANO, S.N. Estudo florístico fitossociológico e de ciclagem de nutrientes em mata mesófila semidecídua, no município de Rio Claro (Estado de São Paulo). Revista Brasileira de Botânica, n.10, p.49-61, 1985.

PAGANO, S.N.; LEITÃO FILHO, H. de F.; SHEPHERD, G.J. Estudo fitossociológico em mata mesófila semidecídua no município de Rio Claro (Estado de São Paulo). Revista Brasileira de Botânica, v.10, p.49-61, 1987.

PEIXOTO, A.L. A vegetação da Costa Atlântica. In: MONTEIRO, S.B.; KAZ, L. (Org.). Floresta Atlântica. Rio de Janeiro: Livro Arte Editora, 1991. p.33-42.

PFEIFER, R.M.; CARVALHO, W.A; SILVA, D.A. ROSSI, M.; MEDICINO, L.F. Levantamento semidetalhado dos solos do Parque Estadual de Calor Botelho (SP). Bolotim Técnico do Instituto Florestal, v.40, n.1, p.75-109, 1986. 
PINTO, M.M. Fitossociologia e influência de fatores edáficos na estrutura da vegetação em áreas de Mata Atlântica na Ilha do Cardoso Cananéia, S.P. Jaboticabal, 1998. 113p. Tese (Doutorado) - Universidade Estadual Paulista "Júlio de Mesquita Neto".

PONÇANO, W.I.; CARNEIRO, C.D.R.; BISTRICHI, C.A.; ALMEIDA, F.F.M.; PRANDINI, F.L. Mapa geomorfológico do Estado de São Paulo. São Paulo: Instituto de Pesquisas Tecnológicas, 1981. 94p. (Monografias)

RIZZINI, C.T. Nota prévia sobre a divisão fitogeográfica (floristica - sociológica do Brasil. Revista Brasileira de Geografia, v.25, n.1, p.3-64, 1963.

ROCHA, F.T. Levantamento florestal na Estação Ecológica dos Caetetus como subsídio para laudos de desapropriação ambiental. Piracicaba, 2003. 155p. Dissertação (Mestrado) - Escola Superior de Agricultura "Luiz de Queiroz", Universidade de São Paulo.

ROMARIZ, D.A. A vegetação. In: AZEVEDO, A. (Coord.) Brasil, a terra e o homem. As bases físicas. 2.ed. São Paulo: Editora Nacional, 1972. v.1, p.521572.

SANCHEZ, M. Florística e fitossociologia da vegetação arbórea nas margens do Rio da Fazenda (Parque Estadual da Serra do Mar - Núcleo de Picinguaba - Ubatuba S.P.) Rio Claro, 1994. Dissertação (Mestrado) - Instituto de Biociências, Universidade Estadual Paulista "Júlio de Masquita Neto".

SANCHEZ, M. Composição florística e estrutura arbórea num gradiente altitudinal da Mata Atlântica. Campinas, 2001. 123p. Tese (Doutorado) - Instituto de Biologia, Universidade Estadual de Campinas. 
SANCHEZ, M.; PEDRONI, F.; LEITÃO FILHO, H. F.; CESAR, O. Composição florística de um trecho de floresta ripária na Mata Atlântica em Picinguaba, Ubatuba, S.P. Revista Brasileira de Botânica, v.22, n.1, p.31-42, 1999.

SÃO PAULO (Estado). Secretaria do Meio Ambiente. Verde perto. São Paulo, 1996. 8 p.

SÃO PAULO (Estado). Secretaria do Meio Ambiente. Mata Atlântica: um projeto de preservação. São Paulo, 1998. 71p.

SCUDELLER, V.V. Análise fitogeográfica da Mata Atlântica-Brasil. Campinas, 2002. Tese (Doutorado) - Instituto de Biologia, Universidade Estadual de Campinas.

SCUDELLER, V.V.; MARTINS, F.R.; SHEPHERD,G.J. Distribution and abundance of arboreal species in the Atlantic Ombrophilous Dense Forest in Southeastern Brazil. Plant Ecology, v.152, p.185-199, 2001.

SERRA FILHO, R.; CAVALLI, A.C.; GUILLAUMON, J.R.; CHIARINI, J.V.; NOGUEIRA, F. de P.; IVANCKO, C.M.A.M.; BARBIERI, J.L.; DONZELI, P.L.; COELHO, A.G.S.; BITTENCOURT, I. Levantamento da cobertura vegetal natural e do reflorestamento no Estado de São Paulo. São Paulo, Instituto Florestal. Boletim Técnico do Instituto Florestal, n.11, p.1-53, 1974.

SETZER, J. Contribuição para o estudo do clima do Estado de São Paulo. São Paulo: Escolas Profissionais Salesianas, 1946. 239p.

SILVA, A.F.B. Composição florística e estrutura de um trecho da Mata Atlância de encosta no municipio de Ubatuba-São Paulo. Campinas, 1980. 153p. Dissertação (Mestrado) - Instituto de Biologia, Universidade Estadual de Campionas. 
SILVA, A.F.B.; LEITÃO FILHO, H. de F. Composição florística e estrutura de um trecho de Mata Atlântica de encosta no Município de Ubatuba (São Paulo, Brasil). Revista Brasileira de Botânica, v.5, n.1-2, p.43-52, 1982.

SILVA, D.C.G. Florística e fitossociologia de um remanescente de mata atlântica no município de Cubatão, SP. Rio Claro, 1999. 90p. Dissertação (Mestrado) Instituto de Biociências, Universidade Estadual Paulista "Júlio de Mesquita Neto.

SIQUEIRA, M.F. Análises florística e ordenação de espécies arbóreas da mata atlântica através de dados binários. Campinas, 1994. 143p. Dissertação (Mestrado) Instituto de Biologia, Universidade Estadual de Campinas.

SUGIYAMA, M. Estudo de florestas da restinga da Ilha do Cardoso, Cananéia, São Paulo, Brasil. São Paulo, 1993. 115p. Dissertação (Mestrado) - Instituto de Biociências, Universidade de São Paulo.

TABARELLI, M.; VILLANI, J.P.; MANTOVANI, W. Estudo comparativo da vegetação de dois trechos de floresta secundária no Núcleo Santa Virgínia, Parque Estadual da Serra do Mar, SP. Revista do Instituto Florestal, v.6, n. único, p.1-11, 1994.

VELOSO, H.P. As comunidades e as Estações Botânicas de Teresópolis, Estado do Rio de Janeiro. Rio de Janeiro: Museu Nacional, 1945. 45p. (Boletim do Museu Nacional, Ser. Botânica, 3)

VELOSO, H.P.; KLEIN, R.M. As comunidades e associações vegetais da mata pluvial do sul do Brasil. I. As comunidades do Município de Brusque, Estado de Santa Catarina. Sellowia, v.9, p.81-235, 1957. 
VELOSO, H.P.; KLEIN, R.M. As comunidades e associações vegetais da mata pluvial do sul do Brasil. II. Dinamismo e fidelidade das espécies em associações do Município de Brusque, Estado de Santa Catarina. Sellowia, v.10, p.9-124, 1959.

VELOSO, H.P.; KLEIN, R.M. As comunidades e associações vegetais da mata pluvial do sul do Brasil. III. As associações das planícies costeiras do quaternário, situadas entre o Rio Itapocu (Estado de Santa Catarina e a Bacia de Paranaguá (Estado do Paraná). Sellowia, v.13, p.205-260, 1961.

VELOSO, H.P.; KLEIN, R.M. As comunidades e associações vegetais da mata pluvial do sul do Brasil. IV. As associações situadas entre o Rio Tubarão (Santa Catarina) e a Lagoa dos Barros (Rio Grande do Sul). Sellowia, v.15, p.57-114, 1963.

VELOSO, H.P.; KLEIN, R.M. As comunidades e associações vegetais da mata pluvial do Sul do Brasil. V. Agrupamentos arbóreos da encosta catarinense situados em sua parte norte. Sellowia, v.20, p.53-126, 1968a.

VELOSO, H.P.; KLEIN, R.M. As comunidades e associações vegetais da mata pluvial do Sul do Brasil. VI. Agrupamentos arbóreos dos contrafortes da Serra Geral situados ao sul da costa catarinense e ao norte da costa sul-riograndense. Sellowia, v.20, p.127-180, $1968 \mathrm{~b}$.

VELOSO, H.P.; RANGEL FILHO, A.L.R.; LIMA. J.C.A. Classificação da vegetação brasileira, adaptada a um sistema universal. Rio de Janeiro: IBGE, 1991. 123p.

VICTOR, M.A.M. A devastação florestal. São Paulo: Sociedade Brasileira de Silvicultura, 1975. 49p. 